Tiziana Suarez-Nani

\title{
Pierre de Jean Olivi et la subjectivité angélique
}

Considéré depuis longtemps comme le chaînon intermédiaire incontournable entre Thomas d'Aquin et Duns $\operatorname{Scot}^{1}$, Pierre de Jean Olivi est désormais reconnu, grâce aux travaux des dernières décennies ${ }^{2}$, dans sa valeur propre, en tant qu'auteur d'une pensée rigoureuse, forte et originale ${ }^{3}$. Si la dernière œuvre du franciscain - la Lectura super Apocalipsim (ou Postilla), point culminant de l'eschatologisme du Moyen Age - ainsi que son engagement pour la cause de la pauvreté ont captivé en un premier moment l'intérêt de la plupart des chercheurs, bien d'autres domaines ont trouvé sous la plume d'Olivi des développements d'une grande valeur spéculative: que l'on songe à sa contribution aux théories économiques, à ses écrits exégétiques, à ses œuvres spirituelles, et, sur le plan philosophique, à sa doctrine de la liberté, à celle de la matière et de l'individuation, à la question du mouvement et du temps, ou encore à sa théorie de la connaissance ${ }^{4}$.

Parmi les nombreux thèmes traités dans ses Questions sur le Ile livre des Sentences de Pierre Lombard on trouve aussi - comme il se doit dans tout commentaire de ce texte - une série de questions angélologiques qui, malgré leur

\footnotetext{
*Nous remercions Zénon Kaluza pour sa lecture patiente et attentive et pour ses suggestions d'amélioration.

1 Cf. P. L. Jarraux, Pierre de Jean Olivi, sa vie, sa doctrine, Etudes franciscaines, 45 (1933), p. 287.

A. Boureau et S. Piron, dans leur Introduction au dernier volume collectif consacré à notre auteur : Pierre de Jean Olivi (1248-1298). Pensée scolastique, dissidence spirituelle et société, Paris 1999, rappellent les étapes saillantes des études oliviennes au cours du XXe siècle : cf. p. 12-13.

Pour la biographie d'Olivi, cf. P. L. Jarraux, art. cit. ; C. Partee, Peter John Olivi : Historical and Doctrinal Study, Franciscan Studies, 20 (1960), p. 215-260 ; P. Péano, article : Olieu, Dictionnaire de spiritualité, vol. XI, Paris 1982, p. 751-762 ; D. Burr, L’histoire de Pierre Olivi (trad. franç. de F.-X. Putallaz), Paris-Fribourg 1997. En ce qui concerne les œuvres (connues ou perdues) on consultera le vol. 91 (1998) de la revue Archivum franciscanum historicum, qui a publié les actes du Colloque qui a réuni à Grottaferrata en 1997 les éditeurs des écrits d'Olivi.

Pour les études concernant ces différents thèmes on consultera les bibliographies suivantes : S. Gieben, Bibliographia oliviana (1885-1967), Collectanea franciscana, 38 (1968), p. 167-195 ; P. Vian, Pier di Giovanni Olivi, Scritti scelti, Roma 1989 ; A. Boureau- S. Piron, Pierre de Jean Olivi, cit., p. 389-399; sur la théorie olivienne de l'intentionnalité nous renvoyons à la récente étude de D. Perler, Theorien der Intentionalität im Mittelalter, Frankfurt 2002.
} 
intérêt, n'ont pas encore fait l'objet d'une étude systématique ${ }^{5}$. A partir de cette constatation, l'examen qui suit entend contribuer à combler cette lacune afin d'apporter une pièce supplémentaire à la reconstitution de la pensée de Pierre de Jean Olivi.

Comme d'autres auteurs du XIIIe siècle, dans ses questions sur les créatures spirituelles Olivi discute des thèmes qui concernent tout autant l'être humain, mais qui dans le domaine angélologique trouvent un cadre de réflexion propice à une plus grande clarté et rigueur argumentative. Aussi, dans ses questions allons-nous rencontrer des clarifications importantes sur sa conception de la matière, de l'individualité, du rapport cognitif, de l'espace et du temps. La considération de ces différents aspects va permettre de répondre à l'interrogation qui guide cette enquête et qui porte sur la subjectivité angélique. Qui est l'ange ? Quel type de sujet représente-t-il ? Quel est son rapport avec la subjectivité humaine? Quelles sont sa valeur et sa fonction dans l'ordre universel ? Et enfin, quel pourrait être le rapport entre la doctrine olivienne des créatures spirituelles et sa conception de la pauvreté ? Ces différentes approches vont nous permettre en un premier moment de dessiner les contours de la subjectivité angélique, mais aussi de mieux saisir le statut de la subjectivité humaine et d'éclairer l'intérêt spéculatif et le projet existentiel d'Olivi.

Il apparaît d'emblée que pour celui qui a reçu l'appellation de vir angelicus $^{6}$, le domaine angélologique représente avant tout le lieu d'une confrontation radicale avec la tradition philosophique. Selon le franciscain en effet, les philosophes se sont largement trompés dans leur conception des substances séparées, et avec eux les théologiens qui en ont adopté certaines thèses sans comprendre leur danger pour la foi chrétienne ${ }^{7}$. La visée première de notre auteur dans le cadre de sa doctrine angélologique sera donc celle d'une révision théorique du statut de l'ange, une révision dans laquelle se joue par ailleurs le rapport avec la philosophie ${ }^{8}$. Cette démarche éminemment critique ne représente cependant pas son dernier mot, car elle s'articule au projet existentiel

\footnotetext{
Dans sa longue monographie sur la philosophie d'Olivi, E. Bettoni s'en tient à quelques considérations générales : cf. Le dottrine filosofiche di Pietro di Giovanni Olivi, Roma 1959, p. 152-159.

$6 \quad$ C'est ainsi que Bernardin de Sienne le caractérise : cf. P. Péano, Olieu, art. cit., p. 760.

Dans l'opuscule De perlegendis philosophorum libris (éd. F.M. Délorme, dans: Antonianum, 16 (1941), p. 31-44), Olivi déclare que les philosophes : « De substantia vero intellectuali separata minimum invenerunt. Unde Aristoteles, XI Metaphysicae, quasi pro magno credidit se probasse per motum orbium existentiam L. quinque motorum vel intelligentiarum. Omnes etiam proprietates, quas eis attribuunt, sunt ut plurimum erroneae, quia locuti sunt de eis tamquam quibusdam diis, sicut ex libro Proculi et ex libro De causis et ex libris Avicennae et Averroys et multis aliis aperte haberi potest » (p. 43). Comme on va le voir, dans les questions angélologiques Olivi sera encore plus catégorique dans sa condamnation des doctrines philosophiques sur les substances séparées.

Sur le rapport d'Olivi avec la tradition philosophique,voir, entre autres, E. Bettoni, Le dottrine filosofiche, cit., p. 55-66 ; O. Bettini, Olivi di fronte ad Aristotele, Studi francescani, 55 (1958), p. 176-197 ; D. Burr, Petrus Ioannis Olivi and the Philosophers, Franciscan Studies, 31 (1971), p. 41-71 et, du même A., L'histoire de P. Olivi, cit., p. 149-180 ; F.-X. Putallaz, Figures franciscaines, Paris 1997, p. 64-78.
} 
porté par l'idéal franciscain. Celui-ci représente sans doute l'intérêt majeur de Pierre de Jean Olivi, l'horizon à partir duquel il a pensé l'homme, l'ange, le monde et la marche de l'histoire vers le salut.

\section{Olivi et la matière}

On ne peut comprendre la réalité angélique dans la conception de Pierre de Jean Olivi sans clarifier sa notion de matière ${ }^{9}$. La systématisation aristotélicienne, qui associe les notions de matière et de forme pour expliquer la composition et le devenir dans le monde naturel, est déjà, en partie, le résultat d'une confrontation avec la doctrine platonicienne de "ylé » et de « eìdos" des notions qui peuvent à leur tour être ramenées à la «complémentarité pythagoricienne du pair et de l'impair et, par delà les présocratiques, à l'opposition de l'eau et de l'esprit, de la terre et du ciel, du mythe sémitique et indo-européen $»^{10}$. Loin de fournir un principe explicatif d'ordre purement physique, la notion de matière a fait l'objet, au cours des siècles, d'élaborations, de clarifications et d'interprétations qui en ont fait un élément important, voire de premier plan, aussi bien en métaphysique ${ }^{11}$ qu'en noétique $^{12}$ ou en théologie $^{13}$. Aussi, la conception de la matière est-elle révélatrice de l'orientation générale du système de pensée dont elle fait partie. Tel est le cas chez Olivi, qui fait de cette notion un thème majeur de confrontation avec les doctrines des philosophes. Pour notre auteur, en effet, l'enjeu est de taille, car la question de la matière est de celles qui importent dans la recherche d'une compréhension des choses conforme à la doctrine chrétienne : in iis que sunt fidei christianae aut multum ei propinqua ${ }^{14}$.

\footnotetext{
9 Comme A. Perez Estèvez l'a bien montré, la doctrine de la matière revêt une importance énorme dans la métaphysique d'Olivi : cf. La materia, de Avicena a la escuela franciscana, Maracaibo (Editorial de la Universidad de Zulia), 1998 (en particulier le ch. IX).

10 Cf. F. Brunner, La doctrine de la matière chez Avicebron, Revue de théologie et de philosophie, 1956, p. 261-279. Pour la conception de la matière chez Aristote, cf. H. Happ, Hylé. Studien zum aristotelischen Materie-Begriff, Berlin-New York 1971.

11 Que l'on pense, par exemple, à la doctrine de la matière comme principe métaphysique chez Ibn Gabirol (ou «Avicebron ») (cf. F. Brunner, art. cit.), ou encore à la conception de David de Dinant, dont l'écho se rencontre jusque chez Giordano Bruno (cf. De la cause, du principe et de l'Un, trad. de L. Hersant, Paris, Les Belles Lettres, 1996, p. 168, ainsi que De vinculis in genere, in : Opera latine circumscripta, Napoli-Firenze 1879-1891, vol. III, p. 693).

12 Que l'on pense à l' »intellect matériel » des commentateurs grecs d'Aristote et des philosophes arabes du Moyen Age.

13 Que l'on songe à la problématique de la transformation de la « quantitas materiae » soulevée par le dogme de la transsubstantiation; à ce propos cf. M. Jammer, Concepts of Mass in Classical and Modern Physics, Harward 1961.

14 Quaestiones In II Sententiarum (dorénavant: Quaest. in II Sent.), qu. XVI, vol. I, p. 337 : nous citons l'édition critique en 3 volumes de B. Jansen, Quaracchi 1922-26.
} 
Qu'est-ce que la matière ? Olivi explique sa conception dans une série de ses Questions sur le IIe livre des Sentences de Pierre Lombard ${ }^{15}$; plus précisément dans les questions XVII : Secundo quaeritur an potentia materiae addat aliquid realiter diversum ad essentiam eius; XVIII : Tertio quaeritur an materia possit esse per se principium efficiens alicuius ; XIX : Quarto quaeritur an Deus possit facere esse materiam sine omni forma ; XX : Quinto quaeritur an materia habeat diversas differentias materiales per quas specificetur, sicut in formis videtur; XXI : Sexto quaeritur an materia per essentiam suam sit una numero in omnibus, corporalibus saltem. Dans la question XVI - Primo quaeritur an in angelis et in omnibus substantiis intellectualibus sit compositio materiae et formae - on trouve également d'importants développements sur la notion de matière, mais en rapport avec le problème particulier de la composition hylémorphique des substances séparées : nous traiterons donc cette question séparément et nous ne retiendrons pour le moment que ce qui contribue à clarifier la réalité de la matière en tant que telle ${ }^{16}$.

Prenant comme point de départ la conception aristotélicienne de la matière première comme pure indétermination et potentialité, Olivi soulève le problème du rapport entre la potentialité et l'essence de la matière. Il tranche d'emblée cette question en affirmant l'identité réelle de la potentialité et de l'essence de la matière ${ }^{17}$. Cette thèse repose sur deux argumentations. La première considère la réceptivité de la matière et peut être résumée ainsi : si la potentialité et l'essence de la matière ne coïncidaient pas, cela impliquerait que la puissance soit reçue dans l'essence de la matière ; mais elle ne pourrait y être reçue que grâce à une puissance ou faculté de réception donnée préalablement, ce qui entraînerait un processus de régression à l'infini dans l'ordre de la faculté de recevoir ${ }^{18}$. Par ailleurs, si la potentialité était différente de l'essence de la matière, elle lui serait inhérente comme forme, car tout ce qui inhère à la matière et la détermine est une forme; mais cela est parfaitement absurde, car la potentialité de la matière signifie précisément l'ordonnancement de la matière à

\footnotetext{
15 Les Quaestiones in secundum librum Sententiarum, qu'il faut distinguer du Commentaire des Sentences, datent des années 1277-1283 et ont été remaniées vers 1295/1296; cf. D. Burr, L'histoire de Pierre Olivi, cit., p. 21 sv.; M. Bartoli, Opere teologiche e filosofiche di Pier di Giovanni Olivi, Archivum Franciscanum Historicum, 91 (1998), p. 455-468; S. Piron, Les ouvres perdues d'Olivi : essai de reconstitution, ibid., p. 357-394.

16 Pour de plus amples considérations sur la notion de matière chez Olivi, cf. E. Bettoni, Le dottrine filosofiche di Pier di Giovanni Olivi, cit., p.263-292, et surtout A. Perez-Estevez, La materia en Juan Pedro de Olivo, Revista de filosofia, 18 (1993), p. 33-61 ainsi que La materia, de Avicena a la escuela franciscana, cit., p. 281-332.

17 Cf. Quaest. In II Sent., qu. XVII , vol. I, p. 357: « Credo tamen cum aliis quod [ratio potentiae et ratio essentiae] penitus sint eadem secundum rem ».

$18 \quad$ Cf. ibid. : «Si enim essent diversae, tunc potentia esset recepta in essentia materiae ; recepta autem esse non posset, nisi materia haberet in se aliam potentiam per quam posset eam recipere, et sic iretur in infinitum ».
} 
l'égard de la forme ${ }^{19}$; il faut en conclure que la potentialité et l'essence de la matière ne font qu'un ${ }^{20}$.

La seconde argumentation considère la nature ou raison propre de la matière. En effet, si on l'envisage abstraction faite de tout le reste, on ne peut la comprendre que comme possible à l'égard de tout ce qu'elle peut devenir : l'essence de la matière réside donc bel et bien dans sa potentialité à l'égard de toutes les actualisations possibles. C'est pourquoi, si essence et potentialité ne coïncidaient pas, la matière pourrait être conçue comme non-possible et nondéterminable et par conséquent comme un étant déjà déterminé par soi, ce qui contredirait sa définition d'étant en puissance ${ }^{21}$. Olivi observe par ailleurs que cette définition implique que la potentialité soit au moins une partie de l'essence de la matière ; mais il se trouve qu'elle ne peut pas en être seulement une partie, car la matière, en tant qu'elle représente un des principes premiers, est une réalité simple ${ }^{22}$; il faut donc en conclure que la potentialité ne fait qu'un avec l'essence de la matière ${ }^{23}$. Olivi refuse ainsi tout écart ou différence entre la matière et sa potentialité : il accepte leur distinction de raison, mais n'admet pas qu'à cette distinction corresponde une différence réelle ${ }^{24}$. Entre la pensée et la réalité il n'y a pas de correspondance directe et nécessaire: aussi, malgré la disposition de la matière à l'égard d'une multiplicité de formes, on ne peut davantage poser une distinction réelle entre ses dispositions; on peut certes distinguer dans la matière plusieurs raisons correspondant à ses différentes potentialités, mais dans la réalité ces raisons coïncident avec l'essence de la matière ${ }^{25}$.

\footnotetext{
19 Cf. ibid. : « Oporteret etiam quod ipsa potentia esset quaedam forma, quia omne quod inhaeret materiae et quod determinat eam aliquo modo est forma materiae, unde et materia ordinatur ad omne quod in se recipit sicut ad suum actum (...). Nemo autem rationabiliter dicere potest quod potentia materiae sit forma, cum per eam non significemus nisi solum ordinem materiae ad formam".

20 Cf. ibid. : « Ratio igitur receptionis et inherentiae clamat ipsam potentiam non esse aliquid diversum ab essentia materiae $»$.

21 Cf. ibid., p. 357-358: "Ostendit etiam hoc ipsa essentia materiae et ratio eius. Omnibus enim aliis amotis ipsa per se est sufficienter possibilis ad omnia quae in ea possunt esse; unde nullo modo potest intelligi nisi ut possibilis. Si autem potentia diceret aliquid ab ea diversum, potentiis amotis ipsa non esset possibilis ad aliquid et ita de se nullum haberet ordinem aut respectus ad suas formas possetque intelligi ut non possibilis et sic per consequens ut a nullo determinabilis; et ita sequeretur quod cum omne ens sit determinabile ab alio aut terminus seu determinatio eius, quod ipsa possit intelligi vere ut quoddam ens de se sufficienter determinatum ».

$22 \quad$ Cf. ibid., p. 358: "Definitio materiae est ens in potentia seu ens possible; ergo possibilitas seu potentia est pars suae definitionis et ita ad minus est pars suae essentiae ; sed non potest esse pars, quin sit idem penitus quod tota eius essentia, cum materia sit unus de primis principiis et ita non possit esse composita ex diversis principiis quorum unum sit genus, alterum vero differentia eius ».

23 Cf. ibid.: « Ergo materia et sua possibilitas erunt omnino idem ».

24 Cf. ibid., p. 356 : « Quidam dixerint quod potentia sit accidens materiae (...), quia ubique sumpserunt pro primo principio quod ubicumque est diversitas rationum realium, semper est ibi diversitas essentialis; constat autem rationem potentiae et rationem essentiae ipsius materiae esse rationes diversas (...), credo tamen quod sint eadem secundum rem ».

25 Cf. ibid., p. 360 : « Materia non habet plures potentias passivas essentialiter inter se differentes, sed in essentia sua includuntur rationes plurium potentiarum absque omni diversitate reali (...). Sic et in materia dicuntur esse plures potentiae propter hoc solum, quia ipsa est per suam essentiam possibilis ad plures formas absque omni diversitate reali ».
} 
L'identification de la nature de la matière et de sa potentialité entraîne une conséquence importante. En effet, l'essence étant ce qui fait d'une réalité ce qu'elle est, elle constitue son noyau irréductible et permanent au-delà de tous les changements qui peuvent l'affecter. Ainsi, à partir du moment où l'essence de la matière est identifiée à sa potentialité, il faudra admettre que cette dernière subsiste malgré l'actualisation de la matière par la forme. Or, c'est précisément ce que défend Olivi, en s'écartant ainsi radicalement de la conception aristotélicienne, d'après laquelle l'actualisation par une forme supprime la potentialité de la matière à l'égard de cette forme. Notre auteur soutient au contraire que la potentialité de la matière subsiste même après sa détermination par la forme. La raison en est que l'actualisation par une forme n'affecte pas l'essence-même de la matière, mais seulement sa relation à la forme : c'est pourquoi, alors qu'avant son actualisation la matière était ordonnée à la forme en tant qu'absente, après son actualisation elle est ordonnée à la même forme en tant que présente en elle ${ }^{26}$. Le résultat de ces considérations est donc que la matière est une réalité différente de la forme, séparée d'elle, bien qu'essentiellement ordonnée à elle. Matière et forme ne sont pas seulement les deux faces d'une même médaille, mais représentent deux réalités distinctes possédant chacune son entité propre. Leur réciprocité est essentielle, mais elle n'annule pas la consistance propre de chacune d'elles. Selon Olivi, la matière est donc un étant à proprement parler, un étant certes sui generis, mais dont la nature ne peut pas être supprimée par sa réduction à la forme qui la détermine: actualitatem essentiae suae [sc. materiae] vere est aliquid, licet indeterminatum $^{27}$.

Sur l'arrière-fond de ces considérations notre auteur, se réclamant de Saint Augustin $^{28}$, critique ouvertement la conception aristotélicienne de la matière comme pure puissance, sans consistance ni actualité propre. En effet, à partir du moment où on définit la matière (comme puissance à l'égard de la forme), on lui reconnaît nécessairement une nature ou essence; or, l'essence renvoie à une certaine actualité, car elle signifie l'acte propre d'une réalité ; par conséquent, si la matière a une essence propre, elle possède également une actualité propre,

\footnotetext{
26 Cf. ibid., p. 362 : « Dicendum quod essentia potentiae quam ante adventum formae habebat tota remanet post adventum formae, sed solum ordo et habitudo eius variatur, quia prius ordinabatur ad formam ut ad absentem, modo vero ut ad praesentem, unde et materia habet adhuc in se potentiam in qua ipsa forma est recepta et fundata $»$.

Ibid., qu. XXI, vol. I, p. 387. En réalité la position d'Olivi est complexe, car elle maintient l'idée d'une certaine actualité de la matière - un motif caractéristique de la tradition augustinienne et source de la doctrine de la pluralité des formes -, mais s'écarte de cette tradition et se rapproche de la doctrine aristotélicienne lorsqu'il considère que la matière n'existe pas actuellement sans une forme: cf. à ce propos E. Bettoni, Le dottrine filosofiche, cit., p. 292.

28 Cf. Confessions XII, 17-20 (PL 32, p. 835-837).
} 
c'est-à-dire une existence indépendante de celle de la forme ${ }^{29}$. Cette thèse est confirmée par plusieurs arguments, dont on retiendra le suivant: rien ne peut être fondé dans une réalité qui ne possède aucune actualité ; aucune puissance passive ni aucune forme ne pourrait donc être fondée dans la matière si celle-ci ne possédait pas une certaine actualité ${ }^{30}$; il faut en conclure que la matière possède une consistance et une actualité propre ${ }^{31}$.

Cela dit, si la matière possède une nature réellement distincte de celle de la forme, son actualité ne peut pas être celle qu'elle reçoit de la forme : d'où vient-elle et en quoi consiste-t-elle? Olivi le clarifie par la confrontation avec l'actualité de la forme : celle-ci est un acte déterminé, c'est-à-dire un terme qui n'est pas déterminable; par opposition, l'actualité de la matière doit être conçue comme étant par essence indéterminée et déterminable ; la matière est ainsi par sa propre essence en puissance à l'égard de ses déterminations possibles ${ }^{32}$. L'actualité de la matière, comme son essence, réside donc dans la potentialité et la réceptivité, ce qui pour notre auteur n'exclut d'aucune façon le fait d'être une réalité à part entière ${ }^{33}$. Le propre de l'essence de la matière est ainsi de posséder l'actualité qui consiste à être en puissance ou, si l'on préfère, la capacité actuelle de réceptivité à l'égard de la forme.

Cette thèse a d'importants retentissements. D'une part, en accordant à la matière une réalité indépendante de celle de la forme, elle la valorise et lui reconnait une richesse propre, qui est celle de tout ce qu'elle est capable de recevoir et de devenir. Dans cette perspective, la matière représente un élément essentiel de transformation et d'évolution de la réalité, car elle porte en elle une variété inépuisable de potentialités : aussi, la matière peut-elle être considérée comme le moteur du dynamisme qui habite l'ensemble de la réalité ${ }^{34}$. D'autre part, par l'équation essence/actualité de la matière = être en puissance, Olivi

\footnotetext{
29 Cf. Quaest. In II Sent., qu. XVI, vol. I, p. 305-306 : « materiam secundum suam essentiam dicit aliquem actum seu actualitatem, distinctam tamen sufficienter ab actu qui est idem quod forma ». A. Perez Estèvez, La materia, cit., p. 288, signale la dépendance d'Olivi sur ce point par rapport à Jean Peckham.

$30 \quad$ Cf. ibid., p. 306 : « Praeterea, nihil potest fundari et stabiliri actualiter in eo quod de se nihil habet actualitatis ; ergo nec potentia passiva nec forma aliqua potest fundari in materia, si ipsa per se nihil habet actualitatis ».

$31 \quad$ Cf. ibid., p. 307 : « Tenendum est igitur, ut credo, quod materia non sit solum potentia, sed praeter hoc quidam solidum habens in se rationem non solum unius potentiae, sed etiam plurium, sicut ipsemet Aristoteles vult; ad contrarias enim formas et disparatas diversas habet secundum eum potentias, quod tamen esse non posset, si ipsa non esset aliud quam mera potentia ».

Cf. ibid., p. 308 : « actualitas huius [sc. materiae] est per suam essentiam indeterminata et determinabilis ; ita per suam essentiam est in potentia ad alia tamquam per suam essentiam possibilis determinari per ea. Forma vero seu actus formalis est per suam essentiam determinatus seu potius terminus et terminatio et ab alio non determinabilis ». Pour la notion de forme, cf. Th. Schneider, Die Einheit des Menschen, Münster 1972, p. 232 sv.

Cf. Quaest. In II Sent., qu. XVI, vol. I, p. 309 : « ipsa [sc. materia] sic est ens quod eius actualitati non repugnat esse in potentia et esse indeterminatum; sed potius hoc convenit sibi essentialiter, esse scilicet in potentia, non respectu sui, sed respectu aliorum quae in ea possunt fieri ».

34 Cf. O. Bettini, L'attivismo psicologico-gnoseologico nella dottrina della conoscenza di Pier Giovanni
} Olivi, Studi francescani, 25 (1953), p. 31-64 et p. 201-223. 
introduit l'idée d'une réalité qui est pure réceptivité, l'idée d'un sujet entièrement ouvert à ce qui peut lui donner forme, c'est-à-dire d'un substrat (matière) dont l'actualité réside dans sa passivité et sa malléabilité. On peut d'ores et déjà imaginer qu'une telle considération de la matière a des retombées théologiques importantes et qu'elle va exercer son influence sur la conception olivienne des créatures spirituelles.

Mais avant d'en arriver là, précisons davantage la réalité sui generis de la matière. Subsistant actuellement en vertu de sa potentialité, la matière se présente comme un substrat capable de recevoir une multiplicité de formes. Or, étant donné que les formes qui peuvent la déterminer sont réellement différentes, voir opposées les unes à l'égard des autres, il y a lieu de se demander si à ces formes correspondent dans la matière des différences matérielles susceptibles de spécifier sa réceptivité en étant réellement distinctes d'elle. A partir des considérations précédentes, on devine que la réponse d'Olivi est négative : dans la matière il y a bel et bien différentes potentialités ou raisons de réceptivité à l'égard de formes diversifiées, mais elles ne se distinguent pas réellement de l'essence de la matière ${ }^{35}$. Faut-il considérer pour autant que la matière première est le substrat actuel, unique et universel de toutes choses?

Olivi examine cette question en rapportant l'opinion qui veut que la matière, en tant que spoliée de toute forme, est une réalité commune et unique en toutes choses ${ }^{36}$. C'est la thèse soutenue par Ibn Gabirol (« Avicebron » pour les latins) dans le Fons vitae - un texte rédigé originairement en arabe vers la moitié du XIe siècle et devenu célèbre dans la culture latine dès le début du XIIIe siècle grâce à la traduction de Jean d'Espagne et de Gundissalinus ${ }^{37}$.

35 Cf. Quaest. in II Sent., qu. XX, vol. I, p. 372-373 : «Quidam aliquando voluerunt dicere, etiam moderni, quod in materia est dare differentias materiales realiter differentes a natura communi materiae cum qua componuntur et quam specificant et inter se invicem oppositas (...). Istud autem non credo quod stare possit ». Olivi invoque à ce propos plusieurs raisons, dont voici quelques extraits significatifs : « Praeterea, ista differentia est in eo cui additur; ergo est ibi aliquo modo essendi in. Et utique iste vel erit inhaerentia accidentalis, vel substantialis, et tunc erit vere forma. Item, ratio materiae est quod sit primum subiectum et quod non sit in alio ; ergo ista differentia habet oppositas rationes ad rationem substantiae materiae », ibid., p. 373 ; « Secundo patet hoc ex ratione specificationis : tum quia haec non poterit intelligi sine aliqua specificatione et determinatione quae materiae respectu generis sui non competit; tum quia specificatio et determinatio seu specificans et determinans sunt vere actus specificabilis et determinabilis et ita vere sunt eius forma et specificabile vere erit eius materia ; tum quia sicut generalis natura formae et specialis dicuntur duae formae, ita et ista dicentur duae naturae materiales vel duae materiae », ibid., p. 374 ; «Tertio patet hoc ex ratione transmutationis seu motus : omnis enim materia terminatur ad aliquid formaliter, quia terminus motus magis habet rationem actus et formae quam motus ; omnis autem motus est actus mobilis ; ergo istae differentiae, cum sint termini motuum per quos introducuntur, magis erunt formales quam ipsi motus », ibid.. De ces différentes raisons il résulte que selon Olivi attribuer à la matière des potentialités ou des raisons de réceptivité réellement différentes de l'essence de la matière reviendrait à introduire dans l'essence de la matière des formes proprement dites. A. Perez Estèvez discute cette problématique dans : La materia, cit., p. 297 sv.

$36 \quad$ Cf. Quaest. In II Sent., qu. XX, vol. I, p. 375 : « Alii autem dicunt quod materia, prout cogitatur ut denudata omni forma, est simpliciter una secundum essentiam et potentiam in omnibus ».

37 Penseur juif qui vécut dans l'Espagne musulmane, Ibn Gabirol naquit à Malaga en 1021 et mourut à Valence en 1055. Porte-parole du néoplatonisme, il s'en écarta aussi sur plusieurs points : cf. S. Munk, Mélanges de philosophie juive et arabe, Paris 1859 ; G. Vajda, La pensée juive au Moyen Age, Paris 1947, p. 75 sv. ; C. 
Défendant précisément la thèse d'une matière universelle préalable à toutes choses et condition de leur existence, Ibn Gabirol est considéré la source de la position caractérisée comme "hylémorphisme universel», répandue dans la culture philosophique et théologique du XIIIe siècle latin - notamment chez les penseurs franciscains ${ }^{38}$ - et dont Thomas d'Aquin a fait sa cible dans le traité sur les substances séparées ${ }^{39}$.

La confrontation d'Olivi avec la position d'Ibn Gabirol mérite d'être relevée, car elle permet de mieux préciser la position de notre auteur. En effet, bien qu'Olivi partage certains points de la doctrine du Fons vitae - et notamment l'idée de la matière comme possibilité d'être ainsi que celle de la composition hylémorphique de tout le créé comme tel ${ }^{40}$-, il n'admet pas la thèse de l'universalité de la matière comme substrat ou support commun et préalable à toutes choses, diversifié seulement par la réception d'une forme. La raison invoquée par notre auteur est très importante, car elle introduit une distinction essentielle dans la réalité de la matière. En effet - poursuit le franciscain -, s'il y avait une seule matière commune à toutes choses, préalable à la réception des différentes formes, il s'ensuivrait que dans la matière spirituelle il pourrait y avoir une forme corporelle et que la matière corporelle pourrait recevoir une forme spirituelle, ce qui est parfaitement absurde ${ }^{41}$. On ne peut donc pas admettre une matière une et unique pour toutes choses, mais il faut poser une distinction irréductible entre la matière corporelle et la matière spirituelle : celleci, en effet, ne peut recevoir aucune forme corporelle, de même que la matière corporelle ne peut pas être informée par une forme spirituelle ${ }^{42}$. Ces deux types de matière diffèrent essentiellement, car la nature de la matière corporelle est de

Sirat, La philosophie juive au Moyen Age, Paris 1983. Le Fons vitae a été édité par C. Baeumker, dans Beiträge zur Geschichte der Philosophie des Mittelalters, Bd. I, Heft 2-4, Münster 1895. Le livre III a été traduit une première fois en français par F. Brunner, Ibn Gabirol (Avicebron), Source de vie, livre III, Paris 1950. Auteur d'importantes études sur Ibn Gabirol, F. Brunner a présenté la conception de la matière du Fons vitae dans son article : La doctrine de la matière, cit., et dans : Platonisme et aristotélisme : la critique d'Ibn Gabirol par St. Thomas d'Aquin, Louvain-Paris 1965. Une traduction intégrale du Fons vitae est également disponible : Salomon Ibn Gabirol, Livre de la source de vie, trad. de J. Schlanger, Paris 1970.

$38 \quad$ Cf. E. Kleineidam, Das Problem der hylemorphischen Zusammensetzung der geistigen Substanzen im 13. Jahrhundert behandelt bis Thomas von Aquin, Breslau 1930, p. 9-46.

39 Cf. De substantiis separatis, c. 5-8; à ce propos cf. P. Ferrer Rodriguez, La inmaterialidad de las sustancias espirituales (Santo Tomas versus Avicebron), Pamplona 1988 (Excerpta et dissertationes in sacra teologia, n. XV), ainsi que F. Brunner, Platonisme et aristotélisme, cit.

$40 \quad$ Ces deux thèses sont partagées aussi par Bonaventure, qui considère la matière comme un principe constitutif universel ; Olivi va s'écarter - comme on va le voir - aussi bien d'Ibn Gabirol que de Bonaventure, car celui-ci, comme le premier, pose l'existence d'une matière simple et unique, indifférenciée et apte à recevoir n'importe quelle forme : cf. Bonaventure, In II librum Sententiarum, d. III, p. I, qu. 1-3 (Opera omnia, t. II, Quaracchi 1885, p. 89 sv.). A ce propos, cf. E. Bettoni, Le dottrine filosofiche, cit., p. 291-292.

$41 \quad$ Cf. Quaest. In II Sent., qu. XX, vol. I, p. 375 : «Sed hoc non videtur posse stare, quia tunc in spirituali materia posset poni, quantum est ex seipsa, forma corporalis, et possemus ibi dare partes, et in corporali posset forma spiritualis poni, et in ea partes non esset dare ex seipsa et per se ». En réalité, cette lecture du Fons vitae ne paraît pas correcte, selon l'interprétation formulée par F. Brunner, Platonisme et aristotélisme, cit., p. 52. 42 Cette considération ne va pas sans problèmes pour l'articulation du corps et de l'esprit dans l'être humain : cf. Th. Schneider, Die Einheit des Menschen, cit., qui montre très bien la complexité de la solution d'Olivi, proche à la fois de la doctrine thomasienne de l'unité substantielle et de celle de la pluralité des formes. 
posséder des parties potentielles - et donc d'être composée en puissance -, alors que la nature de la matière spirituelle est de ne pas posséder de telles parties, c'est-à-dire d'être simple en puissance ${ }^{43}$. Différant dans leurs raisons propres, ces deux types de matière ne sauraient être ramenées à un substrat commun préalable ${ }^{44}$.

L'enjeu de la critique d'Olivi à l'égard de la thèse de l'universalité de la matière réside donc dans la distinction entre la matière corporelle et la matière spirituelle : chez le franciscain cette distinction est de la plus haute importance, car si d'une part elle sauvegarde l'homogénéité du créé, d'autre part elle rend raison des deux manières de subsister que représentent les réalités corporelles du monde sublunaire et les entités spirituelles angéliques. Les définitions respectives de ces deux types de matière permettent par ailleurs de sauvegarder les caractéristiques propres de chacune d'elles : la composition d'un côté et la simplicité de l'autre.

Aussi, faisant retour à la question initiale de la présence en la matière de différences matérielles spécifiant sa réceptivité, Olivi répond-t-il en choisissant une "voie moyenne" entre la différence réelle et l'unité indistincte de la matière. Cette via media consiste à affirmer que dans la matière il y a des raisons différentes (de réceptivité), qui ne se distinguent cependant pas réellement de la matière et ne composent pas avec elle ${ }^{45}$. Celle-ci subsiste - comme on l'a vu en tant que puissance réceptive ou capacité d'être : non pas comme un substrat unique, mais en étant différenciée selon les raisons que sont la composition potentielle de parties (matière corporelle) et la simplicité potentielle (matière spirituelle).

On ne peut que constater à la fois la complexité et l'originalité de la via media choisie par notre auteur : elle consiste à maintenir la raison commune de matière, tout en la différenciant essentiellement; elle nie la subsistance d'une matière commune préalable à toutes choses, mais maintient l'étendue de la raison de matérialité à l'ensemble du créé ${ }^{46}$. Il convient d'observer que la determinatio d'Olivi repose sur deux éléments : d'une part la conviction qu'une

\footnotetext{
43 Cf. Quaest. In II Sent., qu. XX, vol. I, p. 375-376 : « Differunt igitur veraciter materia corporalis et spiritualis secundum definitiones et rationes sibi essentiales (...), quia una haberet multitudinem in potentia et non simplicitatem, alia simplicitatem in potentia et non multitudinem partium $\gg$.

$44 \quad$ Ibid., p. 375 : «Differunt igitur veraciter materia corporalis et spiritualis secundum definitiones et rationes sibi essentiales $»$.

$45 \quad$ Cf. ibid., p. 376 : « Media igitur via videtur hic esse incedendum, ut videlicet dicamus quod materia non habet differentias formales realiter ab ea differentes et realiter cum materia compositas ».

$46 \quad$ Cf. ibid. : « Dicendum igitur quod in materia non sunt aliquae differentiae materiales quae aliquid addant realiter ad essentiam eius, ita quod sit ibi realis unio et compositio ; bene tamen est ibi dare differentes rationes quarum una secundum intellectum communior est et quasi universalis respectu alterius, sicut materiae corporali et spirituali ratio materiae et possibilis est communis. Ratio autem corporeitatis et spiritualitatis indeterminatae a qua magis debet dici possibilis quam actualis sunt earum rationes speciales ».
} 
distinction de raison n'implique nullement une différenciation réelle ${ }^{47}$; d'autre part, en revanche, l'idée de la correspondance nécessaire, dans l'ordre du réel, entre une modalité spécifique de subsistance et la matière en tant qu'élément constitutif de ce mode particulier d'existence ${ }^{48}$. Olivi desserre ainsi le lien entre la pensée et la réalité, mais renforce celui de chaque réalité avec ses propres principes constitutifs. Cette conception de la matière et de sa fonction annonce ainsi d'ores et déjà un des thèmes marquants de la pensée d'Olivi : celui de la consistance et de la primauté de chaque réalité singulière.

Cet aspect est avancé dans la question XXI - An materia per essentiam suam sit una numero in omnibus, corporalibus saltem -, qui reprend la problématique de l'universalité de la matière pour l'appliquer uniquement aux réalités corporelles. La question consiste à savoir s'il faut poser un support matériel commun à toutes les réalités corporelles, différencié seulement par la réception de formes corporelles différentes, de telle sorte que ce type d'entités partagerait un même principe constitutif. La réponse d'Olivi est claire: la matière n'existe pas comme une masse ou un support donné qui fournirait aux choses une partie de leur subsistance ${ }^{49}$. Une telle entité universelle n'existe pas dans la réalité : universale enim secundum rem nullo modo est unum in pluribus $^{50}$. Dans la réalité donnée rien ne subsiste en dehors des entités singulières : l'universel est une abstraction qui ne possède une existence que dans l'ordre de la raison ${ }^{51}$. L'attribution à l'universel d'une subsistance réelle résulte de l'illusion qu'à la pensée corresponde nécessairement la réalité et implique tous les inconvénients qu'Aristote avait déjà relevé par rapport à la théorie platonicienne des idées ${ }^{52}$. Il n'y a donc pas une matière unique préalable aux choses singulières, mais il y a une matière individuée pour chaque réalité individuelle : materia vero prout est in re, semper est individua ${ }^{53}$. L'universalité et l'unité que notre auteur est prêt à admettre est donc celle d'une essence ou raison commune (la potentialité ou capacité réceptive à l'égard de la forme), qui ne subsiste pas comme telle dans la réalité, mais qui est présente comme raison dans chaque entité individuelle ${ }^{54}$, à la manière dont l'humanité possède une

\footnotetext{
$47 \quad$ Cf. ibid., p. $377:$ : Non omnis diversitas rationis realis ponit semper diversitatem realem in essentia super quam fundatur ». Ceci ne signifie pas que la connaissance n'ait pas de fondement objectif : cf. A. Perez Estèvez, La materia, cit., p. 299-300.

$48 \quad$ Cf. ibid. : « Materia autem corporalis est propria materia corporalium et spiritualis spiritualium per essentiam suam, sed non per aliquid reale additum alicui naturae materiali quae sine differentia illa esset communis formae spirituali et corporali ».

49 Cf. ibid., qu. XXI, p. 383 : « Non sunt omnes materiae una massa simplex ».

Ibid., p. 381.

Cf. ibid., qu. XIII, vol. I, p. 247 : « Universalia nullam habent universalitatem nisi solum in intellectu et secundum intellectum, ita quod nihil sit in rebus extra intellectum aliquo modo nisi particulare et individuatum ». 52 Cf. ibid.., qu. XXI, vol. I, p. 381 : « Universale enim secundum rem nullo modo est unum in pluribus, quia infinita impossibilia sequerentur, sicut alibi habet ostendi, et omnia illa inconvenientia quae ostendit Aristoteles sequi ad positiones Platonis de ideis ».

$53 \quad$ Cf. ibid., qu. XX, vol. I, p. 378.

$54 \quad$ Cf. ibid., qu. XXI, vol. I, p. 381 : «Essentia materiae habet unitatem secundum intellectum, habet tamen secundum rem veram diversitatem $»$.
} 
unité de raison et une diversité réelle dans les individus. Aussi, dans l'ordre du réel, la matière est-elle différente dans chaque réalité individuelle, malgré le fait que chaque entité singulière possède la raison commune de matière, à savoir la réceptivité et la déterminabilité : materia est alia numero per essentiam in qualibet re ab illa quae est in alia $r^{55}$.

Dans le prolongement de ces considérations, il apparaît que selon Olivi le singulier ne saurait être une réalité secondaire, participant d'un universel qui le précède et le rend possible, mais est une donnée originaire et unique. En effet, de même que chaque chose se distingue des autres, ainsi les principes constitutifs d'une chose diffèrent des principes constitutifs d'une autre chose: Sicut enim entia sunt distincta realiter, sic et principia eorum constitutiva ${ }^{56}$. Dans cette perspective, chaque réalité créée est véritablement une et unique, première et irréductible ${ }^{57}$. La considération de l'acte de création confirme ce fait : Olivi précise en effet que la création d'un étant est création de tout ce qui appartient à son essence, à savoir de toutes ses parties constitutives. La matière étant une de ces parties, à chaque création d'un étant la matière de cet étant est aussi créée, non seulement dans l'être qu'elle reçoit de la forme (c'est-à-dire sa détermination), mais encore dans son essence de substrat d'être et de forme ${ }^{58}$. Chaque réalité créée est donc une réalité inédite : essentia materiae in quolibet creatur de novo. Ergo ipsa essentia est alia et alia in quolibet creato sicut et esse et sicut forma creata ${ }^{59}$.

Telle est l'issue de la conception olivienne de la matière : la valorisation de son actualité comme puissance de réceptivité aboutit à la valorisation de chaque réalité singulière comme position gratuite et originaire dans l'être. A la manière de l'artiste qui façonne chacune de ses pièces ex novo, avec une matière différente et à partir d'une idée différente, ainsi le créateur façonne chaque créature comme une réalité nouvelle et inédite, comme une expression originaire de sa capacité de création. Cette diversité irréductible n'efface pas pour autant la raison commune de matérialité, qui est celle d'une attente d'être et de forme et qui - comme on va le voir - coïncide en dernière analyse avec la raison de créaturalité. La conception olivienne de la matière conjugue ainsi de manière

\footnotetext{
55 Cf. ibid., p. 386; et encore : « ipsa [sc. materia] ut est sub uno esse per essentiam suam et non solum per esse differt ab alia materia quae est sub alio esse numero ».

$56 \quad$ Ibid., p. 385.

$57 \quad$ C'est ce qui résulte aussi clairement de la conception olivienne de l'individuation : l'individu n'est pas un être secondaire et moindre par rapport à une essence dont il participerait, mais une réalité qui ajoute quelque chose de positif à la raison commune et universelle d'humanité, laquelle d'ailleurs ne subsiste pas en dehors des individus : cf. Quaest. In II Sent., qu. XII, vol. I, p. 226 sv. ; W. Hoeres, Der Unterschied von Wesenheit und Individuation bei Olivi, Scholastik, 38 (1963), p. 54-61.

58 Cf. ibid., qu. XXI, vol. I, p. 385 : «Patet hoc aspiciendo ad creationis veritatem. Quando enim creatur unum ens, creatur vere tunc quidquid est de essentia eius et maxime quod est eius pars constitutiva. Ergo vere tunc creatur materia non solum secundum esse quod recipit a forma, sed etiam eius essentia quam habet sub forma et in qua recipitur tam forma quam illud esse ».

${ }_{59} \quad$ Cf. ibid., p. 385-386.
} 
rigoureuse et originale certains éléments de l'hylémorphisme universel dérivé du Fons vitae ${ }^{60}$ avec une ontologie du singulier : il en résulte une valorisation de la nouveauté de chaque être qui sauvegarde néanmoins la raison commune et universelle de potentialité, de réceptivité et d'ouverture à l'acte créateur.

\section{L'ange et la matière ou la composition hylémorphique des substances séparées}

Confrontés à la thèse de l'hylémorphisme universel, les auteurs du XIIIe siècle étaient amenés à discuter le problème des principes constitutifs des choses : les êtres sont-ils composés ? et si oui, quels sont les éléments qui les composent? La réponse, relativement simple en ce qui concerne les réalités du monde matériel, n'allait pas de soi lorsqu'on envisageait des entités spirituelles comme l'âme humaine et les anges. Ici le problème était double : il y avait d'une part la question générale de la composition, et il y avait ensuite celle du mode de composition susceptible d'affecter ce type de réalités : composition de matière et de forme ou composition métaphysique d'essence et d'être uniquement ? ${ }^{61}$. Il va sans dire que la solution de ces questions dépendait de l'idée qu'on se faisait de ces notions - et notamment de celle de matière -, de même qu'elle relevait de choix fondamentaux au niveau de l'ontologie et de la métaphysique.

L'histoire de cette problématique a déjà été partiellement retracée. Dans sa dissertation de 1930, E. Kleineidam a reconstitué le débat sur la composition hylémorphique des substances spirituelles depuis les années 1230 jusqu'à Thomas d'Aquin ${ }^{62}$. O. Lottin a complété cette enquête en analysant les débuts de la controverse ${ }^{63}$. D'autres travaux ont suivi, consacrés surtout au rapport entre les doctrines d'Ibn Gabirol et de Thomas d'Aquin ${ }^{64}$, mais l'après-Thomas

\footnotetext{
60 Olivi ne se réfère pas explicitement à Avicebron : son hylémorphisme universel est déjà médiatisé par celui de Bonaventure et de ses disciples. A. Perez Estèvez (La materia, cit., p. 285-292) rattache la conception d'Olivi à celle d'Avicenne, médiatisée par les élaborations de Jean Pechkam et de Roger Marston.

61 L'idée de la composition métaphysique des êtres était appuyée sur deux sources : Boèce, qui avait distingué l' »esse » du « id quod est » (cf. Quomodo substantiae in eo quod sint, bonae sint, P.L. 64, p. 1311C et Quomodo trinitas unus Deus, c. 2, P.L. 64, p. 1250C) - une distinction qui sera fixée par Gilbert de la Porrée dans la formule « id quod est » et « id quo est » qu'on retrouve le plus souvent par la suite -, et Avicenne, qui avait distingué l'existence des choses de leur essence (cf. Métaphysique I, 5 ; IV, 2).

$62 \quad$ Cf. Das Problem der hylemorphen Zusammensetzung, cit.

63 Cf. La composition hylémorphique des substances spirituelles. Les débuts de la controverse, Revue néoscolastique de philosophie, 34 (1932), p. 21-41.

$64 \quad$ Cf. F. Brunner, Platonisme et aristotélisme, cit.; J.I. Sarayana, Sobre la inmaterialidad de las sustancias espirituales (Avicebron y Santo Tomàs), Rivista di filosofia neoscolastica, 70 (1978), p. 64-97 ; P. Ferrer Rodriguez, La inmaterialidad de las sustancias espirituales, cit.
} 
reste à faire ${ }^{65}$. Nous allons essayer d'apporter quelques éléments supplémentaires à cette reconstitution en analysant la position d'Olivi, qui, sur ce point comme sur bien d'autres, développe une réflexion rigoureuse et originale.

Au cours du XIIIe siècle, et avant Olivi, l'éventail des positions était suffisamment diversifié pour qu'on s'abstienne de les classifier en fonction de l'appartenance religieuse de leurs représentants ${ }^{66}$. Il reste qu'un certain partage des solutions se laisse dessiner lorsqu'on envisage les sources qui inspiraient et soutenaient les différents choix : l'appel à St. Augustin - largement attesté dans la tradition franciscaine - est souvent un indice de l'adhésion à la thèse de la composition hylémorphique, alors que la référence au Pseudo-Denys oriente décidément vers le refus d'une telle composition et vers la pure spiritualité des anges. Franciscain persécuté, censuré à l'intérieur même de son ordre, Olivi n'en reste pas moins une des personnalités franciscaines les plus marquantes de la fin du XIIIe siècle et un représentant fidèle des orientations majeures de la culture de l'ordre de Saint François. Aussi, la référence à St. Augustin, sans être exclusive, joue-t-elle un rôle important dans sa pensée, et le primat accordé à la volonté et à la liberté entraîne des conséquences majeures dans sa doctrine des créatures spirituelles.

Parmi les questions qui leur sont consacrées, la question XVI discute précisément le thème de leur composition: Primo quaeritur an in angelis et in omnibus substantiis intellectualibus sit compositio materiae et formae. Il convient de relever d'emblée l'étendue de cette question ${ }^{67}$, qui dépasse largement celle des autres interrogations soulevées à propos des substances séparées - un fait qui témoigne de l'importance accordée par notre auteur à cette problématique. Cette quaestio présente la structure habituelle: le compte-rendu ici très détaillé - des arguments contraires à la thèse défendue par l'auteur (22 arguments) et des arguments favorables (6 arguments), la solution ou determinatio de la question, et les réponses aux arguments contraires énoncés dans la première partie.

Nous n'allons pas considérer les objections formulées à l'encontre de la thèse de la composition hylémorphique des créatures spirituelles - des arguments axés essentiellement sur la simplicité, l'incorruptibilité et l'intellectualité des substances séparées, et sur l'idée de la matière comme principe constitutif exclusif des réalités engendrables et corruptibles. Olivi place

\footnotetext{
65 Pour un examen du statut des anges et des substances séparées chez Thomas d'Aquin et Thierry de Freiberg nous nous permettons de signaler notre étude: Les anges et la philosophie. Subjectivité et fonction cosmologique des substances séparées au XIIIè siècle, Paris, Vrin, 2002.

$66 \quad$ C'est ce que relève O. Lottin, art. cit., p. 40.

67 Elle occupe 64 pages de l'édition critique de Jansen : vol. I, p. 292-355.
} 
à juste titre ces considérations du côté de la tradition philosophique et de ses sectateurs, qu'il critique - comme on va le voir-de manière radicale ${ }^{68}$.

La determinatio olivienne est inaugurée par l'énoncé de la thèse qu'il va défendre: credo tamen iuxta communiorem opinionem in eis esse compositionem materiae cum forma et credo quod haec secundum fidem sit sanior et securior et quod altera multum appropinquet errori philosophicae et paganicae infidelitatis $^{69}$. Cette entrée en matière est significative et dévoile d'ores et déjà les deux axes de la démarche d'Olivi - deux directives qu'on retrouvera d'ailleurs dans les autres questions angélologiques. En effet, il ne s'agit pas seulement d'argumenter en faveur de sa propre thèse, mais aussi et surtout de défendre une position jugée plus conforme à la foi chrétienne - ce qui, en vertu de l'appréciation fortement critique de la philosophie ${ }^{70}$, implique la dénonciation des erreurs philosophiques en la matière. Ce souci est constant dans la démarche d'Olivi : il s'inscrit dans la manière dont il comprend son rôle d'intellectuel au service de la foi et il s'accorde à sa théologie de l'histoire ${ }^{71}$. Or, il convient de relever que ce souci est encore majeur dans le domaine angélologique, car selon le franciscain les philosophes ont fait preuve de la plus grande faiblesse précisément dans leurs doctrines sur les substances séparées ${ }^{72}$. Aussi, l'enjeu de cette question XVI est-il de la plus grande importance, car il s'agit de restituer une conception des anges libérée des erreurs d'une tradition philosophique à laquelle les theologi philosophantes ont accordé trop de crédit.

La thèse de la composition hylémorphique des substances séparées est démontrée en quatre étapes : la première repose sur la notion de matière; la deuxième sur la nécessité de la matière dans la constitution de tous étants; la troisième examine la compatibilité de la matière avec les propriétés de la nature angélique ; la quatrième est axée sur la matière comme complément nécessaire à l'existence des anges et de leur espèce.

\section{La nécessité de la matière dans la constitution des étants}

Nous savons qu'Olivi attribue à la matière une actualité propre, fondée dans son essence, et distincte de l'actualité de la forme du fait que celle-ci désigne un acte déterminé et indéterminable, alors que l'acte propre de la

\footnotetext{
68 Cf. Qu. In II Sent., qu. XVI, vol. I, p. $300:$ «Omnes etiam philosophi, tam Platonici quam Peripatetici hoc idem videntur sentire, sicut patet in Libro de Causis et in libro Procli et in dictis Averrois »; ibid., p. 353 : « Ad argumenta autem in contrarium quae de dictis philosophorum sumuntur respondent illi qui credunt philosophis, saltem Aristotelis sequaces in intellectualibus materiam non posuisse » : parmi ces « sequaces Aristotelis » il faut entendre, bien évidemment, Thomas d'Aquin.

$69 \quad$ Ibid., p. 304.

$70 \quad$ Voir supra, note n. 7.

$71 \quad$ Cf. D. Burr, L'histoire de P. Olivi, cit., p. 94.

72 Cf. supra, note n. 7.
} 
matière est indéterminé et déterminable. Dès lors, s'il est vrai que la matière n'existe pas en acte sans une forme qui la détermine à être quelque chose, il n'est pas moins vrai que la matière ne tient pas tout son être de la forme, mais en reçoit seulement la détermination.

Olivi précise d'emblée que la matière ainsi conçue est nécessaire à la constitution de toutes choses. Cette thèse est démontrée à partir d'une triple démarche argumentative.

1) La première est fondée sur l'idée de possibilité ou de puissance passive (ce qui est le propre de la matière) comme raison intrinsèque à toute créature. Une telle puissance est nécessaire à chaque étant, aussi bien en relation à luimême qu'en relation à Dieu et à l'univers. Dans le rapport à soi, la puissance passive constitue le support nécessaire à la perfectibilité du créé : la multiplicité des perfections que chaque étant peut et doit acquérir exige en effet un substrat qui les reçoit et dans lequel elles se succèdent au fur et à mesure de leur acquisition $^{73}$. Par ailleurs, chaque agent créé est orienté vers l'objet de son agir ; une telle inclination exige nécessairement un sujet qui puisse être ainsi tourné (inclinabile, conversum), orienté et disposé à l'égard de son objet, car rien ne peut être acquis sans orientation, saisie et union avec l'objet de l'agir ${ }^{74}$. Cette idée est très importante dans la conception d'Olivi : tout étant créé, en tant que nécessairement imparfait, tend à l'acquisition de ses perfections possibles, si bien qu'il relève de l'essence du créé que d'être un sujet d'intentionnalité, un support orienté vers ce qui le perfectionne. C'est dire que chaque étant créé - et notamment l'être humain - est habité par une intentionnalité qui l'oriente et le dirige vers autre chose que soi. Cet aspect marque aussi la théorie olivienne de la connaissance, en ce qu'elle pose la nécessité de la présence de l'objet vers lequel la faculté cognitive est nécessairement orientée ${ }^{75}$. Aucune activité du créé n'est ainsi concevable qui ne (pré-)suppose par là-même l'intentionnalité de l'agent, comprise comme orientation et ouverture vers ce qui est autre que luimême: cette ouverture est une détermination qui lie l'agir de chaque sujet, qui le rattache à un objet et le limite en le déterminant; aussi, dans cette optique,

\footnotetext{
73 Cf. Quaest. In II Sent., qu. XVI, vol. I, p. 312 : « Non etiam erit completa [sc. creatura] respectu sui sine huiusmodi potentia, quoniam multitudo plurium perfectionum in nullo creato sine hac esse potest (...). Breviter : nullam actionem nullamque alicuius utilis acquisitionem poteris dare in aliqua substantia sine potentia ista $»$. $74 \quad$ Cf. ibid. : « Omne enim agens creatum oportet quod sit virtualiter inclinatum et conversum super suum patiens; omnis autem inclinatio exigit aliquod inclinabile quod per eam dicatur inclinatum et conversum (...). Nihil etiam utile acquirere poterit, nisi possit illud capere et ad illud tendere et duci et illi uniri ».

$75 \quad$ Cf. ibid., qu. LXXII, vol. II, p. 9 : « Nulla creatura potest agere nisi per aspectum virtualiter directum et terminatum in aliquod ens actualiter sibi praesens »; ibid., qu. LXXIV, vol. II, p. 115 : « Oportet quod aut obiectum se praesentet ei aut quod in aliqua imaginatione ei representetur, ita quod actus cognoscendi ipsi obiecto vel eius imagini innitens configuretur seu assimiletur ei ». Pour une analyse de l'intentionnalité chez Olivi cf. W. Hoeres, Der Begriff der Intentionalität bei Olivi, Scholastik, 36 (1961), p. 23-48 et D. Perler, Theorien der Intentionnalität im Mittelalter, cit.; pour son application dans le domaine de la connaissance cf. O. Bettini, Attivismo psicologico-gnoseologico nella dottrina della conoscenza di P. G. Olivi, Studi francescani, s. 3, 25 (50) (1953), p. 31-65 et p. 201-223 ; A. Krömer, Potenzenhierarchie und Dynamismus des Geistes. Ein Beitrag zur Erkenntnismetaphysik des Petrus Johannis Olivi (1248/49-1298), Freiburg (Br.) 1974.
} 
l'intentionnalité est-elle un indice de la finitude du sujet créé. Or, cette capacité et cette nécessité de "se tourner vers» postule une puissance passive et réceptive : bref, un sujet qu'Olivi qualifie de possibile, mobile, ductibile, unibile.

La puissance passive du sujet s'avère être une nécessité également, et à plus forte raison, à l'égard de Dieu. Celui-ci étant le terme de toute aspiration humaine, l'orientation de l'homme vers Dieu est celle d'un sujet capable de le recevoir (capax Dei), prêt à se laisser faire, totalement ouvert à son action. Ce rapport présuppose nécessairement en l'homme une réceptivité qui fait de lui un sujet subicibilis, entièrement à la disposition de Dieu ${ }^{76}$. Cette passivité à l'égard de Dieu est une perfection qui caractérise tout particulièrement la nature intellectuelle en tant qu'elle est, plus que toute autre créature, capax Dei.

En troisième lieu, Olivi considère que la puissance passive ou réceptive est une condition nécessaire dans le rapport de chaque créature au reste de l'univers. En effet, à partir du moment où chaque être contribue à la perfection de l'ensemble, tous les étants se trouvent en relation les uns avec les autres. Aucun d'entre eux ne saurait par conséquent constituer un ab-solu, un être totalement délié de ce qui l'entoure ${ }^{77}$ : bien au contraire, l'intentionnalité et l'ouverture vers ce qui est autre que soi représentent un caractère propre et intrinsèque à tous les étants créés. La connexion et l'unité de l'univers reposent précisément sur cette orientation des uns à l'égard des autres, sur cette ouverture qui rend possibles leurs relations et qui fait de chacun une natura inclinabilis et mobilis. Cette articulation aux autres et à l'univers tout entier exige nécessairement la présence en chaque étant d'une puissance passive et réceptive ${ }^{78}$. Olivi considère cette puissance passive comme une qualité et une perfection, de même - dit-il - que c'est un bien et un signe de noblesse que d'être capable de se mouvoir vers un ou plusieurs lieux ${ }^{79}$. Cet exemple curieux révèle l'importance de ce qui est de l'ordre de la relation et de l'intentionnalité : elle se manifeste déjà sur le plan physique dans la capacité de se rapporter à l'espace et s'accomplit pour les natures intellectuelles dans la docilité à l'égard

\footnotetext{
76 Cf. Quaest. In II Sent., qu. XVI, vol. I, p.311 : « Nulla enim creatura habet plenum ordinem ad Deum, nisi possit a Deo diversimode mutari et ad varia inclinari et diversas perfectiones ab eo suscipere, ita quod plenissime sit subicibilis et subiecta divinae virtutis et eius influentiis et actionibus. Sed hoc non potest plene habere sine potentia passiva $»$.

77 Cf. ibid., p. 312-313: « Et quidem, si bene inspiciatur, quod nullum aspectum nec connexionem nec inclinationem determinatam et quasi partialem ad alia habet ipsum vere est Deus, quoniam omne tale oportet quod sit ens absolutissimum et universalissimum et ab omni ente creato ineffabiliter segregatum ».

Cf. ibid. : « Si igitur ad hoc quod universum sit aliquo modo unum exigitur determinata unio et connexio inter eius partes quae sine inclinabilitate potentiae passivae esse non potest, (...), patens est quod potentia seu natura inclinabilis et mobilis facit ad complementum ipsius universi et omnis substantiae respectu ipsius ».

Cf. ibid., p. 313 : « Nulli debet esse dubium quod omne ens creatum perfectius est cum aliis acceptum et aliis coordinatum quam per se acceptum et ab aliis sequestratum ; et tamen tale oportet ipsum poni, si nullam habet potentiam passivam. Quemadmodum enim videmus quod in nobis posse moveri ad plura loca vel in eodem loco est nobilitatis (...) : sic est universaliter de potentia passiva »; et encore : « in omni creatura intellectuali est magnae libertatis posse se movere ad varia mundi loca » (ibid., qu. XXXII, vol. I, p. 576).
} 
de Dieu. Ainsi, le fait d'être "relié à », tout en étant une caractéristique du créé en tant que fini, loin de représenter uniquement une entrave, s'avère être également une richesse : celle qui réside dans la capacité de recevoir, d'être affecté, d'être modifié, d'être ouvert et de s'articuler au reste du monde. Si l'»ab-soluité » de Dieu est une expression de sa perfection et de sa transcendance, dans l'ordre du créé - qui est incommensurable à la réalité divine - la relation, l'articulation aux autres, le fait de « se rapporter à » sont envisagés comme une dimension de perfection, même s'il ne peut s'agir que d'une perfection relative.

2) La nécessité d'une puissance passive ayant été démontrée, Olivi précise son caractère substantiel ${ }^{80}$ et en fait par là-même une condition ontologique de tous les étants. En effet, cette puissance passive ne saurait être un simple accident du sujet, car dans ce cas, puisque tout accident est reçu dans un support, il faudrait postuler une autre puissance passive réceptive d'un tel accident, ce qui impliquerait une régression à l'infini ${ }^{81}$. Par ailleurs, la raison propre d'une telle puissance passive est d'être un support, un sujet au sens propre de ce qui est sous-jacent: or, puisqu'une telle raison d'être est précisément celle de la substance, il faut en conclure que cette puissance passive est substantielle à chaque sujet. Ceci représente d'ailleurs la condition nécessaire de la perfectibilité et - comme on vient de le relever - de la capacité réceptive à l'égard de Dieu : cette capacité ne saurait être en aucun cas un simple accident, mais inhère substantiellement à chaque sujet ${ }^{82}$. En troisième lieu, le premier substrat (ou support) ne peut aucunement être un accident reçu dans un autre, car dans ce cas il ne serait plus premier; la puissance passive première est donc substantielle à chaque sujet ${ }^{83}$. La même conclusion résulte de la considération de la passivité de cette puissance: son indétermination exige en effet un acte substantiel qui la fait être (comme puissance) avant de recevoir la forme ; cette puissance passive possède donc en elle-même un caractère substantiel ${ }^{84}$. Cet aspect apparaît clairement lorsqu'on envisage la matière corporelle : celle-ci est

$80 \quad$ Cf. ibid., p. 313 : « Secundo autem sciendum quod haec potentia est ipsis entibus necessario substantialis ».

$81 \quad$ Cf. ibid., p. $314:$ : Si potentia ista esset accidens, cum omne accidens sit in alio receptum, adhuc oporteret dare aliud recipiens et aliam potentiam receptivam ».

Cf. ibid. : «Ostendit hoc etiam ratio suppositi et subiecti. Substare enim et subici proprie est substantiae ; (...) nullusque sapiens dicet quod suppositum, inquantum suppositum, seu subiectum, in quantum subiectum, sit accidens (...). Praeterea, quis dicet quod substantia sit capax plurium perfectionum sive a deo sive ab aliis solum per sua accidentia ?».

83 Cf. ibid. : «Cum enim primum recipiens nullo modo possit esse in alio receptum - unde necessario semper dicit aliquid primum in ordine entium (...) - patet quod ipsamet evidenter clamat se esse substantialem entibus ».

${ }_{84}$ Cf. ibid., p. 315 : « Huiusmodi potentia passiva nullum habet per se determinatum modum essendi (...) : ergo oportet quod per aliud simpliciter existat et habeat esse, sed impossibile est quod per aliquod accidens habeat simpliciter per se et primo existere ; ergo oportet quod ab aliquo actu substantiali hoc habeat ; (...) ab actu autem seu a forma substantiali hoc habere non potest, quin vere sit eius forma, sibi autem substantialis esse non potest, nisi e contrario ipsa sit substantialis eidem. Patet igitur quod sua indeterminatione evidenter clamat se esse substantialem $»$. 
le sujet de toutes les formes, qu'elle reçoit en elle-même et par elle-même ; en tant que support, la puissance passive de la matière possède donc un caractère substantiel ${ }^{85}$. Ce même caractère résulte enfin de la considération des facultés propres aux natures intellectuelles; une substance intellectuelle ne saurait en effet être conçue sans une telle puissance passive : d'une part parce qu'elle est susceptible de recevoir les formes intelligibles, et d'autre part parce qu'elle implique un aspect formel actif ${ }^{86}$, qui réside dans l'orientation intentionnelle vers son objet; de là la conclusion qu'une telle puissance ou faculté de déterminabilité ne peut pas être un accident, mais inhère substantiellement à chaque nature intellectuelle.

3) Dans la troisième et dernière étape de sa démonstration, Olivi prouve la nécessité de la matière dans la constitution de tous les étants par le biais de la distinction réelle de la matière et de la forme. Notre auteur déploie ici les conséquences de sa conception de la matière comme réalité possédant une existence et une consistance propre. Si on considère la matière en tant que puissance passive, il apparaît qu'elle reçoit l'acte d'être lorsqu'elle est informée, ce qui implique la réception d'une forme; avant cette réception, la puissance passive existe donc comme étant réellement et essentiellement distincte de la forme ${ }^{87}$. La considération de l'essence de cette puissance passive aboutit à la même conclusion: son essence consiste en effet dans la possibilité et la déterminabilité ; en tant que déterminable par la forme, la puissance passive ne peut donc pas être toujours et déjà informée de manière actuelle ; il s'ensuit que la matière en tant que puissance passive est réellement et essentiellement distincte de la forme ${ }^{88}$. Par ailleurs - insiste Olivi -, le propre d'une puissance passive est de faire abstraction de toute forme, car dans le cas contraire elle ne serait plus une puissance réceptive, mais une réalité déterminée; la puissance passive, qui constitue la raison propre de la matière, est donc réellement et

\footnotetext{
85 Cf. ibid. : «Ostendit et hoc ratio corporalis materiae. In corporalibus enim eadem materia subsistit accidentibus et formis substantialibus (...) et per seipsam seu in se ipsa suscipit omnia (...). Si igitur ita est in materia corporali et si per hoc ipsa clamat se esse substantialem tamquam formis substantialibus substantem et omnibus accidentibus : satis per simile hoc clamat in aliis ».

$86 \quad$ Cf. ibid., p. 315-316 : «Ipsa substantia intellectualis non potest intelligi sine huiusmodi potentia, non solum in quantum est potentia passiva, specierum scilicet et actionum intellectualium receptiva, sed etiam in quantum includit in se aliquid formale et activum ».

Cf. ibid., p. 316 : « Tertio etiam est sciendum quod oportet eam esse essentialiter et realiter distincta a forma. (...) Patet quidem primo ex parte ipsius potentiae. Cum enim de se sit omnino indeterminata ad esse, sicut supra est tactum, oportet quod per aliquem actum accipiat esse simpliciter. Impossibile est autem quin ab illo actu per quem recipiet simpliciter esse differat essentialiter, quoniam aliter respectu eiusdem esset potentia et actus et idem esset realiter recipiens et dans et etiam recipiens et receptum, quoniam potentia ista non posset actum existendi recipere nisi per hoc quod informatur et perfictur ; quod sine receptione formae et perfectionis non potest fieri ».

${ }_{88}$ Cf. ibid., p. 316-317 : «Clamat etiam hoc fundamentalis essentia ipsius potentiae, sc. essentia ipsius possibilis. Essentia ipsius possibilis seu potentia tota, inquantum talis, est indeterminata et tota ab alio determinabilis. Essentia vero formae (...) nihil habet in se indeterminatum nec determinabile (...). Impossibile autem est quod eadem essentia sit secundum se tota indeterminata (...) et quod cum hoc secundum se totam sit purus terminus et pura determinatio $»$.
} 
essentiellement distincte de l'acte formel ${ }^{89}$. Olivi parvient au même résultat par un autre biais encore, notamment lorsqu'il envisage la privation de la forme comme perfectibilité de la matière : cette perfectibilité, en effet, est fondée dans une essence qui existe positivement et de manière indépendante par rapport à la forme qui va la perfectionner; cette essence est précisément celle de la matière en tant que puissance réceptive dont l'actualité est distincte de celle de la forme ${ }^{90}$. A travers ces différentes approches, la distinction de la matière et de la forme est posée comme distinction de deux absolus opposés l'un à l'autre, dont les entités restent irréductibles malgré leur réciprocité ${ }^{91}$. Ce caractère absolu peut être vérifié aussi du côté de la forme : l'essence de la forme première, c'està-dire de celle qui n'a pas encore été reçue dans une matière, est d'être ordonnée à informer ; or, en tant que telle, la forme première est ab-solue à l'égard de tout acte d'information, si bien qu'elle est réellement et essentiellement distincte de la matière ${ }^{92}$.

En posant l'existence de ces deux absolus, Olivi peut faire de la matière une composante essentielle de tout étant, un élément constitutif irréductible, qui ne peut pas être évacué même là où on n'a plus affaire à la matière corporelle du monde qui nous entoure. Il s'agit là sans doute d'une valorisation de la matière, mais aussi de l'affirmation de toute réalité comme pur possible: puissance, possibilité, déterminabilité acquièrent la valeur de caractères intrinsèques à toute réalité créée. Cette affirmation est d'ailleurs le terme visé par l'ensemble de l'argumentation, qui s'achève par l'énoncé du défaut et du manque inhérents au créé: clamat hoc omnis formae creatae multiplex defectus: defectus absolutionis, simplicitatis et illimitationis ${ }^{93}$. Ce triple manque exprime une seule et même chose : la finitude du créé. En effet, une forme qui ne serait pas reçue, c'est-à-dire contractée et limitée par le support ou sujet qui la reçoit, serait une réalité absolument simple, universelle et infinie : bref, elle serait l'être suprême et Dieu lui-même ${ }^{94}$. Telle serait, en dernière analyse, la conséquence de la

$89 \quad$ Cf. ibid., p. 317 : « Potentia enim et eius essentia absolute et simpliciter abstrahit ab omni forma (...); alias haberet determinatum modum essendi et potius haberet rationem formae quam potentiae (...); oportet igitur necessario quod sua essentia omni forma opponatur tamquam potentia actui ».

Cf. ibid. : « Si quis autem diligenter inspiciat quod privatio informitatis et ordo perfectibilitatis secundum quem ipsum possibile refertur ad formam, oportet quod fundentur in aliqua essentia quae aliquid positivum dicat praeter privationem et ordinem praedictum et quod necessario illa essentia aliquem modum entitatis absolutum dicet et non solum purum respectum seu ordinem : inveniet quod ille modus qui sibi absolute competit omnino est oppositus illi modo quem forma in se includit ».

$91 \quad$ Cf. ibid., p. 318 : «Si autem essentia potentiae seu ipsius possibilis et essentia ipsius actus formalis opponuntur ad invicem secundum absolutos modos suae entitatis et non solum secundum suos respectus : tunc simpliciter et generaliter sibi opponentur et non solum per respectum ad hoc vel ad illud. (...) Absoluta igitur oppositio essentiae ipsius possibilis ad essentiam formalem realem diversitatem esse inter se ipsa clamat ».

Cf. ibid., p. 320 : « Patet etiam hoc secundo ex parte ipsius actus formalis. Prima enim forma quae in nullo erit recepta erit omnino alterius generis et rationis ab omni forma in alio recepta et aliquid informante (...), quae illi vero primae formae erit essentiale esse absolutum ab omni ordinatione ad aliquid informandum ».

93 Cf. ibid., p. 320.

94 Cf. ibid., qu. XVI, vol. I, p. 320 : «Omnis enim forma quae non est in alio a se recepta et participata (...) est absolutissima, simplicissima, universalissima et infinitissima, et breviter est summum ens et ipsemet Deus ». 
négation de la matière comme élément constitutif de toutes choses, car supprimer la matière serait refuser ce qui contracte, détermine et limite toute forme créée et par là-même finie. La matière est donc une donnée inhérente à la totalité du créé: elle est son support, la raison de sa possibilité d'être et de sa perfectibilité.

Olivi s'attarde sur l'explication des conséquences fâcheuses qui résulteraient de la négation du concours de la matière dans la constitution de chaque étant. La première serait précisément qu'une forme non-reçue dans un support matériel serait «absolue » : tout ce qu'elle serait, elle le serait en ellemême et par elle-même, indépendamment de tout ordre ou relation à l'égard d'autre chose. Elle serait donc ab-solue au sens propre du terme, c'est-à-dire affranchie de tout rapport: car là où il n'y a pas d'inclination ou d'intentionnalité à l'égard d'autre chose, on est en face d'une réalité absolue qui n'a effectivement aucun besoin de matière ni d'un objet quelconque auquel se rapporter, et qui dès lors subsiste en elle-même et par elle-même ${ }^{95}$. Et puisqu'une telle manière d'exister ne peut être attribuée qu'à Dieu, il faut en conclure que toute forme créée est nécessairement reçue dans un support, essentiellement orientée et reliée à lui, si bien qu'elle n'est que possible, indigente et dépendante ${ }^{96}$. La deuxième conséquence inadmissible serait qu'une forme non reçue dans un support serait absolument simple: en effet, toute composition implique l'union d'une matière et d'une forme; une forme subsistant en elle-même serait donc parfaitement simple, si bien qu'elle embrasserait tout et totalement ${ }^{97}$. Le troisième corollaire inacceptable est enfin qu'une telle forme serait universelle et illimitée, car plus une forme est simple, plus elle est abstraite et plus elle est universelle; par ailleurs une telle forme, en tant que non-composée, n'aurait pas de parties et par conséquent n'aurait pas de limites $^{98}$. L'ensemble de ces attributs n'étant propre que de Dieu, il faut en

\footnotetext{
$95 \quad$ Cf. ibid., p. 321 : « Erit enim absolutissima. (...) quoniam totum quod in ea erit, erit in se ipso manens ; (...) quod ponitur in se ipso perfecte consistere ponitur intra se summam absolutionem habere (...). Omne enim quod sic manet in seipso ad nihil extra se est inclinabile nec inclinatum nec coordinatum (...). Si autem nulla esset ibi protensio aut inclinatio nec aliquis aspectus determinatus, tunc haberet virtutem et actionem absolutissimam nullo modo indigentem materia vel obiecto ».

$96 \quad$ Cf. ibid., p. 322 : « Istae autem conditiones non sunt nisi solius Dei. (...) quod nullo modo competit rationi ipsius possibilis vel potentiae passivae »; ibid., p. 321 : « essentia illa quae de se nihil habet de esse et quae tota est ordinabilis ad illud sicut possibile ad suum actum per quem simpliciter et non solum secundum quid existit habet vere in se totam definitionem materiae $»$.

97 Cf. ibid., p. 323-324: « Partes diversae non possunt aliquid unum constituere, nisi una sit forma alterius vel ambae una forma informentur aut nisi concurrant in eadem materia ; et sic in omni compositione partium semper oportet esse materiam et formam. (...) Oportet igitur quod omnis forma in seipsa manens sit simplicissima (...), ita quod secundum id ipsum sui simplicissimum haberet aliquem ambitum et latitudinem entitatis intentionis et virtutis, ita quod totum et totaliter in eo non differrent. (...) talis autem simplicitatis conditio non videtur posse esse nisi solius Dei ». E. Bettoni, Le dottrine filosofiche, cit., p. 264, considère que l'exigence de relativiser la simplicité des esprits créés est le fondement de la défense olivienne de leur composition hylémorphique.

98 Cf. ibid. : « Erit etiam universalissima et illimitatissima, tum quia absolutissima et simplicissima ; quanto autem aliquid absolutius et simplicius, tanto universalius et abstractius (...). Praeterea, in omni habente limitem est dare terminos, saltem intelligibiliter (...). Cum etiam omni habenti terminum possit fieri additio,
} 
conclure définitivement qu'aucune forme créée ne peut subsister sans un support matériel.

L'autorité du Pseudo-Denys vient renforcer ces considérations. Olivi fait appel à la conception dionysienne du rapport de participation du créé à l'égard du créateur et l'interprète dans le sens d'une différence réelle entre le sujet qui participe et ce qui est participé (par exemple entre une chose belle et la beauté divine subsistante). Pour notre auteur cela équivaut à la différence réelle entre ce qui reçoit et ce qui est reçu, autrement dit entre la matière et la forme ${ }^{99}$. L'appel à Boèce et à sa distinction de l'essence divine et de celle du créé obéit à la même intention : en Dieu seulement l'essence (id quod est) coïncide parfaitement avec elle-même ; dans le créé en revanche, l'essence n'est pas identique à elle-même, car elle résulte d'une composition de parties avec lesquelles elle s'identifie en tant qu'ensemble, mais non pas séparément ${ }^{100}$; cette différence inhérente à l'essence, et antérieure à la composition d'essence et d'être, recouvre pour Olivi celle du support et de ce qu'il reçoit, c'est-à-dire de la matière et de la forme, qui concourent ensemble et nécessairement à la constitution de l'essence de chaque étant créé. Aussi, notre auteur peut-il conclure que ceux qui attribuent aux anges uniquement la composition d'essence et d'être, ou celle du sujet et de ses accidents, contredisent ouvertement les autorités éminentes invoquées en sa faveur ${ }^{101}$. La composition d'essence et d'être - unanimement admise - ne suffit donc pas pour Olivi, car la finitude et l'indigence du créé s'inscrivent déjà au niveau de l'essence à travers la composition de matière et de forme. Tout le créé est ainsi marqué d'une double composition métaphysique, dont le franciscain fait l'objet d'une prise de conscience censée endiguer toute vaine prétention de non-finitude.

\section{Compatibilité et nécessité de la matière dans les substances séparées}

Dans la suite de la question XVI, Olivi précise et clarifie la portée des considérations précédentes par rapport à la réalité angélique. Nous en arrivons ainsi au cœur de notre questionnement et nous allons pouvoir commencer à

\footnotetext{
saltem a Deo, et etiam diminutio, cum non participet totum ambitum et totam actualitatem suae speciei aut sui generis : posset isti formae aliquid addi de sua essentia aut subtrahi ; et ita non haberet absolutionem aut simplicitatem (...) et sic nec essentiam in se manentem ».

99 Cf. ibid., p. 325 : « Et praeterea, Dionysius tamquam christianissimus theologus (...) dicere intendit quod in Deo non differunt pulchrum et pulchritudo, in aliis autem a Deo differunt sicut participans et participatum. (...) Ipsum etiam pulchrum quod vocat participans potius dicit materiam vel aliquid quodcumque informatum ».

$100 \quad$ Cf. ibid., p. 327 : « Reliqua enim non sunt id quod sunt ; unumquodque enim habet esse suum ex iis ex quibus est, id est ex suis partibus, et est hoc atque hoc, id est partes suae coniunctae, sed non hoc vel hoc singulariter » (voir à ce propos: Boèce, De trinitate, II, éd. Loeb, p. 10, 31-37).

$101 \quad$ Cf. ibid. : "Unde illi qui ponunt esse in angelis compositionem solum ex essentia et esse vel ex subiecto et accidentibus expresse iis contradicunt, quia tales compositiones non sunt compositiones ipsius essentiae seu ipsius quod est nec sunt compositiones tamquam ex partibus aliquid totum constituentibus ».
} 
cerner la conception olivienne de la subjectivité angélique, que d'autres questions viendront clarifier davantage. Dans le deuxième volet de cette question, Olivi montre d'abord la compatibilité de la matière avec le statut des substances séparées - an scilicet ratio et natura materiae cum natura angelica possit se compati ${ }^{102}$ - et prouve ensuite sa nécessité dans la constitution des créatures spirituelles - an natura substantiarum intellectualium possit sine materia in suo complemento salvari ${ }^{103}$.

Conformément à ce qui précède, le franciscain ne voit aucune incompatibilité entre la matière telle qu'il la conçoit et le statut des substances séparées: materia in eis posita non repugnat eorum incorruptibilitati aut simplicitati nec eorum intellectualitati nec libertati ${ }^{104}$. Pour comprendre cette affirmation - qui dans l'optique d'un Thomas d'Aquin ou d'un Gilles de Rome aurait représenté une absurdité pure et simple ${ }^{105}$-, il est nécessaire d'en clarifier les termes.

Il convient d'abord de relever que la thèse olivienne de la matière comme composante nécessaire de tout étant créé se situe avant tout sur le plan métaphysique, antérieurement à toute considération de la matière physique comme composante des réalités engendrables et corruptibles. La matière corporelle constitue certes un de ses modes d'actualisation, mais il ne représente en aucun cas le premier ni l'unique mode de subsistance de la matière. En d'autres termes, Olivi refuse l'équation matière $=$ corps, ce qui lui permet de placer la matière au niveau des composantes métaphysiques du réel. Dans cette perspective, la thèse de la compatibilité de la matière avec la réalité angélique s'avère tout à fait justifiée: attribuer aux substances séparées une matière signifie ici tout simplement leur attribuer une puissance passive servant de support à leur forme et composant avec elle la nature angélique - ce qui n'implique nullement une quelconque composante corporelle. Aussi, chez Olivi l'idée de l'immatérialité des anges doit-elle être remplacée par celle de leur noncorporalité : les anges sont des réalités incorporelles, mais non pas immatérielles au sens strict du terme ${ }^{106}$.

La composition matérielle - déclarait notre auteur - ne s'oppose pas à l'incorruptibilité et à la simplicité des anges. Comment cela est-il possible ? L'explication de cet énoncé tient, ici encore, aux deux éléments constitutifs de l'essence angélique que sont la matière et la forme. Nous savons que cette

\footnotetext{
102 Cf. ibid.

103 Cf. ibid.

104 Ibid.

105 Cf. notre etude: Les anges et la philosophie, cit., Ie partie.

106 Cf. ibid., qu. XVI, vol. I, p. 342 : «Dicendum quod tam a Dionysio quam ab aliis sanctis dicuntur angeli esse immateriales non per privationem omnis materiae simpliciter, sed solum per privationem materiae corporalis $»$.
} 
matière n'est pas corporelle, mais spirituelle, si bien qu'elle ne peut être déterminée que par des formes spirituelles ${ }^{107}$. Il n'y aura donc aucune « corruption », contamination ou dégradation possible de la matière angélique vers un état corporel, car dans chaque être matière et forme sont articulées au niveau de l'essence, si bien qu'aucun changement de nature ne peut intervenir. Par ailleurs, la matière spirituelle est déterminable par certaines formes qui, en raison de leur excellence, ne peuvent pas être introduites dans la matière par voie de génération, mais seulement par l'acte de création: tels sont, par exemple, l'intellect et la volonté, qui ne surviennent pas dans l'âme humaine par le biais de la génération corporelle, mais seulement par vertu divine ${ }^{108}$. De même, lorsque les formes à l'égard desquelles la matière (spirituelle) est en puissance sont telles, qu'elles n'ont aucune contrariété les unes à l'égard des autres - ce qui exclut le mouvement - et qu'elles se distinguent seulement numériquement à l'intérieur de la même espèce, dans ce cas ces formes ne peuvent être introduites dans la matière par aucun agent créé. Or, c'est ce qui arrive précisément pour les formes substantielles des anges : en effet, même si la matière de chacun d'eux est susceptible de recevoir, par action divine, les formes de n'importe quel autre ange, elle ne peut en aucun cas les recevoir par voie de mouvement ou par un agent créé ${ }^{109}$. Cela signifie que les anges sont totalement étrangers aux changements que sont la génération et la corruption : les créatures spirituelles ne peuvent donc pas être engendrées ni corrompues ou détruites par un agent créé. Il s'ensuit que, tout en étant composés de matière et de forme, les anges ne sont pas des entités possibles au même titre que les autres créatures : ils sont possibles à l'égard de l'être et à l'égard de Dieu, mais ils ne le sont pas à l'égard de l'acquisition successive de formes substantielles par voie de mouvement. C'est en ce sens précis que les anges peuvent être dits « inengendrables » et « incorruptibles », alors même qu'ils restent des purs possibles à l'égard de Dieu ${ }^{110}$.

107 Cf. ibid., p. 343 : « Quando enim materia ex sua essentia et specie est determinata ad aliquas formas, nullo modo potest tendere ad alias. (...) Et consimiliter materia spiritualis sic est determinata ad formas spirituales quod nullo modo potest esse totaliter exuta ab eis et formis corporalibus indui. Materia igitur spiritualis non habet in se potentiam talem per quam spirituale possit corrumpi et mutari in corporale, sicut nec e contrario materia corporalis hoc habet ».

$108 \quad$ Cf. ibid. : «Quando etiam formae ad quas materia est possibilis, quantum est de se, sunt talis naturae et excellentiae quod per motum introduci non possunt (...). Intellectus autem et voluntas dicunt tales formas quae per nullum motum fieri possunt, etiam a deo, sed solum per absolutum exitum a virtute Dei creante ».

109 Cf. ibid., p. 343-344 : « Quando enim formae ad quas materia est in potentia sunt tales quod sunt eiusdem speciei solo numero differentes vel non habent inter se intelligibilem distantiam seu contrarietatem vel oppositionem talem sine qua non est intelligere motum : tunc per nullum agens creatum nec per aliquem motum poterunt huiusmodi formae fieri in ea. Tales autem sunt formae substantiales angelorum. Et ideo licet eorum materia posset suscipere a Deo formas substantiales cuiuscumque alterius angeli, non tamen per motum hoc posset nec ab aliquo agente creato ».

$110 \quad$ Cf. ibid. : « Talia autem entia, quae scilicet per motum corrumpi aut generari non possunt (...), non vocamus communiter possibilia esse et non esse, immo vocamus ea incorruptibilia et ingenerabilia, quamvis respectu Dei sint mere possibilia ». 
L'incorruptibilité admise comme compatible avec la composition hylémorphique des substances séparées n'est donc pas celle d'une forme pure et subsistante, qui comme telle serait toujours actuelle, mais celle d'une nature composée de matière et de forme spirituelles qui ne peut être ni engendrée ni corrompue par un agent créé. Il s'ensuit que ce type d'incorruptibilité n'est pas un attribut inconditionnel, mais caractérise les anges uniquement par rapport aux créatures inférieures. Les natures angéliques sont et restent des purs possibles à l'égard de Dieu, mais par rapport aux autres créatures ils jouissent du privilège de ne pas être soumis aux mouvements de génération et de corruption. Ainsi, bien que la composition de matière et de forme fasse des anges des entités en puissance, il ne s'agit pas là de la potentialité à l'égard d'une forme absente qui pourrait être reçue par voie de mouvement, mais seulement de la puissance à l'égard de la forme toujours et déjà présente dans leur nature en tant qu'existante $^{111}$. En d'autres termes, il y a une articulation essentielle de matière et de forme dans chaque nature angélique - ce qui maintient sa potentialité ou réceptivité -, mais cette articulation est donnée une fois pour toutes dès la création de chaque ange - ce qui fait que la forme substantielle est toujours et déjà présente actuellement dans la matière spirituelle de chaque substance séparée. C'est là le privilège qui marque le statut de l'ange par rapport au reste du créé, avec lequel il partage néanmoins la double potentialité ou finitude qui réside dans l'ordre à la forme et à l'être ${ }^{112}$.

Matérialité et incorruptibilité des anges sont ainsi compatibles, d'une part parce que leur matière n'est pas corporelle et d'autre part parce que l'incorruptibilité telle qu'elle est conçue ici laisse intacte la finitude des substances spirituelles. Aussi, notre auteur précise-t-il qu'il y a une triple modalité d'incorruptibilité dans les choses. La première se situe au niveau de la matière, qui est en puissance à l'égard de certaines formes, mais en aucun cas à l'égard d'autres : de cette manière, la matière spirituelle ne pourra jamais être déterminée et "corrompue » par une forme matérielle, de même que la matière corporelle ne peut pas être déterminée par une forme spirituelle. La deuxième modalité d'incorruptibilité se situe au niveau de la forme et se vérifie lorsque celle-ci ne peut pas être introduite dans la matière par voie de génération, comme il arrive précisément pour les formes substantielles des créatures spirituelles. La troisième modalité se situe elle aussi au niveau de la forme, et se vérifie lorsque celle-ci domine la matière de telle sorte qu'aucun agent créé pourrait agir en elle et la déterminer vers une autre forme : c'est ce qui arrive

\footnotetext{
111 Cf. ibid., p. 345 : « Est enim in angelis potentia ad formam substantialem (...); sed non est ibi velut ad absentem aut velut ad talem ad quam per motum possit duci, sed solum velut ad praesentem et semper veraciter in se receptam, tamquam ab ea semper informata $»$.

112 A cela s'ajoute la potentialité à l'égard des formes accidentelles, c'est-à-dire qui sont acquises à travers un mouvement : nous allons considérer cet aspect lors de l'analyse de la connaissance des anges.
} 
lors de la résurrection, lorsque l'âme domine parfaitement son corps ${ }^{113}$. Ces trois modalités d'incorruptibilité se vérifient dans des réalités composées de matière et de forme et sont par conséquent compatibles avec la matérialité. Aussi, notre auteur peut-il conclure qu'on ne peut d'aucune manière déduire l'immatérialité de l'incorruptibilité : ex nullo autem istorum trium potest concludi materiam non esse in rebus incorruptibilibus aut non esse unam genere in omnibus ${ }^{114}$. En revanche, du mode particulier d'incorruptibilité des substances séparées on peut bien conclure que leur matière n'est pas du même type que celle des réalités corporelles : quamvis ex primo modo sequatur quod non sit eiusdem speciei in intellectualibus et corporalibus ${ }^{115}$.

La matérialité ne contredit pas davantage la simplicité des substances séparées. La raison de cette compatibilité réside encore une fois dans le statut particulier de la matière spirituelle. En effet, alors que le propre de la matière corporelle est de posséder des parties et des dimensions, la nature de la matière spirituelle est précisément de ne pas posséder de parties et par conséquent d'être simple $^{116}$. La simplicité dont il est question ici n'est donc pas - comme chez les sequaces Aristotelis - celle d'une forme pure, qui ne compose avec rien d'autre et n'est pas reçue dans un support, mais est celle qui inhère à la matière spirituelle en tant que privée de parties. Il s'ensuit que, malgré sa composition de matière et de forme spirituelles, chaque existence angélique actuelle peut être considérée comme une unité simple, car la forme et la matière spirituelles produisent ensemble une unité sans parties. La démarcation aristotélicienne entre matière et forme est transposée par Olivi à l'intérieur de l'aggrégat «matière-forme» et située entre la «matière/forme spirituelle» et la "matière/forme corporelle». Cette démarcation ne supprime pas pour autant leur condition commune, qui est celle d'une même composition et d'une même finitude. Olivi réussit ainsi à sauvegarder la distinction de statut entre les substances spirituelles et les autres créatures, tout en faisant partager aux

113 Cf. ibid., qu. XVI, vol. I, p. 349 : « Incorruptibilitas igitur potest tribus modis rebus inesse : aut ratione speciei ipsius materiae, quando scilicet secundum suam speciem est ita determinata ad aliquas species formarum quod nullo modo est in potentia ad alias. (...) Alio modo potest rebus inesse ratione ipsius formae. Et hoc potest fieri duplici via : aut quia scilicet forma illa est talis naturae quod non potest per motum generari aut corrumpi (...). Et hoc modo competit incorruptibilitas solis substantiis intellectualibus, ut credo; (...). Alio modo ex parte ipsius formae potest hoc fieri, quando in tanta sublimitate tamque patenter tenet materiam sub se quod nullum agens creatum potest in ea imprimere actionem seu impulsum et inclinationem per quam possit vel ad modicum ad formam oppositam inclinari et ab ipsa elongari. Et hoc modo fiet in resurrectione, sicut suo loco magis ostendetur »; après la résurrection, les êtres humains jouiront donc d'une incorruptibilité analogue à celle des anges. Pour la problématique de la résurréction des corps, cf. E. Hugueny, Résurrection et identité corporelle, Revue des sciences philosophiques et théologiques, 23 (1934), p. 94-106; C. Bynum, The resurrection of the Body in Western Christianity, 1200-1336, New York 1995.

$114 \quad$ Cf. ibid., p. 350.

115 Cf. ibid.

116 Cf. ibid., qu. XX, vol. I, p. 376 : « Materia corporalis (...) differentem definitionem habet ab ea [sc. materia spirituali] per hoc quod isti additur altera ratio, scilicet habere partes potentiales vel in potentia, et isti non habere sed potius simplicitatem potentialem vel in potentia ». Cf. A. Perez Estèvez, La materia, cit., p. $310-$ 314. 
premières la même finitude qui marque le reste du créé. Il s'ensuit que les anges sont certes simples par rapport aux autres étants, mais qu'ils ne le sont pas en eux-mêmes, car leur composition (métaphysique) de matière et de forme reste irréductible. Dans cette perspective il s'avère donc impossible d'attribuer à l'ange une simplicité absolue, car cela reviendrait à nier sa condition créaturale $^{117}$.

La matérialité ne s'oppose enfin ni à l'intellectualité ni à la liberté des créatures spirituelles, car ces deux facultés sont fondées sur une puissance passive ou réceptive qui signifie déterminabilité à l'égard d'un objet. Pour la faculté intellectuelle cette disponibilité à être déterminée est doublement motivée : du côté de l'intellect lui-même, car la connaissance implique une certaine réceptivité à l'égard des formes représentatives des objets - et ce malgré la conception « activiste » de la connaissance défendue par notre auteur ${ }^{118}$-, et du côté des objets, car la connaissance est saisie du réel existant, c'est-à-dire du singulier, ce qui implique nécessairement une certaine déterminabilité de la faculté cognitive. On retrouve les mêmes exigences en ce qui concerne la volonté : en effet, bien que la volonté soit une faculté éminemment active voluntas, inquantum est libera, est totaliter activa ${ }^{119}$-, elle est néanmoins essentiellement orientée vers un objet qui en représente le terme ${ }^{120}$; aussi, de manière analogue au rapport de l'intellect à l'objet de connaissance, l'exercice de la volonté présuppose-t-il une puissance passive ou réceptive rendant possible la déterminabilité à l'égard de l'objet, malgré le fait que celui-ci n'exerce aucune causalité efficiente sur la volonté. Cette puissance passive représente, en dernière analyse, la capacité du sujet d'être présent à autre chose que lui-même, c'est-à-dire à l'objet qui constitue le terme de son acte. On constate aisément que cette capacité coïncide avec la raison de matière telle qu'Olivi l'entend : en effet, l'union de la matière et de la forme n'est rien d'autre que la présence de l'une à l'autre ${ }^{121}$. Il s'ensuit que l'intellectualité et la liberté de l'ange sont non

117 Cf. ibid., qu. XVI, vol. I, p. 331 : «Et ideo dicere quod creatura possit esse simplex absque omni compositione est dicere quod possit esse summe simplex et summe absoluta. (...) Summa autem simplicitas non potest communicari creaturae absque contradictione sicut nec summa bonitas ».

Selon Olivi, l'acte de connaissance, spirituel et immanent, est entièrement produit par le sujet connaissant et n'est pas le résultat d'une impression produite par l'espèce : l'objet n'est donc pas cause efficiente de la connaissance ; cela dit, il exerce une causalité propre sur l'acte cognitif, une causalité qu'Olivi appelle « terminative », car l'objet constitue la visée ou le terme de l'acte cognitif. En tant que tel, l'objet est capable de modifier la puissance cognitive, qui trouve en lui le terme de sa tension virtuelle (virtualis protensio) ou de son intentionnalité. Pour une analyse détaillée de cette problématique cf. O. Bettini, Attivismo psicologicognoseologico, cit., p. $201 \mathrm{sv}$

119 Cf. Quaest. In II Sent., qu. LVIII, vol. II, p. 411.

120 Cf. ibid., p. 415 : «Sic suo modo voluntas, quamvis totaliter essentiam praedictorum actuum producat, non tamen potest hoc facere nisi in aspectu et ordine ad aliquod obiectum, nec ipsi actus sunt apti nati produci ab ea nisi in ordine et cum ordine ad obiectum »; ibid., p. 414 : « Assimilatur igitur actus obiecto tamquam suo intimo termino, non tamquam suo efficienti ».

121 Cf. ibid., qu. XVI, vol. I, p. 335-336 : « Dico igitur quod materiam uniri formae non est aliud quam eam per modum possibilis et informabilis esse praesentem formae et formam uniri non est aliud quam eam per modum actus et informantis esse praesentem materiae ». 
seulement parfaitement compatibles avec sa matérialité, mais l'exigent comme condition préalable à l'exercice de leurs actes respectifs.

De la compatibilité avec la condition de l'ange à l'affirmation de la nécessité de la matière dans sa composition il n'y a plus qu'un pas: Olivi le franchit dans la dernière étape de sa démarche - quod sine materia secundum modum praedefinita non possint substantiae intellectuales in complemento suae existentiae et speciei salvari ${ }^{122}$. Selon son procédé habituel, notre auteur ne démontre pas directement son propos, mais relève les incongruences, contradictions et absurdités qui découlent de la position contraire. Le cas échéant, l'absence de matière dans leur constitution ferait des substances séparées des essences pures ne pouvant pas être participées par des sujets individuels. Non-participables et non-participées, c'est-à-dire non reçues dans un support, ces natures seraient des absolus, des entités égales à Dieu ${ }^{123}$. Il s'ensuivrait aussi que les anges seraient des natures invariables et nonréceptives à l'égard de Dieu, précisément parce qu'il n'y aurait pas en eux de puissance passive et réceptive ${ }^{124}$. L'absence de réceptivité signifierait aussi que l'ange ne pourrait pas s'unir à Dieu, car en tant que forme simple il subsisterait en lui-même et ne pourrait d'aucune manière "s'enraciner » dans un autre support $^{125}$. Par ailleurs, l'absence de matière, et par là-même l'incapacité de recevoir et d'être passible (recipere et pati), priverait l'ange de toute orientation et de toute intentionnalité à l'égard d'autre chose que soi ; cela aurait comme conséquence que son intellect serait invariable et infaillible et sa volonté immuable et soustraite au péché ${ }^{126}$. De l'immatérialité de l'ange suivrait également une conséquence inadmissible sur le plan anthropologique, à savoir l'unicité de l'intellect pour tous les êtres humains ${ }^{127}$; c'est là un corollaire à première vue plutôt surprenant, mais qui pour notre auteur est étroitement lié à la thèse de l'immatérialité de l'ange dans la mesure où elle débouche nécessairement sur celle de l'universalité de sa nature: une telle universalité signifierait pour l'ange être identique à son espèce et, par analogie, cela aboutirait sur le plan anthropologique à l'unicité de l'intellect pour l'espèce

\footnotetext{
$122 \quad$ Cf. ibid., p. 327.

123 Cf. ibid. : « Defectus enim materiae secundum rationem supra positam acceptae ponit in eis essentiam omnino imparticipabilem et imparticipatam et sic per consequens Deo aequalem ».

124 Cf. ibid. : « Ponit etiam eos respectu Dei omnino invariabiles, insusceptibiles omnis doni sui et cuiuscumque gratiae seu influentiae suae ».

125 Cf. ibid., p. 328 : « Praeterea quaero an Deus posset unum angelum aut quamcumque substantiam intellectualem sibi personaliter unire ; et quidem secundum fidem nostram oportet concedi quod sic. Sed forma simplex in se ipsa manens et imparticipata nullo modo potest radicari et existere in alio supposito, cum sit per essentiam suam existens in se ipsa (...). Ponit igitur haec positio Deum non posse angelum nec aliquam substantiam intellectualem sibi unire ».

126 Cf. ibid. : « Ponit eorum intellectum omnino inerrabilem et invariabilem et eorum libertatem omnino impeccabilem et immutabilem, impassibilem et impunibilem et imbeatificabilem et penitus ab omni passione seu receptione, et ab omni determinata inclinatione et aspectu, etiam ab omni accidente penitus elongatam ».

127 Cf. ibid. : « Et sicut in sequenti quaestioni patebit, sequitur ex ea in omnibus hominibus unitas intellectus ».
} 
humaine $^{128}$. Dans le même ordre d'idées, il s'ensuivrait que l'âme humaine ne pourrait pas s'unir au corps : en effet, si la nature angélique ne pouvait pas être reçue dans une matière spirituelle lui servant de support, à plus forte raison l'âme humaine ne pourrait pas être reçue dans une matière corporelle ${ }^{129}$.

Le caractère inadmissible de ces conséquences impose l'exigence de la matière comme élément constitutif irrenonçable. Celle-ci s'avère être une condition essentielle non seulement de la subsistance et de l'exercice des opérations cognitives et volitives, mais aussi et surtout du rapport à Dieu, dans lequel le sujet créé ne peut se poser que comme le support d'un pati $^{130}$. La matière n'est, en fin de compte, que cette puissance passive servant de soubassement au déploiment de l'être - par la réception de la forme - et de l'agir - par l'orientation vers l'objet - de chaque sujet créé. Ce n'est que comme telle qu'elle est requise dans les substances séparées, qui sont donc parfaitement affranchies de toute corporéité. Dans l'optique d'Olivi, la thèse de l'immatérialité des anges repose donc sur deux erreurs fondamentales concernant la matière: d'une part l'idée de la matière première comme indétermination pure et simple, dépourvue de toute actualité, et d'autre part l'identification de la matière avec la corporéité. Ces erreurs étant écartées, rien n'empêche de faire de la matière un principe constitutif de toute réalité créée, y compris des substances séparées.

En faisant de la matière un principe universel, Olivi unifie l'ensemble de la réalité créée. Excepté Dieu, tout ce qui existe présente une même composition hylémorphique, indépendamment du fait que la matière en question soit spirituelle ou corporelle. Cette homogénéisation du créé est un aspect très important pour notre propos, car il annonce d'ores et déjà que les anges, tout en étant différents des autres créatures, ne bénéficient pas d'un statut d'exception ou d'une condition naturelle susceptible de posséder une valeur exemplaire. La

\footnotetext{
128 Nous reviendrons sur cet aspect dans la partie consacrée au thème de l'individualité des anges, où il sera question de l'universalité de leurs espèces cognitives. Il convient de relever la rigueur de la démarche d'Olivi et sa capacité de saisir la logique interne de la position adverse : en effet, si les partisans médiévaux de la thèse de l'immatérialité des anges n'auraient jamais souscrit à celle de l'unicité de l'intellect pour tous les hommes, il reste que la figure de l'ange conçu comme forme intellectuelle pure, identique à son espèce, s'apparente singulièrement à l'intellect séparé d'Averroès : nous renvoyons, à ce propos, à notre étude Connaissance et langage des anges selon Thomas d'Aquin et Gilles de Rome, Paris 2003.

${ }_{129}$ Cf. Quaest. In II Sent., qu. XVI, vol. I, p. 328 : « Et ex ea sequitur quod anima rationalis sit ita absolute et perfecte in se ipsa manens quod nullo modo possit corpori aut alicui alteri substantialiter uniri et maxime tamquam participatum in participante et sicut receptum in recipiente. Si enim ratione suae simplicitatis et intellectualitatis nullo modo potest sibi competere quod sit aliquo modo recepta et participata in aliqua materia spirituali et simplici et quasi sui generis : multo minus ex eisdem causis poterit sibi competere quod sit recepta et partecipata in materia corporali $\gg$.

130 L'idée de passivité et de réceptivité, par le biais du même terme « pati », est fortement présente dans la critique que Guillaume de la Mare adresse à la conception thomasienne des substances séparées : cf. Correctorium fratris Thomae, éd. P. Glorieux, in : Les premières polémiques thomistes : I, Le Correctorium corruptorii « Quare », Kain 1927, art. X, p. 49-59, ainsi que les : Declarationes magistri Guilelmi de Mare de variis sententiis $S$. Thomae Aquinatis, éd. F. Pelster, Münster 1956, p. 15. Olivi connaissait bien la position de Guillaume de la Mare.
} 
composition matérielle de l'ange signale précisément la condition de finitude qu'il partage notamment avec l'être humain. Cette condition est plus fondamentale que tout autre attribut - simplicité, incorruptibilité, intellectualité - susceptible d'illustrer la supériorité des substances séparées. Le regard que notre auteur porte sur les créatures spirituelles vise ainsi délibérément à les rattacher au reste du créé. Il convient de relever que ce choix, au-delà des raisons internes à sa conception, obéit également à une critique impitoyable de la philosophie païenne qui - comme Olivi se plaît à le répéter - a exalté les substances séparées au point d'en faire des "dieux ». Concevoir les anges comme des formes pures, non-reçues dans un support, c'est pour notre auteur les considérer comme des réalités absolues, c'est-à-dire divines : Aristoteles (...) illas posuit tamquam quosdam deos et totam naturam suae speciei intra se habentes ${ }^{131}$. L'invective contre cette philosophie, jugée falsissima in se, inanis, fallax $^{132}$, n'épargne pas ses sectateurs médiévaux ${ }^{133}$, coupables de prêter main forte à une conception idôlatre. Face à celle-ci, la tâche que le franciscain se devait d'assumer était claire : non seulement réaffirmer la créaturalité des anges et marquer leur condition d'une double finitude, mais encore les rattacher et les ancrer de manière inéquivocable à la condition commune du créé, afin d'exclure toute ambiguïté quant à leur statut.

\section{L'ange, l'espace et le temps}

\section{L'ange et l'espace}

La réponse à l'interrogation qui guide notre enquête ressort clairement de l'examen du rapport de l'ange à son espèce. L'analyse de cette problématique permet à la fois de saisir la signification et l'enjeu de l'angélologie d'Olivi et de la mesurer aux conceptions qu'il critique. Mais notre auteur prépare longuement sa determinatio. Aussi, si la question XVI nous a déjà introduit à sa manière de concevoir le statut de l'ange, l'analyse d'une autre interrogation s'avère-t-elle indispensable avant d'aborder celle de la réalité spécifique ou individuelle des créatures spirituelles. Il s'agit de la question XXXII, qui inaugure une série de six interrogations qui portent sur la réalité angélique. La problémartique qui nous intéresse ici concerne la localisation des anges: Primo quaeritur an substantia angeli sit in loco corporali ${ }^{134}$ - un thème qui, comme bien d'autres,

\footnotetext{
131 Cf. ibid., qu. XVI, p. 353. Une même critique de divinisation des créatures spirituelles avait été formulée par Henri de Gand, Quodlibet II, qu. 8 (éd. R. Wielocks, Opera omnia VI, Louvain 1983).

132 Cf. ibid., p. 355.

133 Cf. ibid., p. 353 : « Ad argumenta in contrarium quae de dictis philosophorum sumuntur respondent illi qui credunt philosophis, saltem Aristotelis sectatores in intellectualibus materiam non posuisse ».

134 Cf. Quaest. In II Sent., qu. XXXII, vol. I, p. 571.
} 
avait suscité la réaction des censeurs d'Etienne Tempier dans trois articles du syllabus de $1277^{135}$. Le problème de la localisation est capital pour Olivi, et nous allons constater que son examen poursuit d'une part le dessein lié à la thèse de la composition hylémorphique - à savoir l'affirmation de la finitude radicale des créatures spirituelles - et d'autre part pose les conditions de la determinatio relative à la question de l'individualité des anges. En effet, l'analyse de la localisation va permettre de poursuivre le projet de "dés-absolutisation» de l'ange - déjà annoncé par le refus de le considérer comme une forme pure - et de progresser vers l'idée d'une particularisation qui servira de fondement à l'énoncé de son individualité.

Le partage des solutions quant à la problématique de la localisation des substances séparées se situe au niveau du fondement ou de la raison de leur localisation: selon les uns, l'ange est localisé seulement en fonction de ses opérations ou de son agir ${ }^{136}$; selon les autres il est localisé par son être, c'est-àdire per $s e^{137}$. La première position soustrait les créatures spirituelles aux coordonnées spatiales: là l'ange maîtrise l'espace et ne s'y rapporte qu'en fonction d'un agir volontaire; il apparaît par conséquent comme un contenant, plutôt que comme un sujet contenu dans et par l'espace ${ }^{138}$. La seconde position inscrit en revanche les créatures spirituelles dans les coordonnées spatiales, auxquelles elles se rapportent par leur propre être : ici l'ange est contenu dans un espace et ne peut d'aucune façon s'affranchir de ce rapport. Il apparaît ainsi d'ores et déjà que l'enjeu de la localisation est étroitement lié à celui du statut des substances séparées : un statut qualitativement supérieur à celui du reste du créé selon la première option, une condition de dignité proche, sinon égale à celle des êtres humains, dans la seconde position.

Après avoir relevé cette alternative, Olivi justifie l'option qui gagne sa faveur et qui pose la localisation de l'ange per se, mais non pas

\footnotetext{
135 Cf. Chartularium, cit., p. 554-555 : art. $204:$ : Quod substantiae separatae sunt alicubi per operationem (...). Error, si intelligatur, sine operatione substantiam non esse in loco, nec transire de loco ad locum"; art. 218 : «Quod intelligentia vel angelus vel anima separata nusquam est »; art. 219 : "Quod substantiae separatae nusquam sunt secundum substantiam ». Cf. R. Hissette, Enquête, cit., n. 53-54-55, p. 104-110.

${ }_{136}$ Cf. Quaest. In II Sent., qu. XXXII, vol. I, p. 570 : « Quidam enim dicunt quod angeli non sunt in loco nisi solum ratione suae operationis quam faciunt et imprimunt in corporibus mundi, quod est dicere, quod ipsi secundum se non sunt in loco, sed solum operatio ab eis egrediens et in corporibus recepta et manens ». C'est l'opinion, entre autres, de Thomas d'Aquin (cf. notre étude Les anges et la philosophie, cit., p. 87-90), critiquée sur ce point, comme sur bien d'autres, par Guillaume de la Mare, Correctorium, cit., p. 72-77 et Declarationes, cit., p. 29-30.

137 Cf. Olivi, In II Sent., qu. XXXII, vol. I, p. 570 : « Alii vero dicunt quod ipsi secundum se sunt in loco, non tamen dimensionaliter, quia non habent quantitatem corporalem secundum quam possint se commetiri quantitati loci ». Cette opinion est partagée par tous ceux qui suivent les indications du syllabus de 1277 : signalons, entre autres, Guillaume de la Mare - qui représente un point de référence important pour Olivi - et Henri de Gand.

138 Cf. notre étude Les anges et la philosophie, cit., p. 87-90.
} 
dimensionaliter $^{139}$. La localisation des anges per se repose sur trois raisons principales, fondées sur autant de rapports qui selon notre auteur marquent nécessairement l'existence angélique.

1) Le premier rapport est appelé "ordre d'existence ou d'assistance » (ordo existendi seu assistendi) et fonde l'argument suivant: lorsque deux réalités sont données en acte, elles sont nécessairement soit présentes l'une à l'autre immédiatement, soit distantes l'une de l'autre. Deux ou plusieurs entités existant en acte se rapportent donc nécessairement l'une à l'autre de telle manière que ce rapport (respectus) marque leur existence. Cette thèse vaut inconditionnellement au niveau du créé : elle concerne toute réalité donnée, quel que soit son statut. C'est pourquoi - poursuit notre auteur -, si un corps et un esprit existent en acte, il faudra ou bien qu'ils soient présents l'un à l'autre ou bien qu'ils soient éloignés l'un de l'autre ${ }^{140}$. Dans le premier cas il y a localisation de l'esprit (c'est-à-dire de l'ange), car la présence mutuelle implique le rapport au lieu du corps - celui-ci étant par définition inscrit dans les coordonnées spatiales. Dans le second cas, la distance qui les sépare peut être de deux sortes : soit corporelle - ce qui produirait une situation analogue à la précédente et impliquerait par conséquent la présence de l'ange à l'extrémité de cette quantité corporelle intermédiaire -, soit spirituelle. Dans ce dernier cas, de deux choses l'une : soit la réalité spirituelle intermédiaire (entre l'ange et le corps) est présente au corps, soit la distance (spirituelle) qui les sépare n'est pas une distance locale - et dans ce cas il y aurait de nouveau présence de l'esprit au lieu du corps. Dans tous les cas de figure, la thèse de la localisation par la présence mutuelle (ou assistentia) est donc vérifiée, car il n'y a pas de vide entre les réalités données, mais seulement des distances qui peuvent être ramenées à une présence médiatisée ${ }^{141}$. Médiate ou immédiate, la co-présence des choses est donnée avec leur position dans l'être, si bien qu'il n'y a pas de réalité créée qui ne se rapporte pas à autre chose. Ce respectus est nécessaire et relève de l'ordre ontologique : l'existence de chaque chose s'inscrit dans un tissus de relations qui ne peut d'aucune façon être considéré comme une détermination accidentelle, mais qui, au contraire, marque intrinsèquement son être. Les relations qui lient

\footnotetext{
139 Il convient de relever que cette option repose sur deux groupes d'arguments : un premier groupe de quatre raisons est soutenu par des « quidam » (que nous n'avons pas pu identifier), dont les considérations sont jugées ridicules par notre auteur : «Istae autem rationes multis videntur ridiculosae (...). Istis igitur rationibus exclusis, alii moventur propter alias rationes et ultra hoc propter auctoritates fidei catholicae et Scripturae Sacrae » (qu. XXXII, vol. I, p. 572).

140 Cf. ibid. : « datis quibuscumque duobus actu existentibus, aut ipsa sunt sibi immediate praesentia aut sunt $\mathrm{ab}$ invicem distantia; ergo dato spiritu et corpore oportet quod vel sibi immediate coassistant aut quod ab invicem distent $»$.

141 Cf. ibid., qu. XXXII, vol. I, p. 572-573 : « Si [spiritus et corpus] coassistunt, habeo propositum ; si distant, aut ergo per intermediam corporalem quantitatem, et tunc oportebit spiritum esse praesentialiter in termino distantiae per quam distat, et sic iterum habeo propositum; aut distabit per solum intermedium spiritum, ex quo iterum duo sequuntur ex quibus habetur propositum ; primum est quod saltem spiritus intermedius erit praesens illi corpori ; secundum est quod illud quod distat ab altero per solam intermediationem spiritus non distat localiter ab illo, immo est praesens loco eius ».
} 
les choses les unes aux autres - pour ne pas parler du rapport de création continue qui relie les êtres à Dieu - sont des rationes reales, qui désignent les choses «en situation », c'est-à-dire une présence mutuelle inscrite dans la condition de toute réalité créée ${ }^{142}$.

Nous retrouvons ici la notion d'intentionnalité et plus généralement celle de l'orientation de chaque réalité vers autre chose que soi. Nous savons que la matière est le support nécessaire des relations de chaque chose à ce qui l'entoure et que ces relations représentent des perfections ${ }^{143}$ : le rapport à l'espace est un cas particulier de cette orientation qui marque l'être et l'agir des sujets créés ; aussi représente-t-il une perfection, car «la possibilité de se mouvoir et de se rapporter à plusieurs lieux est un signe de noblesse $»^{144}$. La localisation, en tant que rapport de présence/distance, s'inscrit dans l'être des choses et signifie à la fois leur détermination et leur finitude, ainsi que leur capacité de mouvement, d'orientation et de relation ${ }^{145}$. Par conséquent, il n'y a pas de réalité qui ne soit pas localisée, c'est-à-dire qui ne soit pas immédiatement ou médiatement présente aux autres choses. Chaque créature est une partie de l'univers ordonnée aux autres parties, avec lesquelles elle s'accorde pour composer un ensemble harmonieux. Aucun étant ne peut se poser come une réalité abstraite à l'égard de cet ordre, comme une entité subsistant par soi et en soi, désarticulée par rapport à l'ensemble ${ }^{146}$. Il en va de même des anges, qui sont inscrits dans l'univers créé et se rapportent nécessairement à ses parties : cet ordonnancement implique leur présence/distance au reste de l'univers, c'est-à-dire leur localisation ${ }^{147}$. Ce rapport à l'espace est d'ailleurs analogue au rapport avec le temps: celui-ci comme on va le voir - implique que les choses soient ou bien présentes simultanément les unes aux autres, ou bien séparées par la succession temporelle ; c'est pourquoi, de même que chaque réalité est temporelle par son rapport à la succession qui marque la durée, ainsi chacune est localisée par son

\footnotetext{
142 Pour cet aspect fort intéressant de la conception d'Olivi nous renvoyons à : A. Boureau, Le concept de relation chez Pierre de Jean Olivi, dans: A. Boureau-S.Piron (éd.), Pierre de Jean Olivi (1248-1298), cit., p. 41$55:$ l'A. relève la critique olivienne de l'ontologie de la relation et situe Olivi dans la trajectoire qui mène aux conceptions de Guillaume d'Ockham et d'Henri de Harclay.

143 Cf. Quaest. In II Sent., qu. XVI, vol. I, p. 313 : « Omne ens creatum perfectius est cum aliis acceptum et aliis coordinatum quam per se acceptum et ab aliis sequestratum ».

144 Cf. ibid. : « in nobis posse moveri ad plura loca vel in eodem loco est nobilitatis et idem est in omnibus habentibus partialem situm et locum ».

145 A. Boureau, Le concept de relation, cit., p. 50, interprète la relation chez Olivi comme « un équivalent ontologique du mouvement auquel sont soumises les substances créées ».

146 Cf. Quaest. In II Sent., qu. XXXII, vol. I, p. 573 : « Omnia entia creata sunt partes totius universi ; ex quo oportet quod habeant ordinem et connexionem ad totum universum et ad omnes partes eius et hoc non sicut quoddam totum omnia in se comprehendens, sicut facit Deus, sed sicut quaedam pars partialiter et particulariter respiciens illa, quamvis superiora habeant quandam totalitatem respectu inferiorum ; ergo oportet omnia entia creata habere modum existendi non omnino abstractum et absolutum ab omni respectu et connexione ad cetera entia ».

147 Cf. ibid. : « Si angeli habent existentiam omnino abstractam ab omni respectu distantiae et praesentiae ad omnia corpora mundi et e contrario, tunc non viderentur in se habere ordinem et connexionem tamquam partes eiusdem universi ».
} 
rapport de présence/distance à l'égard des choses qui l'entourent ${ }^{148}$. L'enjeu de ce premier argument en faveur de la localisation des anges est donc celui d'une co-présence jugée nécessaire à partir du simple fait de l'existence actuelle des choses. L'existence est ainsi synonyme de co-existence ou, selon le vocabulaire d'Olivi, d'assistance (ordo existendi seu assistendi). Cette assistance (adsistentia) dit le « se rapporter à » qui détermine intrinsèquement tout étant et le localise en l'associant à des coordonnées spatiales ${ }^{149}$.

2) La deuxième argumentation est fondée dans le rapport nécessaire de l'agir à l'égard de son objet : ordo agendi aut influendo in extrinsecum patiens aut apprehendendo et volendo obiectum extrinsecum existens ${ }^{150}$. Ce respectus $\mathrm{du}$ sujet à son objet implique et fonde la localisation de l'ange. Voici la démonstration, articulée en plusieurs raisons, produite par le franciscain : chaque agent créé, avant d'agir sur son objet ou de l'assimiler par la connaissance, est orienté intentionnellement par un regard qui s'étend vers lui de manière à lui être présent - aspectum praesentialiter protensum et fixum ${ }^{151}$; aussi, avant de connaître ou d'agir sur une réalité corporelle, qui est nécessairement déterminée selon le lieu, l'ange doit-il déployer son regard sur elle et s'orienter vers elle ; mais cela n'est possible que si le sujet de cette intentionnalité est présent à son objet, c'est-à-dire s'il co-existe avec lui par une assistance médiate ou immédiate ${ }^{152}$; il faut en conclure que le rapport à l'objet implique la localisation de l'ange, c'est-à-dire la présence au terme de sa visée intentionnelle. Une deuxième raison vient renforcer cette même conclusion : si l'ange n'était présent par lui-même à aucun corps, il n'y aurait pas de raison à ce que son action affecte un objet plutôt qu'un autre; et si l'on objecte que tel ou tel objet est touché du simple fait que la volonté angélique ordonne l'application de l'agir à un objet plutôt qu'à un autre ${ }^{153}$, Olivi répond qu'une telle application exige de toute façon la co-présence de l'agent et du patient ${ }^{154}$. Même en accordant à la

\footnotetext{
148 Cf. ibid. : «Quinto, quia in tempore seu in duratione videmus quod est divisio per immediata, scilicet quod aut res sunt simul duratione seu sunt sibi praesentes aut distantes secundum prius et posterius; ergo a simili videtur hic esse dicendum $»$.

149 Olivi se sert de cette même notion de « respectus » et d' »assistentia » pour expliquer la présence du Christ dans le mystère de l'Eucharistie : cf. D. Burr, Eucharistic Presence and Conversion in Late ThirtheenthCentury Franciscan Thought, Philadelphia 1984 (Transactions of the American Philosophical Society, vol. 74), p. 48.

$150 \quad$ Cf. In II Sent., qu. XXXII, vol. I, p. 572.

151 Il n'est pas aisé de traduire en français cette expression latine, qui rend très bien le dynamisme de la relation intentionnelle avec l'objet (« aspectum protensum »), ainsi que la dimension de co-présence du simple fait de l'intentionnalité («praesentialiter protensum»). Tel est l'énoncé en son entier : «Omne agens creatum prius naturaliter habet aspectum praesentialiter protensum et fixum super suum patiens vel super suum obiectum, antequam agat in illud aut antequam apprehendat illud » (qu. XXXII, p. 574).

152 Cf. ibid., qu. XXXII, vol. I, p. 574: « ergo antequam angelus agat in corporalia vel antequam apprehendat ipsa, prout sunt in suis locis propriis, oportet quod prius aspectus eius sit praesentialiter protensus et fixus in illa ; sed hoc est impossibile, nisi substantia in qua ille aspectus formaliter existit sit ibi praesens, ita quod quibusdam illorum assistat immediate, quibusdam vero mediate, aut omnibus immediate ».

153 C'était la position de Thomas d'Aquin : cf. S. theol. I, 52, 2.

154 Cf. Quaest. In II Sent., qu. XXXII, vol. I, p. 574 : «Item, si angelus secundum se non est praesens alicui corpori, nulla est ratio quare actio ab eo fluens plus fiat in hoc corpore quam in alio. Si enim dicas quod hoc fit a
} 
volonté angélique un tel pouvoir - ce que notre auteur n'est d'ailleurs pas prêt à admettre -, l'application de l'agir angélique à un objet exigerait néanmoins la localisation de l'ange, c'est-à-dire son assistance au lieu de l'objet visé. Olivi produit enfin une troisième raison : aucune puissance finie (limitée) ne peut agir immédiatement (comme s'il n'y avait pas de distance) sur des réalités infiniment distantes, car dans ce cas sa force (ou pouvoir) s'étendrait virtuellement à la totalité de cette distance infinie ${ }^{155}$; mais si la substance angélique pouvait agir sur des lieux du monde sans être présente par elle-même à aucun d'eux, elle agirait précisément indistanter et immediate sur n'importe quel lieu, si bien qu'il n’y aurait pas de raison pour que sa puissance ne s'étende pas à une infinité de lieux ; une telle puissance aurait donc une capacité et une force d'application comprenant l'infinité des lieux possibles ${ }^{156}$ - ce qui est évidemment inadmissible pour toute puissance créée et finie, car ce serait lui attribuer une capacité qui n'est propre que de Dieu ${ }^{157}$. L'ange, en tant que créature dont la puissance est nécessairement finie, a donc une capacité d'agir sur ses objets déterminée et limitée à leur $u b i$, et cette présence au lieu «finitise » et localise l'ange luimême. En d'autres termes, la puissance de l'ange n'est ni infinie ni absolue, mais s'applique à des objets déterminés dont la situation dans l'espace affecte son agir en lui imposant sa présence à leurs lieux, c'est-à-dire sa localisation.

Soucieux de justifier solidement son propos, Olivi prend en considération l'objection selon laquelle la puissance de l'ange s'étend bel et bien à tous les lieux possibles, mais son agir n'affecte qu'un seul lieu à la fois ${ }^{158}$. Notre auteur fait valoir à cet égard plusieurs considérations, axées principalement sur l'idée que si une telle puissance était infinie, il n'y aurait pas de raison pour qu'elle n'agisse pas simultanément sur une infinité d'objets et de lieux. Le problème se concentre donc sur le statut de la puissance des créatures spirituelles: la considérer virtuellement infinie équivaut pour le franciscain à lui accorder une éfficacité tout autant infinie, c'est-à-dire une capacité réelle d'actualisation. Dans la perspective de notre auteur, la finitude de tout étant créé implique une

voluntate eius ordinante actionem plus in hoc fieri quam in alio, hoc nihil est, quia suum velle vel nolle nihil facit ad hoc nisi applicando potentiam activam ad patiens ; sed applicare non potest, nisi illa potentia fiat praesens patienti ».

$155 \quad$ Cf. ibid. : « Item nulla potentia finita potest immediate et indistanter super infinite distantia, quia omne quod [hoc] potest (...) habet in se potentialem aspectum virtualiter continentem totum ambitum illius distantiae infinitae $\gg$.

$156 \quad$ Cf. ibid. : « Sed si substantia angeli absque omni praesentia sui ad loca mundi potest agere in quodcumque illorum : utique aget in illa indistanter et immediate, quia ipsa actio recepta in locis illis erit saltem immediate coniuncta suo efficienti immediato seu primo et proximo, et qua ratione potest hoc super loca mundi, eadem ratione est ex se potens in infinita loca ; ergo potentia angeli haberet infinitum ambitum virtualiter attingentem omnia loca possibilia Deo ».

157 Cf. ibid. : « Praeterea, potentia quae sic indistanter et immediate potest in omnia, scilicet in hoc vel in illud, est potentia absolutissima ; quae soli competit Deo ».

$158 \quad$ Cf. ibid., p. 574-575 : « Si dicatur quod potentia angeli non potest simul agere in omnia, sed solum disiunctive in quodcumque illorum, ita quod, si agat in unum, non agit in reliquum, contra hoc arguitur (...) ». Il s'agit encore de l'opinion de Thomas d'Aquin : cf. S. theol. I, 52, 2. 
limitation et une détermination qui affecte aussi le rapport à l'espace, si bien que chaque réalité créée est nécessairement localisée par elle-même.

3) Cette même conclusion résulte du troisième argument mis en place par Olivi et fondé sur le rapport qui consiste dans l'ordo movendi se ipsum. Il revient à la liberté de chaque créature intellectuelle - explique notre auteur - de pouvoir se mouvoir vers différents lieux du monde ainsi que de pouvoir s'associer aux choses ou se distancer d'elles ${ }^{159}$; mais une telle possibilité exige la présence de l'ange au lieu ${ }^{160}$. En effet, le mouvement vers un terme présuppose l'éloignement par rapport au terme précédent ; l'ange ne pourra donc pas se déplacer vers un lieu sans quitter le lieu précédent, c'est-à-dire sans y avoir été présent. Par ailleurs, le mouvement vers un lieu présuppose l'orientation virtuelle vers lui - le franciscain utilise ici le vocabulaire déjà rencontré dans la deuxième argumentation : [angeli sunt] virtualiter protensi in terminum motus $^{161}$-, et cette protensio implique nécessairement une présence médiate ou immédiate au terme visé. Olivi précise encore que l'ange ne peut pas se localiser lui-même par simple voie d'influence (influxus) - de manière analogue à la propagation de la lumière - car dans ce cas la présence locale se réduirait à une détermination qualitative ${ }^{162}$. Si l'ange était capable de se donner ainsi immédiatement sa présence dans un lieu, il s'ensuivrait d'ailleurs qu'il pourrait également se donner un mode d'être absolu, affranchi de toute présence $^{163}$. Et enfin, d'une telle éventualité il résulterait que l'instant dans lequel l'ange se trouverait dans un lieu serait suivi immédiatement de l'instant dans lequel il se trouverait dans le lieu successif, auquel cas son mouvement serait mesuré par une succession d'instants discontinus ${ }^{164}$; cette conséquence

\footnotetext{
159 Le terme utilisé par Olivi pour exprimer cette distance ou éloignement est celui de « elongare » : il convient de relever que « elongatio » est un terme clé du Fons vitae d'Ibn Gabirol, où il signifie la diversité du créé due à son éloignement par rapport à la souce première (cf. J. Schlanger, Salomon Ibn Gabirol. Livre de la source de vie, Paris 1970, p. 24)

$160 \quad$ Cf. Quaest. In II Sent., qu. XXXII, vol. I, p. 576 : « In omni creatura intellectuali est magnae libertatis posse se movere ad varia mundi loca et posse se associare rebus et res sibi et iterum posse se elongare ab eis ; sed hoc est impossibile, nisi sit praesens alicui loco mundi ».

$161 \quad$ Ibid.

162 Cf. ibid. : «Item angelus non potest sibi dare praesentiam localem per simplicem influxum, influendo scilicet eam in se, sicut influit lux lucem, quia tunc ipsa praesentia localis esset quasi qualitas absoluta ».

163 Cf. ibid. : Item, quando angelus dabit sibi illum modum existendi per quem erat absolutus ab omni praesentia loci ; et e contrario, quando auferet sibi omnem praesentiam loci, tunc eo ipso dabit sibi illum modum existendi absolutum et abstractum omni loco ».

$164 \quad$ Cf. ibid., p. 577 : « Sequetur etiam quod instans possit esse immediate post instans, quia dato quod in hoc instanti angelus sit in hoc loco, constat quod immediate potest facere quod non sit hic (...); quod licet quidam in angelicis mutationibus dicant esse possibile, tamen simpliciter et universaliter est impossibile ». Ce « quidam » est de nouveau Thomas d'Aquin, qui soutient l'idée que le mouvement angélique se réalise selon une succession d'instants, conformément au statut du temps discontinu qui mesure l'agir des substances spirituelles (cf. S. theol. I, 53, 3 ; De instantibus, c. 1, 3 et 4). Pour cette problématique nous renvoyons à notre étude Tempo ed essere nell'autunno del Medioevo, Amsterdam, 1989, p. 31-37 et 118-140, ainsi qu'à P. Porro, Forme e modelli di durata nel pensiero medievale, Louvain, 1996. Cette position est aussi celle de Gilles de Rome dans les traités De mensura angelorum et De motu angelorum, auxquels Olivi n'a toutefois pas pu se référer, si on accepte la datation de leurs œuvres respectives. Pour la problématique du lieu chez Gilles nous renvoyons à l'excellent article de C. Trifogli, La dottrina del luogo in Egidio Romano, Medioevo, 14 (1988), p. 235-290.
} 
n'est pas admise par Olivi, qui refuse de soustraire le mouvement des anges au temps successif et continu qui mesure l'existence des êtres sublunaires ${ }^{165}$. Bien au contraire, selon le franciscain le mouvement des créatures spirituelles est continu, ce qui exige le passage par des lieux intermédiaires ainsi que la présence de l'ange à ces lieux. Les substances séparées ne peuvent donc pas se soustraire à la détermination locale, mais sont localisées par leur être dès lors qu'elles exercent leur liberté de mouvement et qu'elles se déplacent d'un lieu à l'autre. Les trois rapports d'assistance, d'action et de mouvement exigent par conséquent la localisation de l'ange, c'est-à-dire la présence spatiale aux autres réalités données.

A ces trois arguments notre auteur ajoute quelques considérations supplémentaires fondées dans l'analogie entre l'ange et l'âme humaine. Celle-ci n'est pas présente dans le corps seulement comme une forme dans la matière, mais aussi comme une substance présente à la substance du corps et à son lieu ${ }^{166}$, car la coexistence de la forme dans la matière signifie sa présence dans le lieu de la matière. Cette présence est d'ailleurs la condition requise pour que l'âme puisse s'orienter et se rapporter aux autres corps du monde : le début de ce rapport se trouvant dans le lieu du corps qu'elle anime, l'âme doit donc nécessairement être présente à ce lieu ${ }^{167}$. A partir de l'analogie entre l'âme et l'ange - sur laquelle on reviendra -, Olivi peut alors conclure que chaque substance spirituelle est nécessairement localisée par sa présence aux réalités matérielles ${ }^{168}$.

\section{Une hypothèse : la suppression des corps et ses conséquences}

Tout en ayant largement démontré son propos, notre auteur se préoccupe de clarifier davantage sa pensée : ad evidentiam huius veritatis. Pour ce faire il évoque une hypothèse qui s'avère significative: s'il n'existait aucun corps - ditil - il faudrait en déduire que les anges ne sont pas localisés ; mais à partir du moment où des corps existent, les créatures spirituelles sont déterminées localement, car elles ne peuvent pas ne pas être présentes aux corps actuellement

\footnotetext{
165 Cf. Quaest. In II Sent., qu. IX : « An esse creatum sit successivum »; nous reviendrons sur cette problématique.

Cf. qu. XXXII, vol. I, p. 577 : « Praeter hoc autem arguitur ad principale ex existentia animae nostrae in corpore quae non solum est in eo sicut forma in materia, sed etiam sicut substantia praesens substantiae corporis et loco eius ».

167 Cf. ibid. : « Rursus anima cum corpore aspicit praesentialiter corpora mundi et loci, alias non videret praesentialiter loca et corpora mundi ; sed initium sui aspectus est in loco ubi corpus suum existit, ergo est ibi localiter seu praesentialiter $»$.

168 Le franciscain corrobore sa position également par des arguments d'autorité. Les Ecritures accréditent en effet la thèse de la localisation des anges par leur être lorsqu'elles attribuent des lieux précis aux démons, aux âmes des damnés, aux bienheureux ou encore à l'âme du Christ, ainsi que dans les passages où les anges sont dits descendre du ciel pour accomplir leur mission auprès des êtres humains. Jérôme, Bède, Strabon et surtout Jean Damascène confirment enfin ces assertions en situant les anges dans des lieux déterminés.
} 
existants ${ }^{169}$. A partir de cet énoncé - qui confirme que la localisation est le résultat d'un respectus - une conclusion semble donc assurée, à savoir que, puisque notre expérience prouve que des corps existent, les anges sont nécessairement localisés.

Curieusement cependant, Olivi ne s'en tient pas à ce résultat et, s'appuyant sur une expérience de pensée inspirée par la condamnation de $1277^{170}$, il reformule la même hypothèse sous la forme de l'interrogation que voici: que se passerait-il si Dieu supprimait tous les corps ou si des corps étaient créés après la création des anges? Autrement dit, s'il n'y avait pas de coexistence avec des corps, les anges seraient-ils néanmoins localisés ? Le long développement accordé par Olivi à cette hypothèse laisse entendre que son enjeu était important : il résidait - comme on va le vérifier - dans la thèse que la localisation des substances séparées est bien le résultat de leurs rapports avec les réalités matérielles, mais qu'elle n'est pas pour autant une simple détermination accidentelle ; bien au contraire, le rapport au lieu affecte toute créature dans son être même.

$\mathrm{Si}$ donc tous les corps disparaissaient, est-ce que les anges se rapporteraient aux mêmes lieux auxquels ils se rapportaient alors que ces corps étaient là ? La première réponse de notre auteur consiste à dire que la destruction des corps entraînerait la destruction du rapport des anges à ces corps, ce qui équivaudrait à la suppression du mode d'être qui consistait dans la présence à ces corps. Cette suppression n'affecterait cependant pas les rapports des anges entre eux, qui resteraient situés aux mêmes distances, à la manière dont les parties de la circonférence du ciel resteraient distantes les unes des autres si les corps intermédiaires étaient détruits ${ }^{171}$. En effet, bien qu'il n'y aurait dans ce cas aucun espace ou quantité intermédiaire ${ }^{172}$, il subsisterait néanmoins le même rapport de distance et de lieu, si bien qu'il faudrait poser une même quantité d'espace pour remplir l'intervalle survenu et pour satisfaire l'exigence de leur distance mutuelle ${ }^{173}$. La suppression des corps ne supprime donc pas purement

\footnotetext{
$169 \quad$ Cf. ibid., p. 578-579 : « Sciendum primo quod si nullum corpus esset, tunc angeli essent sine loco corporali ; corpore autem posito in esse non possunt non esse praesentes corpori aut alicui parti eius ». ${ }^{170}$ Duns Scot fera aussi appel à cette expérience de pensée : cf. O. Boulnois, Du lieu cosmique à l'espace continu? La représentation de l'espace selon Duns Scot et les condamnations de 1277, in : Miscellanea Mediaevalia, 25 (1998), p. 327.

171 Cf. ibid., p. 579 : « Dicendum ad hoc quod si Deus annihilando corporalia loca in quibus erant angeli, nollet miraculose angelos existere, tunc oporteret quod simul cum praedicta annihilatione auferret angelis modum existendi quem habent in locis corporalibus. (...) Tunc autem distarent ab invicem eo modo quo partes circumferentiae caeli diametraliter distarent ab invicem, dato quod omnia corpora et loca intermedia essent annihilata ».

172 Cf. ibid. : « quamquam enim tunc nullum spatium nullaque realis quantitas seu distantia esset in medio » : Olivi reste ainsi attaché à la doctrine aristotélicienne du lieu, qui n'admet pas un espace sans objets. 173 Cf. ibid. : « nihilominus partes sphaerae caelestis haberent ad se eandem habitudinem situs et distantiae quam prius habebant, ita quod tantum spatium et non maius nec minus posset poni inter eas ad replendum seu supplendum exigentiam mutuae distantiae earum $»$.
} 
et simplement le rapport des anges au lieu, mais laisse intact l'ordonnancement à la détermination spatiale : habitudinem situs et distantiae.

Olivi clarifie sa position en prenant en considération trois opinions, dont deux feront l'objet de sa critique. Une première opinion veut que, une fois les corps supprimés, les anges posséderaient un autre mode d'être selon lequel ils seraient présents les uns aux autres - un mode d'être qu'ils perdraient dès que les corps seraient de nouveau présents ${ }^{174}$. Notre auteur ne partage pas cet avis et le critique longuement. De ses considérations retenons ce qui suit: si par un tel mode d'être, plus noble que celui de la présence aux corps, un ange était présent à tous les autres, selon cette même modalité il pourrait être présent aux corps sans besoin d'acquérir un tel mode lors de la destruction des corps ni de le perdre au moment de leur restauration. Par ailleurs, si par ce mode d'être chaque ange était présent à tous les autres, cela signifierait : ou bien que tous seraient situés en un même point - ce qui est impossible; ou bien que ce mode d'être posséderait une étendue infinie par laquelle chacun coexisterait à une infinité d'anges - ce qui est également impossible ; ou encore que ce mode équivaudrait simplement à la suppression de la distance, sans pour autant constituer une véritable présence - ce qui est tout autant inadmissible. Enfin, de même que la subsistance en soi n'ajoute rien à la substance, ainsi un tel mode d'être, par lequel les anges seraient en eux-mêmes et non pas dans des lieux corporels, n'ajouterait rien à la substance de l'ange, si bien que ce mode resterait présent aussi longtemps que sa substance ne changerait pas, et ce indépendamment de la présence ou de l'absence des corps.

Ce dernier aspect fournit l'occasion d'un développement très significatif sur le rapport du sujet à sa localisation. L'attitude sceptique du franciscain à l'égard des catégories aristotéliciennes ${ }^{175}$ devient ici manifeste dans ce qu'on peut considérer comme une réduction de la catégorie de lieu à celle de la relation ${ }^{176}$. Selon notre auteur, la détermination spatiale n'est pas un accident qu'on pourrait supprimer sans conséquences pour la substance à laquelle il inhère. Etre « ici » ou " là » ajoute véritablement quelque chose au sujet: non pas une qualité ou essence absolue, mais un mode d'être grandement (multum) relatif qu'on appelle « localisation » ou « situation » ${ }^{177}$. Etre localisé c'est donc exister d'une certaines manière : ce que la localisation ajoute, à savoir le rapport au lieu, affecte la modalité d'existence des choses. Etre localisé c'est exister

\footnotetext{
174 Cf. ibid., p. 584 : « Primus est quod angeli haberent tunc quendam alium modum essendi secundum quem essent omnes sibi invicem presentes, quem quidem modum restitutis corporibus perderent $»$.

175 Cf. E. Bettoni, Le dottrine filosofiche di Pier di Giovanni Olivi, cit., p. 201-215.

176 A. Boureau, Le concept de relation, cit., p. 43, a montré la « réduction mentaliste » de la catégorie de la relation opérée par Olivi.

177 Cf. Quaest. in II Sent., qu. XXXII, vol. I, p. 586 : « Dicendum quod ubi seu esse hic vel illic addit aliquid ad rem quae est hic vel illic, non tamen aliquid quod debeat dici qualitas vel forma absoluta seu absolute respiciens suum subiectum, sed potius dicit quendam modum essendi multum relativum qui locatio vel situatio vocatur $»$.
} 
«par rapport à », c'est posséder un mode d'être relationnel. L'observation du mouvement local en tant que déplacement d'un lieu à un autre atteste la réalité de cet ajout: le point de départ du mouvement, son terme et le déplacement intermédiaire ajoutent véritablement quelque chose au mobile, car si tel n'était pas le cas, le mobile serait toujours dans le même lieu. Etre dans des lieux différents c'est donc acquérir de nouveaux modes relationnels, c'est-à-dire exister par rapport à d'autres lieux. Cette modalité d'existence est une condition qui accompagne toute étant créé : pour cette raison Olivi n'accepte pas l'hypothèse que Dieu pourrait créer un lieu sans une réalité localisée ou une réalité sans lieu; il y aurait là contradiction, car le lieu fait partie des modes d'être corrélatifs inséparables de l'existence actuelle de chaque sujet ${ }^{178}$. Ainsi, même si le sujet ne dépend pas du lieu, il est néanmoins déterminé par lui dans sa modalité d'être au point de ne pas pouvoir en être séparé ${ }^{179}$. Les choses sont donc localisées par elles-mêmes, ce qui veut dire qu'elles se rapportent au lieu de telle manière qu'il est impossible d'imaginer quelque chose sans la situer dans l'espace.

Cette modalité d'existence trouve sa raison ultime dans la condition créaturale : chaque créature existe comme une réalité partielle et limitée, comme une entité essentiellement relative, liée - ou susceptible de l'être - à tout ce qui peut lui être ajouté. Aucune créature ne possède un être absolu : être affranchi du rapport à l'espace, c'est-à-dire indéterminé localement, signifierait précisément posséder un être immense, qui s'étend à la totalité des lieux actuels et possibles ${ }^{180}$. Aucune créature ne peut donc être posée dans l'existence en dehors de tout lieu ni, à plus forte raison, dans tous les lieux possibles à Dieu, mais se situe toujours dans un lieu déterminé et proportionné à sa grandeur, c'est-à-dire à son quantum d'être ${ }^{181}$. Par conséquent l'ange, en tant que créature,

\footnotetext{
178 Cf. ibid., p. 586 : « Quod vero contra hoc dicitur, quod scilicet Deus posset miraculose facere ipsum ubi absque re locata et ipsam rem absque omne ubi : dicendum quod illa accidentia quae sic dicunt actuales et correlativos modos essendi quod in suo intellectu seu in sua ratione necessario includunt actualem existentiam subiecti non possunt absque contradictione fieri absque aliquo subiecto ». Olivi reste ainsi attaché à l'idée aristotélicienne du « lieu-attribut » et ne saisit pas l'opportunité, offerte par la condamnation de 1277, d'utiliser la toute-puissance divine pour penser le lieu autrement : cette possibilité sera saisie par Duns Scot et aboutira à des résultat particulièrement intéressants chez Thomas Bradwardine et Nicole Oresme ; à ce propos, cf. O. Boulnois, Du lieu cosmique à l'espace continu ?, cit., et les nombreux travaux d'E. Grant sur la conception du lieu aux XIIIe et XIVe siècles (une partie de ces travaux est réunie dans le volume Studies in mediaeval Science and Natural Philosophy, London 1981).

179 Cf. ibid., qu. XXXII, p. 587 : « Licet etiam subiectum a suo accidente non dependeat, quasi conservetur ab ipso : nihilominus sic sunt limitata secundum suam speciem ad aliquos modos essendi et se habendi quod non possunt absque contradictione poni in esse sine aliquo tali accidente ».

$180 \quad$ cf. $i b i d$. : « Praeter hoc autem potest altius dari huius ratio ex eo quod omnis res creata, cum sit limitata ad esse partiale seu particulare et ad esse relatum et connexum seu connexibile ad omnia quae sibi intra vel extra superaddi possent, quod impossibile est eam habere esse absolutissimum ab omni respectu locali aut habere esse immensum, attingens absolutissime et immensissime omnem locum actualem et etiam possibilem ».

181 Cf. ibid. : « hinc est quod [creatura] non potest poni nec extra omnem locum nec in omni loco Deo possibili ; ex quo relinquit quod semper oportet eam esse in aliquo loco suae limitatae magnitudinis comproportionato ». Cette position sera adoptée aussi par Duns Scot : cf. O. Boulnois, Du lieu cosmique à l'espace continu?, cit., p. 322.
} 
ne peut pas se soustraire au lieu, même si sa présence en lui est d'ordre spirituel. Il s'avère ainsi que par la réduction du lieu à un mode d'être relationnel et par la réduction ultérieure de la relation à une condition intrinsèque à l'existence créaturale, la localisation investit les substances spirituelles antérieurement et au-delà de leurs rapports aux corps actuellement existants. L'hypothèse de la suppression des corps n'a donc finalement pas d'incidence sur la localisation des substances séparées, qui se rapportent nécessairement au lieu du simple fait de leur existence créée.

L'examen de la deuxième position face à l'hypothèse de la suppression des corps aboutit à la même conclusion. Cette position veut que l'ange possède simultanément deux modes d'être: l'un par lequel il se rapporte aux lieux corporels et l'autre par lequel il est toujours présent aux autres anges, ou du moins lorsque les corps ont été supprimés ${ }^{182}$. Olivi refuse cette double modalité de présence pour deux raisons : en effet, si le second mode d'être était un seul et le même pour tous les anges, il faudrait en conclure que les substances intellectuelles sont toujours présentes les unes aux autres de la même manière ce qu'Olivi juge inadmissible à partir de l'expérience intérieure des différentes modalités de présence de notre âme à celle des autres ainsi qu'aux anges et aux démons ; si par contre ce second mode d'être était diversifié selon le nombre, il y aurait alors entre eux des situations et des distances spirituelles plus ou moins grandes - mais selon Olivi cela ne paraît pas possible, sauf dans le cas où l'un d'entre eux dépasserait l'autre par sa substance et sa puissance ou par ses habitus et leurs actes. La deuxième raison du refus de cette position réside en ce que pour le franciscain ce mode d'être ne signifie finalement rien d'autre que la présence de l'ange en lui-même, si bien que par un tel mode d'être l'ange n'est pas réellement présent ou distant par rapport aux autres anges ${ }^{183}$. Notre auteur conteste donc l'utilité d'un mode d'être - celui par lequel l'ange serait présent aux autres anges indépendamment des corps - qui ne produit pas véritablement une présence du sujet aux autres sujets angéliques: selon Olivi, lorsque les anges sont distants les uns des autres, leur présence mutuelle exige la relation à leurs lieux respectifs, une relation qui doit tenir compte de la distance intermédiaire. C'est dire que les substances intellectuelles ne peuvent pas faire abstraction de la distance qui les sépare objectivement, et ce indépendamment de l'existence des $\operatorname{corps}^{184}$. Il apparaît ainsi que notre auteur n'admet pas la

$182 \quad$ Cf. ibid., qu. XXXII, p. 588 : « Secunda positio est, quod dum angelus existit in loco corporali, habet simul cum hoc quendam alium modum essendi qui sibi remanet, quando omnibus corporibus annihilatis perderet illum modum secundum quem in locis corporalibus existebat; secundum autem illum alium modum semper est praesens ceteris angelis aut saltem quando corporibus annihilatis non essent ab invicem localiter distantes ». 183 Cf. ibid., p. 589 : « Secundo arguitur : quia ille alius modus essendi non videtur aliud ponere quam angelum esse in se ipso ; per hoc autem quod angelus est in se ipso non est praesens neque distans alteri angelo, sicut nec sunt corpora quae utique praeter suas situationes locales semper habent suum esse substantiale secundum quod sunt semper in se ipsis ».

${ }_{184} \quad$ Cf. ibid., p. 589 : « Huius autem necessitas non est ex hoc quod intellectualia a corporalibus directe seu causaliter dependeant, sed solum obiective et intermediative, quando habent videre aliqua in locis corporalibus 
possibilité d'une présence spirituelle indépendante de toute détermination locale, et que par conséquent "présence» équivaut à «présence au lieu». Rien n'échappe à cette exigence, car toute existence créée est une existence relationnelle. La relation au lieu fait donc partie intégrante de la condition créaturale même si cette articulation n'est pas de dépendance, mais relève d'un ordre instrumental (obiective et intermediative). La présence de chaque réalité créée à une autre est donc aussi et nécessairement la présence à son lieu.

Cette idée est corroborée par un dernier argument: ce qui convient à quelque chose selon les raisons les plus communes et universelles est premier par rapport à ce qui lui revient par sa raison spécifique ${ }^{185}$; or, la particularité, la limitation et la finitude caractéristiques du créé constituent des raisons plus communes que la spécificité et l'intellectualité des substances séparées; de là la conclusion que la présence au lieu affecte les anges de telle manière que leur localisation est première, bien qu'inférieure en dignité à d'autres modalités de présence intellectuelle ${ }^{186}$. Le franciscain exprime ainsi sa conviction quant à l'homogénéité du créé, une conviction qui était déjà véhiculée par la thèse de la composition hylémorphique des substances séparées : la matière y représentait en effet un fonds commun, une condition d'être unifiant l'ensemble de la réalité. Dans cet ordre d'idées, la relation nécessaire à l'espace semble pouvoir être envisagée comme un déploiement de la puissance réceptive et relationnelle de la matière constitutive de toutes choses.

Il reste à relever la troisième et dernière opinion relative à l'hypothèse de la suppression des corps. C'est à elle que Pierre de Jean Olivi donne implicitement son accord : selon celle-ci, l'ange maintiendrait sa relation au lieu corporel même si tous les corps étaient supprimés, de telle manière que la distance entre les anges resterait exactement la même avant et après la destruction des réalités matérielles ${ }^{187}$. C'est donc toujours une même thèse qui est avancée, à savoir que la localisation détermine les substances séparées indépendamment de l'existence des corps : au terme de son examen, l'hypothèse

existentia ; tunc enim intellectualis aspectus non potest dirigi et ferri ad illa, nisi dirigeatur ad illa loca in quibus existunt ».

$185 \quad$ Olivi ajoute : «même si ces dernières sont plus complètes et premières dans un ordre de dignité »; cf. ibid., p. 590 : « Illud quod competit alicui secundum communiores rationes est prius eo quod sibi competit secundum specificas rationes (...) licet istae sint completiores et pro tanto dignitate primitatis digniores ».

186 Cf. ibid. : « particularitas autem et limitatio seu finitas sunt communiores rationes quam sint specifica seu angelica intellectualitas angelorum ; localis autem praesentia et distantia competit angelo et omni enti creato propter eorum particularitatem finitam et limitatam ad hic et nunc, et ideo, licet sit imperfectior quibusdam aliis praesentialitatibus intellectualibus, nihilominus iuxta modum praedictum est aliquando prior ».

187 Cf. ibid. : « Tertia positio est, quod eandem habitudinem localem quam habet angelus ad locum corporalem, quando est in ipso, retinet seu retineret, quantum est ex se, si omnia loca corporalia annihilarentur, ita quod inter angelos prius localiter distantes posset poni tantae distantiae quantitas quanta prius erat inter eos et non aliqua maior ». Cette thèse semble orienter vers l'idée, qui sera développée au XIVe siècle, d'un lieu sans corps : Olivi n'a toutefois pas retenu cette implication, car il est resté attaché à la conception aristotélicienne du lieu comme extrémité du corps contenant : « ubi locale proprie sumptum in sua ratione continet assistentiam alterius extremi, scilicet loci corporalis » (ibid.). 
en question a désormais perdu sa force critique à l'égard de l'énoncé de la localisation des anges. Certes, dans l'ordre naturel les corps jouent la fonction de points de référence ou de termes de toute détermination spatiale, mais ils ne représentent pas pour autant la condition sine qua non de la relation des anges au lieu. Aussi, malgré l'explicit de cette question XXXII - eligat igitur quicumque vult aliquam trium praedictarum aut aliquam aliam meliorem -, seule la troisième position s'avère conforme à la conception d'Olivi: rationes autem quae pro hac positione fieri possent facile est colligere ex praedictis ${ }^{188}$. L'être de l'ange, comme celui des autres créatures, est un esse relatum: la détermination à l'égard de l'ubi le concerne dans son être-même et marque sa condition indépendamment de l'existence des réalités corporelles et de manière plus fondamentale que ses prérogatives de substance intellectuelle.

\section{L'ange et le temps}

Bien que les considérations qui précèdent laissent deviner quel sera le rapport de l'ange avec le temps, nous allons néanmoins clarifier brièvement cet aspect afin de compléter le portrait des créatures spirituelles en relation aux coordonnées spatio-temporelles.

Rattachant étroitement la réalité du temps à celle du mouvement, Olivi critique la conception augustinienne et subjectiviste du temps et le considère comme une réalité extramentale ancrée dans la succession ${ }^{189}$. Expression objective des changements et du devenir qui marquent chaque chose, le temps est cependant aussi une dimension intrinsèque qui fait de toute existence créée une réalité temporelle ${ }^{190}$. De même que la relation à l'espace, ainsi la succession temporelle détermine toute réalité créée, sans distinction. Les anges n'échappent donc pas au temps, mais sont déterminés à l'hic et nunc ${ }^{191}$. Cette soumission à la succession temporelle tient autant à l'agir qu'à l'être des substances séparées : Olivi le prouve dans la question IX, qui porte précisément sur la dimension de succession inhérente à toute réalité créée: an esse rerum creatarum, spiritualium saltem, sit successivum vel habeat totam durationem suam simul ${ }^{192}$.

\footnotetext{
$188 \quad$ Ibid., p. 591.

189 A ce propos cf. R. Imbach-F.X. Putallaz, Olivi et le temps, dans: A. Boureau-S. Piron (éd.), Pierre de Jean Olivi, cit., p. 27-39. Pour la conception du temps en relation à la théorie économique d'Olivi, cf. G. Todeschini, Olivi e il mercator cristiano, ibid., p. 217-237 : en particulier p. 233.

$190 \quad$ Olivi associe étroitement sa conception de la réalité extramentale du temps à une « ontologie de la temporalité des créatures » : cette conception répond cependant également à une « exigence formulée par sa théologie de l'histoire » : cf. R. Imbach-F.X. Putallaz, art. cit., p. 38.

191 Cf. Quaest. in II Sent., qu. XXXII, vol. I, p. 590 : « propter eorum [sc. angelorum] particularitatem finitam et limitatam ad hic et nunc $»$.

192 Quaest. in II Sent., qu. IX, vol. I, p. 159.
} 
Selon son procédé habituel, notre auteur relève les inconvénients et les absurdités qui découlent de la position contraire à la sienne. Ici encore on peut identifier la cible de sa critique dans la doctrine thomasienne - mais non exclusive de Thomas d'Aquin -, selon laquelle les anges ne sont pas soumis au temps continu qui mesure le devenir du monde sublunaire et qui dépend du mouvement céleste : selon l'Aquinate, en effet, l'agir des anges est mesuré par un temps "discontinu » et leur être par l'éviternité (aevum), qui est une durée non successive ${ }^{193}$. L'opinion de Pierre de Jean Olivi est diamétralement opposée: l'être de toutes les créatures s'inscrit dans la succession temporelle ${ }^{194}$. De son point de vue, la thèse de la simultanéité (relative) de l'être des créatures spirituelles entraînerait une série d'inconvénients majeurs. Et tout d'abord par rapport au commencement de l'être : en effet, si la durée des anges se donnait toute entière simultanément, il serait impossible que l'un d'entre eux fut antérieur aux autres, car Dieu lui-même ne pourrait pas créer un ange avant un autre $^{195}$. De manière analogue, du point de vue du terme de l'être, il s'ensuivrait que Dieu ne pourrait rien ajouter à leur durée, ni par conséquent faire durer un ange plus longtemps qu'un autre - ce qui est inadmissible, car contraire à la finitude du créé ${ }^{196}$. Troisièmmement, il s'ensuivrait un inconvénient lié à la dépendance permanente des êtres à l'égard de Dieu : en effet, si toute la durée de l'existence des anges était simultanée, c'est-à-dire toujours et totalement présente, Dieu ne pourrait pas cesser de la conserver et l'existence angélique ne pourrait pas ne pas être (ce qui reviendrait à poser sa nécessité), car il est contradictoire d'affirmer qu'une réalité n'est pas ou que Dieu ne la conserve pas pendant qu'elle est ${ }^{197}$. Olivi évidencie par ailleurs un quatrième inconvénient, à savoir l'impossibilité que l'ange coexiste à différents instants et par là-même à la succession temporelle ${ }^{198}$; le franciscain n'est pas prêt à admettre une telle conséquence : c'est pourquoi, par analogie avec la présence au lieu, il insiste sur

193 Cf. Thomas d'Aquin, S. theol. I, 53, 3 ; I, 61, 2 ; Quodlibet I, 3, 2. A propos de la conception thomasienne cf. W. Wieland, Kontinuum und Engelzeit bei Thomas von Aquin, in : Festschrift für C.F. von Weizsäcker, éd. E. Scheibe-G. Süssmann, Göttingen 1973, p. 77-90, ainsi que notre étude Tempo ed essere nell'autunno del Medioevo, cit., ch. 3.

$194 \quad$ Cf. Quaest. in II Sent., qu. IX, vol. I, p. 165 : « Alii vero non minus catholici dicunt quod esse omnium creatorum est successivum seu in successione (...). Et istis magis assentiendo iudico ; nam durationem cuiuscumque rei creatae ponere totam simul multa inconvenientia includit $»$.

$195 \quad$ Cf. ibid. : «Si enim aeviternorum duratio est tota simul praesens, tunc impossibile est unum eorum esse vel fieri prius altero, in tantum quod nec Deus potuisset vel posset facere unum prius altero ».

196 Cf. ibid. : « Secundo patet hoc intuendo ad eorum finitatem vel terminum. Si enim tota duratio eorum esset simul, nihil poterit addi, etiam a Deo, durationi eorum; et tunc Deus non posset facere unum plus durare quam reliquum ; quod, ut credo, non solum est falsum, sed etiam infidele $»$.

197 Cf. ibid., p. 169 : « Hoc ipsum autem magis patet attendendo ad tertium, scilicet ad eorum dependentiam qua a Deo dependent. (...) Secundum hoc autem [scilicet eorum simultaneitatem] nec Deus poterit intelligi posse cessare [conservationem eorum] nec aliquod aeviternum posse annihilari; rem enim non esse dum est, est contradictio manifesta ; et eodem modo Deum non facere rem, dum eam facit sive pro illo nunc pro quo eam facit. Sed si tota duratio et existentia aeviternorum est simul et sic tota sibi praesens, non potest intelligi non fore $(\ldots) »$.

198 Cf. ibid., p. 170 : « Hoc etiam magis patet attendendo ad quartum, sc. ad coexistentiam eorum qua tempori et temporalibus coexistunt. Si enim duratio angeli tota est simul et simplex, impossibile est quod possit coexistere diversis nunc temporis et continuae successioni eius ». 
ce que l'ange coexiste nécessairement avec les réalités successives et se trouve par là-même déterminé temporellement. La coexistence avec le devenir successif des autres créatures exclut ainsi la simultanéité de l'exister angélique, car simultanéité (= non succession) et succession sont des modalités d'être incompatibles ${ }^{199}$. La considération de l'agir montre par ailleurs que l'ange luimême est soumis à la succession, car chaque opération de son intelligence et de sa volonté fait suite et est suivie d'un acte du même type ${ }^{200}$. Et enfin - conclut Olivi -, si on envisage la raison propre de la durée, on ne peut qu'en déduire que l'existence angélique est successive: la durée exprime en effet la continuation de l'être et implique la diversité des parties qui se succèdent et qui la composent. Il n'y a donc pas de durée sans étendue temporelle et sans succession : prétendre le contraire serait comme prétendre qu'un corps étendu et continu ne soit pas composé de parties ${ }^{201}$. Il faut donc admettre que la durée de l'existence angélique s'étend dans le temps, qu'elle est successive et que l'ange est temporel au même titre que les autres réalités créées.

Excluant tout moyen terme entre la succession continue et une totale simultanéité, Olivi doit soumettre l'ange à la première, car la simultanéité n'est propre que de l'éternité divine. Affranchir l'ange de toute succession serait lui attribuer une existence non-finie dans le temps et par conséquent l'assimiler à Dieu. C'est ce qu'ont fait Aristote et ses partisans: posuerunt eas [scilicet substantias separats] tamquam deos, licet inferiores Deo summo ${ }^{202}$. Face à cette dérive - et même si des doutes subsistaient - il faut tenir fermement que l'aevum, ainsi que l'existence des anges qu'il mesure, est marqué par la succession, car il est moins dangereux d'assimiler l'éviternité au temps que de la priver de succession: maius et periculosius inconveniens est et, ut credo, evidentius tenere aevum non esse successivum quam tenere quod sit eiusdem speciei cum tempore. L'éviternité est ainsi résorbée dans le temps continu, afin de maintenir

\footnotetext{
199 Aussi, Olivi n'admet-il que deux mesures et modalités de durée : le temps, défini par la succession de l'avant et de l'après, et l'éternité, définie par l'absence totale de succession. « Les deux concepts sont antithétiques et irréductibles », écrit $\mathrm{O}$. Bettini, La temporalità delle cose e l'esigenza di un principio assoluto nella dottrina di Olivi, Antonianum, 28 (1953), p. 163. Olivi traite du nombre des mesures de la durée dans la question X : « Quarto quaeritur an sint solae duae durationes numero rerum creatarum vel plures (...)».

$200 \quad$ Cf. ibid., qu. XI, vol. I, p. 173 : «Quinto patet idem aspiciendo ad eorum operationem. (...) succedit enim una operatio alteri durante eodem esse angeli, utpote quando de uno obiecto transit ad aliud vel quando de velle transit ad nolle et e conrario ; ergo idem esse angeli commetitur se duobus nunc sibi succedentibus consimilis generis et speciei cum suo; sed hoc est impossibile, nisi in sua duratione cadat successio ».

$201 \quad$ Cf. ibid., p. 174 : « Cum enim ratio durationis (...) dicat eiusdem permansionem et hoc sit idem quod dicere eiusdem esse iterationem seu continuationem (...); ipsa tamen iteratio est alia et alia et continuatio varias partes habet ex quibus componitur (...) ; unde idem videtur dicere quod duratio non habeat extensionem et successionem quod dicere quod aliquod corpus sit quantum et continuum et tamen nullam habeat partium extensionem nec compositionem ».

202 Ibid., p. 175. Dans l'optique d'Olivi les sectateurs médiévaux d'Aristote ne se sont pas rendus compte qu'il y avait contradiction à accepter certaines prémisses non contraires à la foi sans accepter leurs conclusions : « isti autem in parte dicta eorum accipientes, pro tanto videlicet visa sunt eis non repugnare fidei, visi sunt non attendisse quod contradictio implicabatur in accipiendo partem dicti cum abiectione partis alterius quae fidei aperte contrariabatur $»$.
} 
la temporalité des substances séparées et de conjurer le danger de leur assimilation à Dieu ${ }^{203}$.

Dans la conception d'Olivi, l'ange est donc associé à l'espace et au temps. Exister, c'est être présent à soi et au reste du créé, et cette présence s'inscrit nécessairement dans les coordonnées spatio-temporelles. Rien, en dehors de Dieu, peut être conçu comme non-spatial ou intemporel. Chaque existence créée, du simple fait de son existence, est engagée dans des rapports essentiels qui la localisent et la rendent temporelle. Aussi, espace et temps représentent-ils une objectivation du caractère intrinsèquement relationnel du créé, ils constituent les termes d'un rapport qui marque la condition créaturale et qui, en dernière analyse, signifie la dépendance de toutes choses à l'égard de Dieu ${ }^{204}$. Il convient de relever que le maître-mot de cette conception de la localisation et de la temporalité des substances séparées est celui de respectus. Sa fonction est double : d'une part il sert à justifier philosophiquement la détermination spatiale et temporelle de chaque créature; et d'autre part la notion de respectus remplit également une fonction critique à l'égard de la philosophie païenne, à laquelle Olivi reproche d'avoir absolutisé les substances séparées. Concevoir les créatures spirituelles comme des êtres relationnels c'est précisément empêcher leur absolutisation, c'est-à-dire leur divinisation: omnis res creata, cum sit limitata (...) ad esse relatum et connexum seu connexibile ad omnia (...), impossibile est eam habere esse absolutissimum ab omni respectu ${ }^{205}$. Opérer la «dés-absolutisation» des substances séparées : voilà le but poursuivi par le franciscain dans les textes que nous venons de parcourir. Par cette association à l'espace et au temps, Olivi marque les limites qui placent l'ange résolument du côté du créé et qui évitent toute ambiguïté quant à son statut.

\section{L'ange et son espèce ou l'individualité des substances séparées}

Les considérations qui précèdent sur la composition hylémorphique, la localisation et la temporalité des créatures spirituelles nous permettent désormais d'aborder la question du rapport de l'ange à son espèce.

Cette problématique est analysée dans la question XXXIII : Secundo quaeritur an in quolibet angelo sit tota sua species secundum totum ambitum

\footnotetext{
203 La quaestio IX se clôt sur cet énoncé : « Hoc solum indubitanter assero quod in aevo est successio, quoniam ex capitulo opposito multa fidei contraria sequi videntur» (p. 187).

204 O. Bettini, La temporalità delle cose, cit., a montré comment l'idée de temporalité postule, chez Olivi, celle d'un principe premier absolu.

${ }_{205}$ Quaest. in II Sent., qu. XXXII, vol. I, p. 587. Rappelons un autre passage déjà rencontré dans la question XVI, p. 322 : «Omnis actus in aliud relatus (...) semper videtur dicere actum alicuius possibilis ».
} 
suum, ita quod extra ipsum non possit esse aliud individuum eiusdem speciei ${ }^{206}$. Olivi rapporte sept arguments en faveur de la thèse que chaque ange forme une espèce, dont quatre portent sur l'universalité de la connaissance angélique - un motif fortement accrédité par l'autorité du pseudo-Denys. Selon ces arguments, l'étendue universelle de la connaissance postule la nature universelle du sujet qui la produit, c'est-à-dire sa subsistance comme espèce et non pas comme individu $^{207}$. Aussi, la discussion sur la nature spécifique de l'ange est-elle étroitement liée à l'examen de sa connaissance et notamment à la vérification de son caractère universel. Pour cette raison, Olivi procède à sa determinatio en deux moments : d'abord il discute et critique la thèse de la réalité spécifique des créatures spirituelles (qu. XXXIII) et ensuite il analyse le statut de leur connaissance (qu. XXXIV) ${ }^{208}$.

\section{L’individualité des anges}

La position qui considère chaque ange comme une espèce ${ }^{209}$ est fondée sur deux thèses: celle de l'immatérialité de l'ange et celle de l'individuation par la matière. Le franciscain ne partage ni l'une ni l'autre de ces thèses, pour des raisons à la fois philosophiques - haec positio est rationi et veritati contraria et théologiques - [haec positio] est in fide valde periculosa ${ }^{210}$. Les raisons philosophiques nous sont connues : il s'agit de la doctrine de l'hylémorphisme universel et de la singularité des principes constitutifs de chaque chose. Olivi va donc appliquer ces options fondamentales au statut des substances séparées pour montrer le danger de leur assimilation à une espèce. Sa démarche est structurée en quatre groupes d'arguments, qui explicitent les axes fondamentaux de sa critique: la durée de l'existence angélique, sa localisation, la puissance et l'efficacité de l'agir des anges et le statut de leur essence ${ }^{211}$. Il convient d'insister sur le fait que pour le franciscain l'assimilation de chaque ange à une espèce signifie sa capacité d'embrasser l'étendue totale de l'espèce - angelus comprehendit totam suam speciem secundum totum suum ambitum ${ }^{212}$ - et par conséquent son affranchissement par rapport à toute limite, ce qui équivaut

\footnotetext{
$206 \quad$ In II Sent., qu. XXXIII, vol. I, p. 591.

207 Cf. ibid., p. 592: "Universalis scientia non potest esse in aliquo subiecto, nisi ipsum sit secundum suam naturam universale".

208 Cf. ibid., p. 594-595: "Quoniam autem illud propter quod praecipue quidam theologi ponunt eos habere totam suam speciem est universalitas scientiae et specierum quam in eis ponunt, credentes se in eis sequi non solum verba philosophorum, sed etiam verba Dionysii supradicta : idcirco iuxta hoc quaeratur an sint in eis species universales $\gg$.

Cf. Thomas d'Aquin, S. theol., I, 50, 4, mais aussi Albert le Grand, De causis et processu universitatis a prima causa, 1. II, tr. 2, c. 4, éd. W. Fauser, Münster 1993 (Opera omnia, editio coloniensis, t. XVII), p. 97. 210 Quaest. in II Sent., qu. XXXIII, vol. I, p. 597.

211 Cf. ibid. : «Quod patet si consideremus in eis primo rationem suae durationis seu existentiae, secundo rationem suae localitatis seu assistentiae, tertio rationem suae virtutis seu potentiae et efficace [sic in textu], quarto rationem suae quidditatis seu essentiae ». Ibid., p. 596.
} 
finalement à faire de l'ange une entité d'ordre universel. Cette universalité est la source de tous les inconvénients et dangers dénoncés par notre auteur.

Du point de vue de la durée, une telle universalité aurait comme conséquence l'éternité de la nature angélique: l'universel, en effet, fait abstraction par rapport au nunc, c'est-à-dire par rapport à toute détermination ou limitation temporelle, si bien qu'il embrasse l'étendue du temps passé, présent et futur. Si on pose l'existence actuelle d'un tel universel, il faudra admettre qu'il embrasse la totalité du temps et que par conséquent il est éternel ${ }^{213}$. Olivi clarifie cet aspect par analogie avec l'espèce humaine: si l'humanité comprenait de manière actuelle la totalité des individus humains passés, présents et futurs, elle serait présente à la totalité du temps et subsisterait comme entité éternelle. Or, c'est bien ainsi que ses adversaires conçoivent la nature angélique, c'est-à-dire comme une entité universelle qui embrasse actuellement et totalement l'étendue de sa nature : une telle entité est donc nécessairement éternelle. Par ailleurs, l'adéquation entre l'essence et l'être implique que si l'essence d'une réalité est universelle, son être ou son existence le sera également ${ }^{214}$; par conséquent, si la nature des anges était universelle, leur être posséderait une durée permanente et universelle, comprenant toutes les durées passées et futures. En outre, toute nature universelle et infinie, qui possède par là-même une existence infinie, aura une plus grande capacité et actualité d'être que n'importe quelle nature particulière: si on admet la thèse de la réalité spécifique des anges, il faudra donc admettre que la durée de leur existence se rapporte à la durée de chaque âme humaine et à celle du Christ comme l'infini au fini et comme l'universel au particulier. A partir de ces considérations, Olivi conclut qu'attribuer à chaque ange une nature universelle reviendrait à en faire une entité éternelle et nécessaire à la fois, c'est-à-dire excluant toute possibilité de non-être, car ce qui existe en acte éternellement ne peut pas tomber dans le non-être ${ }^{215}$. A ce danger majeur s'ajoutent par ailleurs tous les inconvénients qui se rattachent à la thèse de l'éternité du monde et qui peuvent être ramenés à la contradiction fondamentale entre l'idée de créature et celle d'infinité ${ }^{216}$.

\footnotetext{
213 Cf. ibid. : « Attendendo igitur primo eorum durationem sequitur ex positione universalitatis quod angeli habeant aeternitatem tam secundum praeteritum quam secundum futurum (...). Cum enim universale abstrahit ab omni differentia temporis, ita quod non limitatur nec includitur sub praefixo tempore $(. .$.$) : si tale universale$ ponatur in actu secundum totum ambitum suae universalitatis, oportet quod actualiter et secundum rem praedicta sibi conveniant et etiam omnia illa quae universalibus per intellectum abstractis attribuit intellectus $\gg$.

214 Olivi associe l'essence et l'existence en une unité de même condition : non seulement, selon le franciscain essence et existence sont une seule et même réalité, dont elles n'expriment que différentes raisons (cf. Quaest. in II Sent., qu. VIII, vol. I, p. 147). Sur les critiques formulées par Olivi à la distinction de l'essence et de l'existence - fortement accentuée à la même époque par Gilles de Rome -, cf. E. Bettoni, Le dottrine filosofiche, cit., p. 173-192.

$215 \quad$ Cf. ibid. , p. 598: "Ex praedictis tamen non solum sequitur quod habeat eternitatem omnia simul attingentem, sed etiam quod sit purum necesse, nullam habens possibilitatem ad non esse, quia pro tempore pro quo non solum est actu sed etiam aeternaliter fuit non potest cedere in non esse".

216 Cf. ibid. : « Sequuntur etiam ex praedictis omnia illa inconvenientia quae ad positionem aeternitatis mundi sequuntur ». Olivi discute et critique cette thèse dans la question $\mathrm{V}:$ « an mundus ab aeterno fieri potuerit ».
} 
De manière analogue, l'universalité de la nature angélique affecterait sa relation à l'espace en la rendant présente à tous les lieux et à toutes les choses existantes ou possibles ${ }^{217}$, à la manière dont l'humanité - si elle comprenait en acte la totalité des individus existants et possibles -, serait présente dans l'infinité des lieux occupés par eux. Une telle présence de l'ange à tous les lieux serait par ailleurs une présence totale à chacun d'eux, car la simplicité de la nature angélique serait telle qu'il n'y aurait en elle aucune partialité ou limitation: dès lors l'ange serait partout à la manière dont Dieu est partout présent $^{218}$. Cette capacité de présence totale et universelle aurait enfin comme conséquence que l'ange pourrait pénétrer dans tous les esprits humains, car sa substance et sa force excèderaient infiniment celle des hommes ${ }^{219}$.

En troisième lieu, Olivi envisage la puissance des substances séparées du point de vue de leur capacité réceptive d'abord, et dans l'optique de leur capacité active ensuite. Du premier point de vue, l'universalité de la nature angélique aurait comme conséquence que tout ce qui serait reçu en elle serait universel : en effet, en raison de l'articulation essentielle entre la nature d'un sujet, ses puissances et ses accidents, aucune détermination accidentelle particulière ne peut inhérer à un sujet universel. De là suivrait encore une autre conséquence, à savoir que les habitus de l'ange, de même que la grâce reçue ainsi que sa science, seraient tout autant universels : ils seraient par conséquent supérieurs à ceux de l'âme du Christ et des bienheureux à la manière dont l'universel dépasse le particulier ${ }^{220}$. Un autre corollaire s'y ajouterait également, à savoir qu'aucun vice ne pourrait être attribué aux démons, ni aucune révélation particulière aux anges bons ou mauvais; de même, il serait impossible qu'un même vice ou habitus soit présent dans plusieurs anges. Mais l'universalité de la nature angélique aurait en réalité et surtout comme conséquence qu'elle ne pourrait recevoir aucun accident, car dans une telle nature il n'y aurait pas de puissance réceptive : il n'y aurait donc en elle aucun habitus ou acte différent de sa substance; les anges posséderaient ainsi de manière immuable et à jamais

\footnotetext{
217 Cf. ibid. : « Attendendo etiam secundo ad eorum localitatem seu existentiam, sequitur ex praedicta positione quod adsit quilibet angelus omnibus locis et omnibus entibus, non solum existentibus, sed etiam possibilibus fieri ».

218 Cf. ibid. : « Sequitur etiam quod adsit cuilibet rei et loco totus et totaliter, quia natura angelica sic universalis tantae erit simplicitatis necessario quod nullam vel partialitatem vel divisibilitatem erit in ea dare, etiam ita parum sicut in Deo ; ergo nullum locum nec aliquam rem respiciet partialiter, sumendo partialitetem qualemcumque ex parte sua ; ex hiis autem sequitur quod erit ubique eo modo quo Deus ponitur esse ubique ». $219 \quad$ Cf. ibid. :, p. 599: « Praeterea ex praedictis videtur sequi quod poterit illabi et erit illapsus omnibus mentibus, (...), sed etiam ex hoc quod eius substantia et virtus erit in infinitum virtuosior et simplicior quam mentes nostrae ».

220 Cf. ibid. : « Attendendo etiam tertio ad eorum virtutem, potentiam et efficaciam videtur primo sequi quantum ad potentiam recipiendi quod quidquid in eis erit receptum aut recipi poterit necessario erit universale ; (...). Ex hiis videtur iterum sequi quod omnis habitus et actus gratiae et gloriae et cuiuscumque scientiae sint in eis universales; et tunc sequetur (...) quod transcendant gratiam et gloriam, meritum et praemium et omnes habitus et actus animae Christi et aliarum animarum beatarum, sicut universale transcendit suum particulare et sicut infinitum transcendit finitum ».
} 
l'état de bonté et de grâce reçu au moment de leur création. Accepter de telles conséquences - conclut Olivi -, serait tout simplement concevoir les anges comme des dieux, à la manière dont les philosophes païens avaient conçu les substances séparées : sic indubitanter philosophi pagani senserunt et locuti sunt de eis tamquam de quibusdam diis aeternis et omnino invariabilibus ${ }^{221}$.

L'examen de la puissance angélique du point de vue de sa capacité active aboutit à une conclusion analogue. Selon Olivi en effet, il faut admettre que ce qui résulterait de l'agir d'une nature universelle serait tout aussi infini et universel. Dès lors, l'amour et la vision de Dieu et de soi-même seraient infinis, car produits par une volonté et un intellect possédant une efficacité infinie ${ }^{222}$. Pire encore, il faudrait admettre que ce que les anges verraient et aimeraient de Dieu, ils le verraient et l'aimeraient avec une intensité et un excès que Dieu luimême ne pourrait pas surpasser. Et enfin, puisque toute nature universelle possède une essence, une puissance, une existence et une simplicité infinies, l'ange non seulement existerait en lui-même et par lui-même, mais il pourrait créer, par sa volonté, une infinité de choses ${ }^{223}$.

Reste à considérer le dernier groupe d'arguments à l'encontre de la thèse de la réalité spécifique des substances séparées. Il repose sur l'examen de leur essence et relève, comme précédemment, une série d'inconvénients majeurs. Premièrement, tout ce qui serait inclus dans l'essence d'un ange y serait de manière universelle et infinie, c'est-à-dire non participée, si bien que toute convenance de deux anges en une raison univoque essentielle serait impossible ${ }^{224}$. Olivi relève ici ce qu'on pourrait appeler le solypsisme de l'ange : forme pure et universelle, non reçue et non particularisée dans un sujet individuel, l'ange resterait en lui-même et pour lui-même et n'aurait rien à partager avec ses semblables, car un tel partage - ou " convenance en une raison commune »- impliquerait la réceptivité à l'égard de la raison commune et sa participation dans un sujet(-substrat). La fermeture sur soi d'une telle nature universelle et unique aurait aussi comme résultat que l'ange ne serait compris dans aucune catégorie - celles-ci s'appliquant à une multiplicité d'individus partageant une raison commune ${ }^{225}$-; de même, ses actes de connaissance et de

\footnotetext{
$221 \quad$ Ibid., p. 600.

222 Cf. ibid. : « Amplius, attendendo ad eorum potentiam activam sequitur quod quidquid exibit ab eorum potentia activa secundum totum suum conatum est infinitum et universale. Et tunc visio et dilectio qua Deum vel seipsos vident et diligunt erit universalis et infinita ».

${ }_{223}$ Cf. ibid., p. 601: "Praeterea, cum omnis natura universalis habeat infinitam essentiam et virtutem et infinitam existentiam et simplicitatem: videtur quod omnis talis natura erit in seipsa existens (...). Amplius sequitur quod possint res, etiam infinitas, solo suo imperio creare ».

224 Cf. ibid., p. 601-602: “Attendendo etiam quarto ad eorum essentiam vel quidditatem primo quidem ex praedicta positione sequeretur quod omnis ratio quae in essentia unius angeli includetur, sive sit ratio generis sive differentiae, sive ratio entis et veritatis et unitatis et consimilium, quod secundum totum suum ambitum sunt in eo, ita quod nulli duo angeli poterunt aliquo modo convenire univoce in aliqua ratione essentiali ».

${ }_{225}$ Cf. ibid., p. 602: "Tunc sequitur quod angeli non sint in aliquo uno praedicamento, immo etiam quod nullus eorum sit sub aliquo genere vel praedicamento".
} 
volonté n'auraient aucun rapport de convenance avec les actes cognitifs et volitifs des autres anges. Faire de chaque ange une espèce irait donc à l'encontre de toute communauté de nature et d'action parmi les créatures spirituelles. L'affirmation des adversaires, d'après laquelle les anges ne se différencient que par les différents degrés de leur intellectualité, ne permet pas de corriger cette conséquence : en effet, si tel était le cas, leur distinction n'impliquerait pas une différence spécifique ${ }^{226}$, si bien qu'il y a contradiction à faire de chaque ange une espèce et à poser néanmoins entre eux une communauté de nature, différenciée uniquement par leurs degrés de perfection ${ }^{227}$.

Olivi observe enfin que la thèse de la réalité spécifique des anges apparaît insoutenable même du point de vue de la toute-puissance divine: en effet, si Dieu pouvait créer une nature angélique subsistant comme entité spécifique et universelle, il pourrait faire de même avec n'importe quelle raison générale d'étant créé et produire un étant qui posséderait en lui-même toute la raison d'être selon la modalité la plus générale et la plus abstraite. En continuité avec ces considérations, Olivi observe encore que toutes les raisons présentes dans un ange - qu'il s'agisse de la raison d'être ou de celle d'unité - n'y seraient pas à titre de formes participées, mais à titre de réalités subsistantes, si bien qu'il posséderait l'étendue totale de la raison, de l'être et de la vérité. Or, admettre de telles conséquences - comme il a déjà été relevé - équivaudrait à faire de l'ange un dieu : ex quo indubitanter sequitur quod quilibet eorum sit vere summum ens et summus Deus ${ }^{228}$. Bref, concevoir l'ange comme une entité universelle c'est le concevoir comme étant à la fois créature et Dieu ${ }^{229}$.

Tel est le danger inhérent à la thèse de l'ange-espèce, un danger déjà dénoncé par d'autres ${ }^{230}$, mais que notre auteur exprime avec une emphase particulière : Ex omnibus autem praedictis satis colligi potest quam periculosum sit iste error, quia ex hoc ponitur in creatura immensa aeternitas, immensa localitas seu praesentialitas, immensa simplicitas et quod nullum in eis est accidens particulare et quod in eis nulla passio vel receptio et quod quidquid est

\footnotetext{
226 Cf. ibid., p. 602-603: "Praeterea, in natura eorum intellectuali non videtur posse poni differentia nisi secundum gradus intellectualitatis et libertatis superiores et inferiores, actualiores et minus actuales; sed talis differentia non mutat speciem (...); non enim intellectus ex eo quod fit essentialiter intellectualior et voluntas ex eo quod fit liberior videtur mutare speciem $»$.

Il convient de relever que cette critique d'Olivi, certes habile, ne paraît pas légitime si on considère de près la position thomasienne (que notre auteur vise le plus souvent) : selon Thomas, en effet, la différence de degré ne produit pas une différence d'espèce lorsqu'elle résulte de l'intensité ou de la distension plus ou moins grande d'une même forme ; mais dans le cas des anges, les différences de degré résultent de formes différentes, si bien qu'il y a là véritablement une différence d'espèces : cf. S. theol., I, 50, 4, ad 2: « Ad secundum dicendum quod magis et minus, secundum quod causantur ex intensione et remissione unius formae, non diversificantur specie. Sed secundum quod causantur ex formis diversorum graduum, sic diversificant speciem (...). Et hoc modo angeli diversificantur secundum magis et minus ».

228 Quaest. in II Sent., qu. XXXIII, vol. I, p. 604.

229 Cf. ibid. : « sic imaginans angelum universalem imaginatur eum esse simul creaturam et Deum ».

Par exemple Henri de Gand, Quodlibet II, qu. 8, éd. R. Wielocks, Opera omnia VI, Louvain 1983, p. 42.
} 
in eis est eorum substantia et quod quantum ad naturam, gratiam et gloriam transcendunt in infinitum animam Christi $(. . .)^{231}$. Faire de l'ange une espèce c'est lui attribuer une coïncidence totale avec soi, une identité accomplie et autosuffisante, qui, conjuguée à l'universalité, ferait de lui une réalité sans limites dans l'être, l'espace, le temps et l'agir, c'est-à-dire une réalité absolue et divine. S'il fallait réduire l'ensemble de la critique d'Olivi à un seul motif " coupable» de la divinisation des créatures spirituelles, c'est donc l'universalité qu'il faudrait retenir. Cet attribut est en effet synonyme d'actualité d'être sans limites, d'une étendue totale dans l'espace et le temps, et d'une capacité et puissance d'agir infinies. Ceci correspond bien à ce que les philosophes païens ont dit à propos des dieux ${ }^{232}$, mais va à l'encontre de la raison propre du créé, qui réside dans la partialité, la participation, la réceptivité, la dépendance, en un mot : dans la finitude. Par conséquent, accepter jusqu'au bout la créaturalité de l'ange exige le refus de son assimilation à une espèce : Positio igitur quae tenet quod plures aut omnes angeli sunt aut esse possunt eiusdem speciei est tenend ${ }^{233}$. Les anges sont des individus au même titre que les êtres humains: aucune de leurs prérogatives ne peut effacer ou relativiser la condition individuelle qu'ils partagent avec le reste du créé ${ }^{234}$. La doctrine chrétienne de la création et l'ontologie du singulier s'accordent ici pour combattre l'idée de la subsistance d'une quelconque entité universelle, qu'il s'agisse des substances séparées ou des idées platoniciennes: Fides autem catholica et eius sana ac recta intelligentia abhorret realem universalitatem in quocumque creato $^{235}$. Pour cette raison, Olivi conclut sa démarche en dénonçant la thèse averroïste de l'unicité de l'intellect pour tous les hommes : il s'agit là d'une erreur analogue à celle qui vient d'être réfutée, car elle attribue la subsistance en tant qu'entité abstraite et universelle à une forme (l'intellectualité) qui ne peut exister que dans un substrat individuel ${ }^{236}$. Pour Olivi tout ce qui est de l'ordre de l'espèce possède donc un même statut : qu'il s'agisse de l'ange-espèce, de l'humanité, de la blancheur ou de l'asinité, on a toujours affaire à une abstraction de l'esprit qui ne subsiste pas comme telle dans la réalité. Seules les entités individuelles existent véritablement.

\footnotetext{
231 Quaest. in II Sent., qu. XXXIII, vol. I, p. 604.

232 Cf. ibid. : « dicta philosophorum de pluralitate deorum ».

233 Ibid., p. 605.

234 Aussi, Olivi interprète-t-il l'universalité des anges supérieurs dont parle le Pseudo-Denys (cf. De caelesti hierarchia, c. XI, $\S 2$, PG 3, p. 286) comme un excès de dons - science, etc. - par rapport aux anges inférieurs, et non pas comme une détermination de leur être : « dicendum quod Dionysius per nomen universalitatis intendit significare quendam supereccessum scientiae et aliorum donorum qui est in superioribus angelis respectu inferiorum $\gg$.

235 In II Sent., qu. LXXII, vol. III, p. 29.

236 Cf. ibid., p. 604: "Et isto etiam errore fortissime astruitur quod non sit in omnibus hominibus nisi unus intellectus, quia omnia illa per quae probatur universalitas naturae specificae in quolibet angelo possunt adduci aeque efficaciter ad probandum quod tota species intellectus humani est in una substantia universaliter recollecta ».
} 


\section{La particularité des espèces angéliques}

La problématique du statut de l'ange étant étroitement liée à celle de l'universalité de ses représentations cognitives, une analyse exhaustive du problème exige l'examen du statut de ses représentations intelligibles. Notre auteur entreprend cet examen dans la question XXXIV : Tertio ad illud quod iuxta hoc quaerebatur [an in angelis sint species universales]. Voici les données du problème : les partisans de la réalité spécifique des anges leur attribuent la connaissance au moyen de représentations universelles, grâce auxquelles ils connaissent une multiplicité d'individus par la seule saisie de la représentation de leur espèce ou de leur genre ${ }^{237}$. Olivi rejette catégoriquement cette position ${ }^{238}$ et lui oppose la thèse suivante : teneo quod in nullo angelo nec in aliqua penitus creatura est dare huiusmodi species praedictam universalitatem habentes ${ }^{239}$. Comme d'habitude, notre auteur défend sa position par la réduction à l'absurde de l'opinion contraire. Le cas échéant, tous les inconvénients relevés dans la question précédente restent valables, mais d'autres s'y ajoutent.

La première conséquence réside en ce que les créatures spirituelles connaîtraient simultanément une infinité d'objets, car une seule représentation universelle peut comprendre une totalité infinie, comme par exemple la représentation de la série infinie des nombres ou celle de la divisibilité infinie d'un continu ${ }^{240}$. La deuxième conséquence serait la connaissance de tous les objets indépendamment de leur existence actuelle, car tous seraient représentés par une seule et même similitude ${ }^{241}$. Cette difficulté implique à son tour, à titre de corollaires, que les anges connaîtraient les objets futurs de la même manière qu'ils connaissent les réalités passées ou présentes; qu'ils connaîtraient de la même manière les actes futurs, passés et présents, pour autant qu'ils rentrent

\footnotetext{
237 Cf. ibid., qu. XXXIV, vol. I, p. 609-610: "licet sequaces primae positionis teneant quod in angelis sint species universales et quod in superioribus sunt universaliores quam in iis qui sunt inferiorum ordinum et insuper volentes quod universalitas earum sit talis quod per unam similitudinem apprehendetur tota una natura specifica cum omnibus individuis suis"; c'est l'opinion de Thomas d'Aquin, S. theol. I, 55, 3; De veritate, qu. 8, a. 10; Super librum de causis exp., prop. X. Gilles de Rome va défendre ces mêmes idées avec beaucoup de vigueur dans le De cognitione angelorum, rédigé entre 1286 et 1288/89: si on accepte la datation des Quaest. in II Sent. d'Olivi, à savoir 1277-1283, le franciscain n'a pas pu faire référence à Gilles de Rome, sauf si le remaniement dont elles ont fait l'objet vers 1295/96 (cf. S. Piron, Les ouvres perdues d'Olivi : essai de reconstitution, cit., p. 361 ) a porté aussi sur ces questions angélologiques.

238 Guillaume de la Mare l'avait fait avant lui : cf. Correctorium, cit., a. XVIII et a. XX, p. 79-84 et p. 87-

91.

239 Quaest. in II Sent., qu. XXXIV, vol. I, p. 610.

240 Cf. ibid. : « Primo quidem, quia ex hoc sequitur quod angeli uno actu cognoscant infinita, etiam illo modo quo nec Deo cognitio infinitorum potest attribui, utpote quod per modum unius entis et unius totius seu unius aggregati infinita simul cognoscant ; (...). Sequeretur etiam quod cognoscant actu et simul totam divisibilitatem et divisionem continui, acsi tota esset expleta ; et consimiliter cognoscent, saltem supremi angeli, infinitam speciem numerorum ».

241 Cf. ibid., p.610-611: "Sequeretur etiam quod (...) semper uniformiter omnia cognoscant ac per consequens quod individua quae non sunt cognoscant esse actu, sicut et illa quae sunt, et e contrario quod illa quae sunt cognoscant non esse actu, sicut et illa quae non sunt, quoniam uniformiter et per eandem similitudinem omnia simul repraesentantur".
} 
dans une même espèce d'opérations; et enfin, qu'ils saisiraient les objets absents comme s'ils étaient présents, si bien que les variations affectant chaque objet individuel leur seraient inconnaissables ${ }^{242}$. A ces difficultés, qui concernent le rapport à l'objet de connaissance, s'en ajoutent d'autres relatives au statut de ces représentations et de l'ange qui les possède. Un premier inconvénient réside en ce qu'il pourrait y avoir une représentation si universelle et compréhensive des espèces et des genres qu'elle serait en dehors de tout genre, et posséderait par conséquent un caractère absolu et divin ${ }^{243}$. Appliqué à l'ange qui connait, le même raisonnement permet de formuler l'hypothèse que Dieu pourrait créer un ange supérieur à tous ceux qui existent et possédant une représentation d'une telle ampleur qu'elle lui permettrait à elle seule de connaître la totalité des étants ; cette hypothèse peut d'ailleurs être radicalisée dans le sens que Dieu pourrait toujours créer un ange supérieur aux précédents, et ce à l'infini, ce qui aboutirait à la création d'un ange égal ou supérieur à Dieu lui-même ${ }^{244}$. Olivi évoque enfin une dernière difficulté du côté du sujet angélique, à savoir que pour la même raison pour laquelle l'ange posséderait des représentations universelles, il posséderait aussi des habitus de volonté ayant une étendue universelle et lui permettant d'atteindre la totalité des objets particuliers compris sous un seul objet général.

En résumé, selon Olivi - tributaire ici, au moins en partie, de Guillaume de la Mare et d'Henri de Gand - la thèse des représentations universelles comporte une double série d'inconvénients: du côté du rapport à l'objet ces espèces s'avèrent inadéquates, car incapables de saisir le singulier dans sa réalité actuelle et changeante. Du côté du sujet, la possession d'espèces universelles postulerait une nature universelle et des capacités d'étendue universelle, autant à l'égard des objets de l'intellect qu'à l'égard de ceux qui rentrent dans le domaine de la volonté. Pour le franciscain, la gravité de ces conséquences exige

\footnotetext{
242 Cf. ibid. : « Sequeretur etiam quod ita cognoscant futura contingentia sicut praesentia et praeterita (...). Et ultra hoc cognoscent omnes locutiones et operationes quae sunt eiusdem generis cum praesenti cogitatione vel locutione vel operatione. (...) Sequetur etiam quod ita cognoscant quaecumque absentia, quantumcumque longe distantia, sicut et praesentia (...). Sequetur etiam quod nullam variationem in obiectis cognoscere possint". L'ensemble de ces critiques figure aussi chez Guillaume de la Mare, Correctorium, cit., a. XVIII.

$243 \quad$ Cf. ibid., p. 611-612: "Hic ponitur quod una species per aequivalentiam seu potius per praevalentiam comprehendat in se omnes proprias rationes generales omnium individuorum et omnium specierum et generum quae per ea cognoscuntur aut cognosci possunt, acsi imaginaretur unam lucem (...). Et indubitanter talis forma esset extra omne genus et super omne genus ac per consequens vere idem quod summus Deus ».

$244 \quad$ Cf. ibid., p. 612: "Sequetur etiam quod gradatim ascendendo Deus poterit facere unum angelum et unam speciem in eo tantae altitudinis quod per illam cognoscet totum ambitum entis aut saltem totum ambitum unius generis generalissimi (...); eadem ratione poterit facere quod alius eo superior possit in totum ambitum unius generis generalissimi et iterum quod alius eo superius possit in totum ambitum entis (...), et sic semper in infinitum". Cette critique de la thèse de l'universalité des espèces angéliques n'est pas nouvelle : elle est ébauchée par Guillaume de la Mare (cf. Correctorium, cit., a. XX, p. 88-89) et se rattache à la problématique du « status in supremo » (qui consiste à savoir s'il existe un ange si parfait que Dieu ne pourrait pas en créer un autre encore plus parfait) formulée par Henri de Gand dans le cadre de la discussion sur l'unité de l'éviternité : cf. Quodlibet XI, qu. 11 ; à ce propos, cf. P. Porro, "Ponere statum ». Idee divine, perfezioni create e ordine del mondo in Enrico di Gand, Mediaevalia 3 (1993), p. 109-159.
} 
le refus de leur fondement, au-delà et indépendamment des preuves en faveur de sa propre position.

Olivi corrobore néanmoins sa conception par quelques éléments qui en démontrent la légitimité en dehors de sa fonction critique. S'engageant sur le terrain de la connaissance universelle, le franciscain nie d'emblée que l'universalité des notions abstraites soit présente dans l'intellect qui les conçoit de manière à le rendre lui-même universel : en effet, ce qui est présent dans la faculté intellectuelle y figure à titre de similitude ou de représentation d'un objet, et ne peut donc pas affecter l'intellect dans son être-même. Cet aspect mérite d'être clarifié, car il permet de mieux dégager la conception de notre auteur. Selon Olivi, le propre d'une représentation n'est pas d'être réellement ce qu'elle représente, mais d'en rendre compte par mode d'imagination ${ }^{245}$. Dès lors, même si l'espèce représente pour l'intellect l'universalité qu'il attribue aux choses, il ne s'ensuit pas pour autant qu'elle est universelle, mais seulement qu'elle représente l'universel ${ }^{246}$. Entre la pensée et la réalité il y a une fracture irréductible, car la modalité d'être de ce qui existe en dehors du sujet est radicalement différente de la modalité d'être des contenus de son intellect. Leur rapport est uniquement de l'ordre de la représentation et il se réalise dans l'acte par lequel le sujet saisit intentionnellement son objet - celui-ci n'exerçant d'ailleurs aucune causalité efficiente à l'égard de la connaissance ${ }^{247}$. A partir de là, la représentation d'un objet, même lorsqu'elle traduit une notion universelle, ne saurait déterminer la modalité d'être de l'intellect qui la conçoit, car elle n'est présente en lui que comme image ou expression de l'objet. De son côté, l'intellect qui pense l'universalité dans les choses ne pense pas pour autant qu'elle est réellement présente dans les choses - ce qui n'empêche pas qu'il puisse saisir dans un concept la convenance d'une pluralité de choses singulières ${ }^{248}$, en concevant l'universalité comme si elle n'était pas multipliée dans les individus. La différence radicale qui sépare l'existence réelle de l'existence dans la pensée permet alors de concevoir sans fausseté une réalité qui n'existe pas, précisément parce que la représentation de quelque chose n'est pas la réalité de cette chose. Dans ce cas, la vérité de la connaissance est sauvegardée pour autant que le sujet est conscient de cette distinction

\footnotetext{
245 Cf. Quaest. in II Sent., qu. XXXIV, vol. I, p. 614: "Universalitas quam intellectus attribuit naturis rerum in abstracto et universaliter intellectis non est sic in intellectu ut ponat in eo aliquam realem universalitatem ; non enim est ibi nisi sicut res imaginata in imaginatione aut sicut repraesentatum in repraesentante, repraesentantia autem non sunt secundum rem illud quod repraesentant $»$.

246 Cf. ibid. : «Quamvis igitur species repraesentet intellectui universalitatem quam rebus attribuit, non propter hoc sequitur quod sit universalis, sed solum ex hoc sequitur quod sit repraesentativa universalitatis ». 247 Cf. O. Bettini, Attivismo psicologico-gnoseologico, cit., p. 208 sv.

248 Cf. Quaest. in II Sent., qu. XXXIV, vol. I, p. 615: "Intellectus autem, quando cogitat in rebus universalitatem, non sic cogitat hoc quod ita credat esse in re et absolute et realiter (...); cogitat enim tunc quod quamvis res non sit in se universalis, tamen intellectui sic absolute absque sua individuatione offertur, acsi non esset individua et acsi non esset in individuis multiplicata, sed potius acsi esset in eis sine omni sui plurificatione existens, quia tunc non cogitat eam, prout in ea differunt, sed solum prout in ea conveniunt ».
} 
fondamentale : il est alors possible de penser une rose en hiver, dès lors qu'on ne pense pas qu'elle existe réellement ${ }^{249}$.

Ces précisions sont étroitement liées au refus de considérer l'objet comme cause efficiente de la connaissance. Selon Olivi, celle-ci est l'œuvre exclusive de la faculté cognitive, qui s'assimile l'objet par l'aspectus qui l'oriente intentionnellement vers lui. La connaissance résulte de ce que le sujet s' « imbibe» de l'objet en tant que terme (causa terminativa) de sa visée intentionnelle $\mathrm{e}^{250}$, ce qui rend parfaitement inutile la représentation en tant qu'impression de l'objet dans la faculté cognitive. Par ailleurs, l'objet propre de l'intellect n'est pas la nature abstraite des choses, mais la réalité dans son individualité. A partir de là, la représentation d'un objet coïncide en réalité avec l'acte d'intellection du même objet, et le contenu de cette représentation est singulier et particulier comme l'objet qu'elle représente ${ }^{251}$. Il n'y a donc pas plus d'universalité dans les choses que dans l'intellect : l'objet de la connaissance est singulier et la représentation qui résulte de sa visée intentionnelle l'est également.

Ces quelques éléments de la doctrine olivienne de la connaissance ${ }^{252}$ clarifient sa critique à l'égard des espèces universelles angéliques. En effet, audelà des conséquences déjà relevées, il s'avère à présent que pour Olivi l'idée d'une représentation qui serait elle-même universelle est autant inadmissible que celle d'une nature universelle réellement subsistante. L'universalité ne peut être que le signifié d'une représentation particulière, pour autant que l'intellect opère une conversion générale sur tous les objets qui lui sont présents et considère leur convergence en une raison commune ${ }^{253}$. L'ange ne dispose donc pas de

$249 \quad$ Cf. ibid., p. 614-615: "Si dicas quod [species] non potest repraesentare non ens, saltem veraciter, species autem repraesentat huiusmodi universalitatem absque omni falsitate, dicendum quod non ens bene potest repraesentari absque omni falsitate, solummodo quod per hoc non affirmetur quod ita sit in re, unde imaginans rosam in tempore quo nulla est rosa non est falsus, nisi crederet quod ita esset in re ».

250 Cf. Quaest. in II Sent., qu. LXXII, vol. III, p. 36: "vis cognitiva generat actum cognitivum cum quadam informativa imbibitione actus ad obiectum et cum quadam sigillari et viscerali tentione obiecti, idcirco eo ipso quod sic gignitur, fit ipsa similitudo et sigillaris expressio obiecti”.

$251 \quad$ Cf. ibid., p. 37: «Sciendum quod quia actus cognitivus obiecti individualis est terminatum in ipsum, in quantum est hoc individuum et non aliud, ideo de essentia talis actus est quod sit propria similitudo huius individui, in quantum huius et quod non sit similitudo aliorum individuorum eiusdem speciei, pro quanto individualiter differunt $a b$ isto ». L'exigence que le singulier soit connu par des espèces particulières avait déjà été formulée avec force par Roger Marston, Quaestiones disputatae de anima, qu. 2, éd. Quaracchi 1932, p. 227244 ; pour un panorama de ce problème chez les franciscains de la fin du XIIIe siècle cf. G. Bonafede, $L a$ conoscenza del singolare nella scuola francescana del secolo XIII, Collectanea franciscana, 22 (1952), p. 5-52. 252 A ce propos nous signalons, entre autres, B. Jansen, Die Erkenntnislehre Olivis, Berlin 1921 ; O.

Bettini, Attivismo psicologico-gnoseologico, cit. ; E. Bettoni, I fattori della conoscenza umana secondo Olivi, Rivista di filosofia neoscolastica, 47 (1955), p. 8-29 et, du même A., Pier di Giovanni Olivi critico dell'intelletto agente, Studi francescani, 52 (1955), p. 19-41, ainsi que Il realismo moderato di P. di Giovanni Olivi ̀̀ autentico ?, ibid., 48 (1956), p. 231-251 ; C. Bérubé, La connaissance de l'individuel au Moyen Age, MontréalParis 1964, p. 100-106 ; K. Tachau, Vision and Certitude in the Age of Ockham, Leiden 1988, p. 39-54 ; L. Spruit, Species intelligibilis, Leiden-New York-Köln 1994, vol. I, p. 215-224.

${ }_{253}$ Cf. Quaest. in II Sent., qu. LIX, vol. II, p. 543-544: “Aspectum autem hic voco conversionem virtualem seu intentionalem potentiae ad obiectum. (...) Et horum aspectum quidam est universalis, quidam vero 
représentations universelles comme moyens d'intellection de ses objets ${ }^{254}$, mais, à la manière de l'être humain, il connaît chaque chose séparément et directement par l'intentionnalité (aspectus protensus) qui le relie à elle. Olivi peut alors conclure que: magis sit assentiendum primo modo qui tenet quod species sit particularis et quod plures ideas et res per plures species videamus aut per unam ex pluribus aggregatam ${ }^{255}$.

\section{Les anges et les espèces innées}

Les représentations universelles étant ainsi supprimées et toute homogénéité entre le contenu de la représentation et la modalité d'être de la faculté cognitive annulée, la critique de la thèse de la réalité spécifique des substances séparées est désormais achevée. Les anges sont des individus au même titre que les êtres humains et leurs opérations de connaissance et de volonté se jouent dans le rapport immédiat avec leurs objets. Reste à savoir quelle est la modalité de leur connaissance : comment des créatures purement spirituelles peuvent-elles se rapporter directement à des objets corporels ? Qu'en est-il des espèces innées de toutes choses, dont les anges étaient pourvus selon bon nombre des penseurs de l'époque ? Nous allons clarifier brièvement ces questions à partir d'un texte où Olivi prend explicitement position face à cette problématique: Quinto quaeritur an [angelus] intelligat et videat omnia per species innatas $^{256}$.

La connaissance au moyen de représentations innées était attribuée aux substances séparées par ceux-là même qui les concevaient comme des formes pures identiques à leur espèce. Ces penseurs - que l'on songe à Albert le Grand, Thomas d'Aquin ou Gilles de Rome ${ }^{257}$ - attribuaient aux créatures spirituelles un statut et une modalité d'agir nettement supérieurs à ceux des êtres humains: pour la connaissance cela signifiait que les anges connaissent leurs objets sans en être affectés, au moyen de représentations reçues directement de Dieu dès leur création; il s'agissait donc d'une connaissance a priori, rendue possible par des similitudes représentatives servant de miroirs de leurs objets ${ }^{258}$. S'attaquer à la

particularis. Universalem autem voco generalem conversionem ad omnia obiecta quae sibi praesentia dici possunt ; sicut oculus eo ipso quod est apertus et actualiter directus ad exteriora, aspicit totum hemisphaerium, sicut et quilibet punctus lucis solaris $»$.

254 Cf. qu. XXXIV, vol. I, p. 615-616 : « quod sit in intellectu quoddam obiectum abstractum in quo intellectus intelligat et speculetur obiectum quod est in rebus extrinsecis existens $(\ldots)$ : hoc est falsum ».

$255 \quad$ Ibid., p. 626.

256 Cf. ibid., qu. XXXVI, vol. I, p. 629.

257 Cf. nos études: Les anges et la philosophie, cit., et Connaissance et langage des anges, cit.

258 Cette conception était appuyée notamment sur l'autorité d'Augustin et du Liber de causis : pour Augustin il s'agissait d'un passage du De Genesi ad litteram (c. 8 ; PL 34, 269) affirmant que les réalités inférieures aux anges étaient présentes en eux de manière intelligible avant même d'être créées ; pour le Liber de causis il s'agissait de la proposition $\mathrm{X}$, où on lisait que « omnis intelligentia plena est formis ». Voici deux passages d'une grande clarté où Thomas d'Aquin fait usage de ces autorités : S. theol .I, 55, 3 : « Substantiae 
thèse des représentations innées c'était donc viser une conception globale des substances séparées, touchant à leur statut, à leurs capacités et à leur fonction dans l'univers créé.

Pierre de Jean Olivi connaissait bien cette position : il la rapporte en l'attribuant à quidam magni, dont il partage l'idée que les réalités corporelles ne sauraient exercer une causalité efficiente sur la connaissance angélique, mais dont il se distancie résolument quant à la thèse des espèces innées ou connaturelles. Parmi les raisons de sa critique, on ne retiendra ici que les plus significatives ${ }^{259}$.

Une première difficulté concerne le statut de ces représentations. S'appuyant sur l'autorité de St. Augustin, Olivi observe que de telles espèces cognitives, en absence des objets et des actes de connaissance respectifs, se situent nécessairement dans la mémoire; par conséquent, lorsque l'intellect veut connaitre quelque chose, il va se tourner vers l'une de ses représentations, qui va constituer son objet premier; toutefois, par cet acte de conversion, l'intellect n'est pas présent à l'objet, mais seulement à sa similitude représentative, car la similitude présente dans la mémoire ne rend pas compte de l'objet en tant que présent $^{260}$. Cette première difficulté révèle une des exigences majeures de la noétique de notre auteur, à savoir la conversion intentionnelle sur l'objet luimême: l'intellect doit être praesentialiter conversus sur la chose et non pas sur sa représentation. Comme l'être humain, l'ange est soumis à cette exigence et ne peut pas connaître véritablement son objet à travers l'écran d'une similitude représentative.

La deuxième difficulté va dans le même sens et réside dans le fait que des espèces universelles ne représentent et ne font connaître que l'universel. La connaissance du singulier comme tel exigerait donc une espèce particulière pour chaque réalité individuelle, ce qui impliquerait la présence d'une infinité

\footnotetext{
vero superiores, id est angeli, sunt a corporibus totaliter absolutae, immaterialiter et in esse intelligibile subsistentes : et ideo suam perfectionem intelligibilem consequuntur per intelligibilem effluxum, quo a Deo species rerum cognitarum acceperunt simul cum intellectuali natura. Unde Augustinus dicit, II super Genesim ad litteram, quod « caetera, quae infra angelos sunt, ita creantur, ut prius fiant in cognitione rationalis creaturae, ac deinde in genere suo »; Summa contra Gent., II, 98: "Intellectus substantiae separatae totaliter perficitur per formas intelligibiles, quantum ad cognitionem naturalem. (...) Et propter hoc dicitur in libro De causis quod « intelligentia plena est formis », quia scilicet tota potentialitas eius est completa per formas intelligibiles ». Pour cette problématique nous renvoyons à notre étude : Connaissance et langage des anges, cit., Ière partie.

259 Guillaume de la Mare critique lui aussi la thèse des espèces innées, mais principalement au nom de la réceptivité de la connaissance : cf. Correctorium, cit., a. XVIII, p. 79-84.

260 Cf. Quaest. in II Sent., qu. XXXVI, vol. I, p. 630: “Contra primum videtur posse multipliciter argui : Et primo ex conditione specierum innatarum. Constat enim secundum Augustinum, quod species illae quae manent in absentia actuum non existunt in acie intelligentiae, sed potius in memoria; sed tales non applicantur ad res exteriores, quin potius, quando per tales species aliquid intelligimus, tunc intellectus convertitur ad eas tamquam ad prima sui obiecta, ita quod tunc nullo modo est praesentialiter conversus ad res exteriores ».
} 
d'espèces dans l'intellect angélique ${ }^{261}$. Ici encore le problème tient à l'impossibilité de connaître l'objet dans sa singularité à travers une médiation conceptuelle dont le contenu est universel. Dans la perspective d'Olivi la relation directe avec l'objet est irremplaçable, car elle constitue la condition sine qua non de sa connaissance.

Une autre difficulté, liée à l'impossibilité de connaître le singulier par des représentations a priori, mérite également d'être signalée en raison de la justification qu'elle implique. Le franciscain observe que lorsque quelqu'un se fait une image de quelque chose qu'il ne connaît pas - par exemple d'une ville lointaine -, il ne peut pas savoir si cette fiction correspond véritablement à la réalité qu'elle représente avant de voir directement cette réalité ${ }^{262}$; d'où la conclusion que la similitude d'une chose ne peut pas en assurer la connaissance. Il apparaît d'emblée que les termes de cette critique ne sont pas pertinents à l'égard de la thèse des espèces innées, car celles-ci, du point de vue de leurs défenseurs, ne sauraient d'aucune façon être assimilées à des images fictives fabriquées par le sujet. Bien au contraire, les espèces innées ou connaturelles ne peuvent encourir aucune sorte de fausseté, car elles dérivent directement des exemplaires divins; c'est pourquoi elles assurent une connaissance plus adéquate que celle qui résulte de l'impression des choses elles-mêmes et qui emprunte la médiation du sensible. Olivi ne semble donc pas tenir compte ici de la dérivation divine des espèces innées, et il les critique comme s'il s'agissait de représentations analogues à celles que produit le sujet humain.

En réalité, si on envisage la conception olivienne dans son ensemble, il apparaît que cette occultation est fondée sur deux raisons majeures. Il y a d'une part la critique générale des espèces en tant que médiations cognitives : dans cette optique le statut particulier des espèces innées importe peu, car il s'agit toujours de médiations qui empêchent un rapport direct avec l'objet. D'autre part, et plus fondamentalement, il y a la critique olivienne des idées divines : selon le maître franciscain - qui s'oppose sur ce point autant à Thomas d'Aquin qu'à Bonaventure - Dieu crée les choses immédiatement hors de lui, sans passer par un exemplaire intermédiaire, car celui-ci introduirait une dépendance dans l'agir divin. A plus forte raison, Dieu ne connaît pas les choses au moyen de ses

261 Cf. ibid., p. 630-631: "Constat enim quod ex speciebus universalium (...) non potest repraesentari nisi universale (...). Ergo (...) non poterimus devenire in cognitionem rerum particularium seu in cognitionem particularitatis earum, (...) nisi habeantur species omnium individuorum cuiuscumque generis, prout habent individuationes a se invicem distinctas (...) ; ergo oportet quod haberent infinitas species infinitorum particularium $\gg$.

Cf. ibid., p. 631: "Praeterea, Augustinus VIII De Trinitate, capitulo 6, dicit quod si ille qui numquam vidit Alexandriam fingat seu formet sibi imaginem eius (...), numquam tamen posset scire ipsam esse veram imaginem eius, nisi videret ipsam urbem. (...) Sed secundum modum praedictum ponuntur angeli videntes per solam compositionem seu confictionem specierum ; ergo nihil per hoc de particulari statu rerum scire poterunt $\gg$. 
idées, mais les connaît en leur étant toujours immédiatement présent ${ }^{263}$. En d'autres termes, Olivi refuse tout intermédiaire noétique dans l'agir et la connaissance de Dieu, et ce au nom de la liberté divine et de la capacité de la volonté d'être cause totale de ses actes: Dieu agit parce qu'il le veut et son efficacité s'étend immédiatement à tous les objets de son vouloir ${ }^{264}$. Or, s'il en est ainsi, l'ange n'a pas à recevoir de Dieu des représentations des choses qui seraient en quelque sorte des copies d'exemplaires que Dieu lui-même ne possède pas. Olivi passe donc sous silence l'origine divine des espèces innées, car il conteste tout simplement la présence en Dieu des exemplaires dont elles sont censées dériver ${ }^{265}$. A partir de là, il peut envisager les espèces des substances séparées à la manière des représentations humaines et les frapper d'une même critique.

La suite des griefs formulés à l'encontre de la thèse des représentations connaturelles reprend et accentue l'idée de leur incapacité à fournir une connaissance adéquate du singulier - et notamment des changements qui l'affectent - du fait qu'elles empêchent le rapport direct avec l'objet ${ }^{266}$ : en dehors de ce rapport, point de connaissance véritable et assurée, non seulement de la singularité des choses, mais aussi et surtout de leur existence ${ }^{267}$. Toute connaissance véritable réside dans l'intellection particulière d'une réalité singulière : celle qui fait recours à une espèce ne sera par conséquent qu'une remémoration ou une imagination de l'objet, mais ne produira jamais la présence immédiate - aspectus, intuitus - à la vérité de la chose ${ }^{268}$.

\footnotetext{
263 A ce propos nous renvoyons à S. Piron, La liberté divine et la destruction des idées chez Olivi, in : A. Boureau-S. Piron (éd.), Pierre de Jean Olivi, cit., p. 71-89.

$264 \quad$ Cf. ibid., p. 85 et p. 89.

265 Plus loin dans le même texte, Olivi montre qu'il connaît bien le motif de la dérivation divine des idées angéliques, mais il s'y réfère pour relever que de telles espèces seraient semblables aux exemplaires dont elles dérivent plutôt qu'aux choses elles-mêmes ; cf. Quaest. in II Sent., qu. XXXVI, vol. I, p. 637-638 : « Species ita parum possent esse actu similes rebus praeteritis sicut et futuris (...). Quia ipsimet ponunt species angelorum innatas ab exemplari eterno immediate fluxisse ; ergo secundum eos rationem suae similationis trahunt ab exemplari ; ergo sufficit quod sint actu similes illi (...)».

266 Olivi formule à ce propos une hypothèse curieuse qu'on pourrait intituler « jouer à cache cache avec les anges » : « Praeterea, est quod angelus existens in caelo velit me videre qui sum Narbone et ipse hoc nescit : tunc non poterit me videre, nisi prius applicet speciem ad locum Narbone ; et cum ipse nesciat plus me ibi esse quam Parisius vel Romae aut quam in quocumque alio loco : ergo nesciet ad quem locum debeat species applicare ; ex quo poterit frequenter contingi quod primo applicabit species ad omnia alia loca quam ad locum Narbone in quo ego sum. Et iterum poterit contingere quod quando applicabit species ad locum Narbone, quod ego prius recesserim inde et iverim Romam vel alibi, et sic continget quod tunc non poterit me videre ibi. Et iterum poterunt similia de aliis locis contingere. Ex quo quam absurda sequantur satis de se patet ».

$267 \quad$ Cf. ibid., p. 634-635: "Cum enim secundum Anselmum, Proslogion, 2 capitulo, aliud sit cogitare rem, aliud cogitare rem esse, quamvis per speciem repraesentetur res, non propter hoc per eam repraesentatur rem esse. (...) Esto etiam quod repraesentent rem esse : non propter hoc oportet quod vere et certitudinaliter repraesentent eam esse. Esto etiam quod hoc facerent : oporteret aliquid aliud addi ad species vel variari ad hoc quod eandem rem repraesentarent non esse seu aliter se habere. Ergo per solas species innatas non videtur posse haberi certitudo de rerum esse et non esse ».

$268 \quad$ Cf. ibid., p. 639: "ipsi [angeli] numquam possint res videre, sed solum eas quasi ut absentes imaginari seu rememorari, quia numquam intuitus eorum figitur in ipsa veritate rei, sed solum in quadam intellectuali similitudine ipsius, ac per consequens sequitur quod veritatem eius nude non intueatur ».
} 
Le franciscain considère ensuite brièvement un autre élément important de l'option en faveur des représentations innées, à savoir leur caractère connaturel un caractère résultant de ce que les anges possèdent ces espèces dès leur création. Après avoir rendu compte de la justification de cet attribut, Olivi situe explicitement cette position en continuité avec la tradition philosophique : secuti sunt autem in hoc paganos philosophos qui ponunt quod intelligentiae sunt naturaliter plenae formis ${ }^{269}$. Notre auteur refuse cette position, d'une part en raison des privilèges qu'elle accorderait aux substances séparées, et d'autre part à cause des absurdités qui en découleraient. Pour ce qui est des privilèges, Olivi n'est pas prêt à admettre que l'intellect connaît sans le concours de l'objet et que de surcroît il en possède la similitude représentative selon une modalité d'être supérieure à celle de la chose elle-même ${ }^{270}$. Quant aux absurdités, notre auteur signale le fait qu'une influence naturelle des anges supérieurs sur les inférieurs résultant des capacités naturellement supérieures des premiers - irait à l'encontre de la liberté des inférieurs, et que d'autre part cette prérogative naturelle signifierait, par exemple, que Lucifer pourrait toujours exercer son influence sur les anges qui lui étaient soumis ou que les anges bons pourraient transmettre la lumière de la vérité aux démons ${ }^{271}$. Ces objections à l'encontre de la naturalité des représentations angéliques montrent bien la réticence d'Olivi à accorder à un type particulier de créature des privilèges d'ordre naturel qui la distingueraient essentiellement du reste du créé.

De cette critique émerge par ailleurs l'élément volonté/liberté, qui fait le contrepoids de la nature et qui possède, pour notre auteur et la tradition franciscaine en général, une valeur sans doute majeure : dans cette perspective, une influence naturelle et nécessaire, c'est-à-dire permanente, des anges supérieurs sur les inférieurs ne peut pas être admise, car elle compromet la liberté de l'inférieur ${ }^{272}$. Une telle influence est sans doute réelle et bénéfique,

\footnotetext{
269 Ibid., p. 641-642.

270 Cf. ibid., p. 642: "ex primo sequitur quod intellectus, ante etiam quam gignat in se species, habeat in sua essentia similitudinem rerum, etiam altiori modo quam habeant in se species ab eo genitae; quia omne influens speciem absque coadiutorio obiecti seu terminativi habebat in se modo altiori rationem similitudinis influxae, quia similitudo sic influxa totam rationem suae essentiae trahit a suo agente".

271 Cf. ibid., p. 643: "Dicere etiam quod superiores angeli ordine naturali et necessario et nullo modo interpolabili semper influant in inferiores huiusmodi species seu aliquod lumen determinans eos ad obiecta valde est absurdum et contra naturalem libertatem eorum; et multo magis hoc est absurdum de animabus separatis et maxime de reprobis et damnatis. Quis enim ferat audiens quod Lucifer naturali ordine et necessario influat in illos angelos quibus fuit prelatus ab initio suae creationis aut quod angeli boni naturaliter et necessario influant lumen veritatis in daemones seu in animas damnatas?»

272 Cela ne signifie d'aucune manière qu'Olivi refuse la structure hiérarchique du monde angélique ou la fonction illuminatrice des anges supérieurs à l'égard des inférieurs ; au contraire, il adopte la doctrine dionysienne - dont il présente différentes interprétations dans le De angelicis influentiis (éd. F. Delorme, in : Sancti Bonaventurae Collationes in Hexaemeron et quaedam bonaventuriana selecta, Quaracchi 1934, p. 363417) -, mais il signale son intérêt surtout pour la valeur instrumentale de la hiérarchie sur le chemin de la participation et de la vision de Dieu : dans cette optique il valorise les actes hiérarchiques de purification, d'illumination et de perfectionnement, mais juge ridicule la transmission hiérarchique de connaissances qui ne s'inscrivent pas dans la démarche qui mène à Dieu : « Numquid ridiculosissimum est dicere quod quando
} 
mais il ne faut pas la considérer pour autant naturelle ou nécessaire : pour Olivi son utilité semble se jouer dans l'ordre de la charité et de l'assimilation à Dieu plutôt que dans celui de la connaissance naturelle ${ }^{273}$.

Signalons enfin un dernier grief formulé par Olivi à l'égard de la thèse des espèces innées. Selon les partisans de cette thèse, la connaissance naturelle de l'ange emprunte uniquement le moyen des espèces connaturelles, car elles sont non seulement suffisantes, mais lui assurent une connaissance parfaite de tous les objets créés. Or, selon notre auteur cette position signifie que sans de telles espèces l'ange ne pourrait rien connaître, même si l'objet lui était présent : cette implication est facilement prouvée par le fait que les partisans des espèces innées refusent l'attribution à l'ange d'un intellect agent et d'un intellect possible, ce qui empêche toute connaissance par voie de réceptivité et d'abstraction ${ }^{274}$. Une telle position est parfaitement absurde aux yeux du franciscain, qui, contrairement à ses adversaires, y voit une faiblesse plutôt qu'une prérogative: ex hoc sequitur quod intellectus eorum sit multo impotentior quam noster, immo etiam multo impotentior oculi nostri ${ }^{275}$. Mais Olivi dénonce surtout le contresens qui réside dans l'impossibilité de connaitre un objet tout en lui étant présent ${ }^{276}$ : en effet, compte tenu de l'importance de la coexistence des choses et de leurs rapports mutuels, le franciscain ne peut pas admettre que la coprésence d'un sujet et d'un objet ne produise pas la connaissance. Celle-ci, sans être causée par l'objet à titre d'efficient, résulte néanmoins d'un rapport immédiat qui se passe des espèces intelligibles: par conséquent, attribuer aux anges une connaissance entièrement médiatisée par de telles espèces signifierait compromettre totalement leurs rapports cognitifs.

$\mathrm{Au}$ terme de cette longue discussion le lecteur est invité à choisir entre trois opinions : la première - que notre auteur ne discute pas - attribue aux anges la connaissance par espèces acquises ${ }^{277}$; la deuxième représente une voie moyenne, car elle défend l'idée que les anges connaissent en partie au moyen de

\footnotetext{
angelus ab alio addiscit quod ego cras curram, quod tunc perficiatur in omni puritate aut quod tunc alter tradat ei de sua eccessiva castitate?».

$273 \quad$ Cet aspect est prouvé par l'ensemble de la Quaestio de angelicis influentiis ; voici un passage parmi d'autres : «Si autem inferior per superiorem ad maiorem Dei participationem seu ad maiorem Dei visionem et fruitionem adducitur, tunc clarum est quod inferior per hoc fit purior et castior, tamquam per hoc magis participans illam puritatem quae Deus est et tamquam per hoc puritate caritatis caeterarumque virtutum ac totius substantialis gloriae magis plenum » (p. 390-391).

$274 \quad$ Le point de référence est ici encore Thomas d'Aquin, qui nie que l'ange possède un intellect agent et un intellect possible, car l'intellect angélique et ses intelligibles sont toujours en acte : cf. S. theol., I, 54, 4.

$275 \quad$ Quaest. in II Sent., qu. XXXVI, vol. I, p. 644.

276 Cf. ibid. : « Praeterea, esto quod Deus creet aliquam rem cuius speciem eis ab initio non dedit (...): tunc ipsi non poterunt videre rem illam, quantumcumque sit eis praesens, nisi infundatur eis de novo similitudo illius; quod valde absurdum est dicere".

277 C'est l'opinion de Guillaume de la Mare, qui conçoit la connaissance des anges à la manière de la connaissance humaine, c'est-à-dire réceptive à l'égard des objets : cf. Correctorium, cit., a. XVIII, p. 79-84.
} 
représentations innées et en partie par des espèces reçues des $\operatorname{choses}^{278}$; la troisième position s'écarte de l'alternative espèces acquises/espèces innées et soutient que la connaissance angélique est engendrée par l'intellect en présence de l'objet, qui intervient dans la connaissance en guise de cause «terminative ${ }^{279}$. Cette troisième option est de toute évidence celle de Pierre de Jean Olivi, qui refuse autant la médiation des espèces intelligibles - et notamment des espèces innées - que la causalité efficiente de l'objet - c'est-àdire les espèces acquises -, et conçoit la connaissance comme le résultat de l'orientation intentionnelle du sujet vers l'objet qui termine son acte. Conscient de l'originalité de sa position et de son écart par rapport aux doctrines des maîtres de son ordre ${ }^{280}$, Olivi déclare, avec un détachement seulement apparent, que : licet nullam [istarum opinionum] curem asserere, ultima tamen modicitati mei iudicii probabilior videtur et magis catholicae fidei consona, nisi esset contraria communi opinioni ${ }^{281}$. La théorie des espèces innées est donc totalement rejetée par notre auteur, qui attribue aux anges la même modalité cognitive qu'aux êtres humains, à savoir une connaissance dans laquelle le sujet joue un rôle éminemment actif, mais où la présence immédiate de l'objet est requise comme terme de l'aspectus exercé par le sujet ${ }^{282}$.

Avant de conclure cette partie, il convient de signaler brièvement la dernière question consacrée par notre auteur à la connaissance des substances séparées : il s'agit de la question XXXVII, qui porte sur le problème de la simultanéité de la connaissance angélique - an intellectus angeli possit per virtutem suae naturae simul cognoscere plura ${ }^{283}$. Comme les thèses discutées précédemment, celle-ci aussi a été défendue par les partisans du statut de l'ange comme forme pure intellectuelle ${ }^{284}$. La confrontation d'Olivi avec cette thèse ne

\footnotetext{
278 Olivi ne discute pas non plus cette opinion, qui figure dans la Summa fratris Alexandri, p. II, qu. 22 , m. 3, Quaracchi 1924, t. II, p. 184B-185B, ainsi que chez Bonaventure, In II Sent., d. 3, p. 2, a. 2, qu. 1, Quaracchi 1885, Opera omnia, t. II, p. 120 ; cette opinion est partagée aussi par Richard de Mediavilla, In II Sent., d. III, qu. II, a. 6, (Brixiae 1591 ; repr. Frankfurt 1963, p. 64), qui soutient que l'ange connaît l'universel et les réalités singulières incorruptibles par des espèces innées, et les entités particulières par des espèces reçues des choses. ${ }_{279}$ Cf. Quaest. in II Sent., qu. XXXVI, vol. I, p. 646: "Tertia vero dicit quod per species ab intellectu genitas non simpliciter et absolute, sed ad praesentiam obiecti et praevia conversione et virtuali defixione intellectus ad ipsum, ita quod obiectum cooperatur ibi per modum terminativi”.

$280 \quad$ Pour les différentes options à l'égard de la problématique des espèces cognitives dans l'ordre franciscain, cf. F. Prezioso, L'attività del soggetto pensante nella gnoseologia di Matteo di Acquasparta e di Ruggero Marston, Antonianum, 25 (1950), p. 259-326 ; G. Bonafede, La conoscenza del singolare nella scuola francescana, cit.

281 Quaest. in II Sent., qu. XXXVI, vol. I, p. 647.

282 Pour plus de précisions quant à la conception olivienne du processus cognitif on lira le questions LXXII-LXIV, dans lesquelles Olivi précise les différents types de causalités qui interviennent dans la production de la connaissance. Signalons enfin qu' Olivi conclut la qu. XXXVI par l'examen d'une quatrième position, qu'il réfute entièrement : il s'agit de l'opinion d'Henri de Gand, qui attribue aux anges la connaissance au moyen d'un « habitus scientialis » : cf. Quodlibet IV, qu. 7 et 21 et Quodlibet V, qu. 14. La position d'Henri de Gand est réfutée de manière très détaillée par Gilles de Rome, dans le traité De cognitione angelorum (qu. IV) : nous avons rendu compte de cette discussion dans notre étude Connaissance et langage des anges, cit.

283 Quaest. in II Sent., qu. XXXVII, vol. I, p. 654.

284 Nous pouvons renvoyer une fois encore à Thomas d'Aquin, S. theol., I, 52, 2, où l'Aquinate soutient que l'ange connaît simultanément par voie naturelle (c'est-à-dire par ses espèces) une multiplicité d'objets
} 
nous réserve aucune surprise et s'inscrit en parfaite continuité avec ce qui précède. Récusant la position qui nie à l'ange toute possibilité de connaître simultanément et par voie naturelle plusieurs contenus, notre auteur se range du côté de l'opinion qui veut que l'intellect des substances séparées soit à même de connaître plusieurs contenus de connaissance, pour autant qu'ils peuvent être ramenés à une unité de corrélation ou de coordination ${ }^{285}$. Une telle simultanéité est non seulement possible, mais aussi éxigée dans les actes de comparaison, de choix ou de jugement: dans ces cas, la connaissance simultanée de plusieurs données s'avère même absolument nécessaire. Cela dit, selon Olivi il ne s'agit pas là d'une capacité exclusive de la connaissance angélique, mais c'est au contraire une exigence qui marque tout aussi bien la connaissance humaine. L'attribution à l'ange de cette forme de simultanéité ne signifie donc pas l'octroi d'un privilège ou d'une condition supérieure à celle de la connaissance humaine. De ce point de vue, Olivi ne cède en rien aux partisans du statut privilégié des anges ${ }^{286}$, mais reconnaît simplement aux substances séparées la capacité de remplir une exigence que la connaissance humaine est aussi en mesure de satisfaire.

La saisie simultanée de plusieurs contenus est ainsi admise sous la condition de leur unité de corrélation ou de coordination. Il ne s'agit donc pas de l'unité simple d'une représentation, mais d'une unité complexe et composée, qui réunit plusieurs éléments en les coordonnant et en les articulant les uns aux autres $^{287}$. Toute faculté cognitive créée connaît en effet par un regard (aspectus) unificateur orienté vers ses objets, à la manière dont l'œil voit plusieurs choses dans l'unité d'un seul regard ${ }^{288}$. De même, l'ange s'oriente ou se rapporte à plusieurs réalités par un aspectus qui s'étend et qui produit sa coexistence avec elles, pourvu qu'elles soient en continuité les unes avec les autres ou

\footnotetext{
lorsque ceux-ci sont unifiés dans un seul intelligible ; en revanche, il peut connaître simultanément la totalité de ses objets lorsqu'il connaît par voie surnaturelle les choses dans l'esprit divin. Gilles de Rome a discuté cette question de manière très complète dans la question VII du De cognitione angelorum; à ce propos nous renvoyons à notre article : Conoscenza e tempo. La simultaneità del conoscere angelico in Egidio Romano, dans: L. Cova-G. Alliney (éd.), Tempus, aevum, aeternitas. La concettualizzazione del tempo nel pensiero tardomedievale, Firenze 2000, p. 67-87.

${ }_{285} \quad$ Cf. Quaest. in II Sent., qu. XXXVII, vol. I, p. 657: "Alii vero dicunt quod intellectus tam angelicus quam humanus potest simul plura videre, sub aliqua tamen unitate alicuius correlationis seu coordinationis". ${ }_{286}$ Chez Thomas d'Aquin ou Gilles de Rome cela signifie, par exemple, que l'ange qui considère la représentation « espèce humaine » connaît par là-même tous les individus compris sous cette espèce. ${ }_{287}$ Cf. Quaest. in II Sent., qu. XXXVII, vol. I, p. 664: "dici potest quod quandocumque aliqua plura simul apprehenduntur sub aliqua coordinatione unius totalis numeri vel unius loci vel unius temporis vel unius totius compositi ex eis constituti vel unius correlationis secundum quam ad se invicem vel ad aliquod tertium comparantur, tunc oportet in eis esse unitatem coordinationis vel simultatis vel compositionis vel correlationis". ${ }_{288}$ Cf. $i$ bid. : « Cum enim nulla potentia creata possit aliquid apprehendere, nisi actualiter aspiciat illud, totalis autem aspectus unius potentiae oportet quod habeat aliquam unitatem. (...) Sic etiam sensibiliter experimur quod qumvis oculus plura simul aspiciat, numquam tamen hoc facit nisi sub uno totali aspectu ; unde oportet quod omnia quae simul videt sic se habeant quod sub illo uno totali aspectu possint conspici et apprehendi ».
} 
coordonnées les unes aux autres ${ }^{289}$. Cette unité de coordination est indispensable à la saisie simultanée de plusieurs objets, que ce soit par connaissance naturelle ou surnaturelle, car l'intellect créé n'intellige que par le fait de se rapporter aux objets par son regard intentionnel ${ }^{290}$.

Loin d'être un privilège, la simultanéité admise par Olivi s'avère être étroitement liée aux conditions qui marquent toute connaissance créée, et notamment à l'exigence d'orientation intentionnelle et de coprésence que nous avons déjà rencontrées précédemment. Le «se rapporter à » (respectus), la «tension vers» (protensio), l'articulation avec le reste du créé (connexio) exigent en effet une unité de coordination qui les rende possibles. Dieu n'a pas besoin d'une telle unité, car il ne saisit pas les choses par un regard intentionnel, mais voit tout simultanément dans son essence ${ }^{291}$. Tout étant créé, en revanche, est un esse relatum, connexum seu connexibile: l'unité de coordination dont il est capable est simplement la condition requise pour que son intentionnalité produise la coexistence et la coprésence avec ce qui l'entoure. Intimement liée à la protensio, cette unité est donc un indice de finitude avant d'être l'indicateur d'une capacité. Ne pas reconnaître cette forme d'unité-simultanéité signifierait désarticuler les êtres de ce qui les entoure, supprimer leur possibilité de se rapporter les uns aux autres, nier l'orientation intentionnelle qui, pour Olivi, marque intrinsèquement toute existence finie. En synthèse, notre auteur est prêt à accorder aux anges la capacité d'une unité-simultanéité de coordination, qu'on ne saurait cependant confondre avec l'unité simple de la simultanéité divine. Le statut de l'ange reste ainsi profondément marqué par la finitude qu'il partage avec le reste du créé.

\section{L'ange et l'âme humaine}

Un dernier point de vue va enfin nous fournir quelques éléments utiles pour préciser le statut de l'ange dans la conception de Pierre de Jean Olivi. Il s'agit du rapport avec l'âme humaine, qui fait l'objet de la question LVI: Secundo quaeritur an pars intellectiva animae rationalis quae communiter mens

\footnotetext{
289 Cf. ibid. : « Sic etiam dicimus quod unus angelus oportet quod sit in pluribus partibus sui loci secundum unum totalem aspectum suae substantiae seu secundum unam totalem coexistentiam; unde non posset existere simul in pluribus locis, ita quod in uno haberet totalem existentiam et in alio aliam totalem aut ita quod illa loca nullam habeant inter se continuitatem vel contiguitatem vel coordinationem ».

$290 \quad$ Cf. ibid. : « Haec est igitur unitas sine qua nec naturaliter nec supernaturaliter seu miraculose potest intellectus creatus aliqua plura simul videre ; semper enim oportet quod sub uno totali aspectu ea videat $\gg$.

291 Cf. ibid., p. 665: « Hoc autem in Deo non oportet, quia Deus non videt per protensionem aspectus, sicut nec est in pluribus locis per applicationem suae substantiae, sed suum videre est sua essentia; et hinc est quod Deus potest simul infinita finita videre".
} 
vocatur sit eiusdem speciei cum parte intellectiva angeli ${ }^{292}$. Il va sans dire que leur différence spécifique était défendue par ceux qui, concevant l'ange comme une forme pure, posaient des différences spécifiques entre les anges euxmêmes $^{293}$. L'enjeu de cette confrontation est donc important, car il concerne en profondeur la conception de l'être humain, celle de l'ange et celle de leurs rapports dans l'univers créé.

Conformément aux choix théoriques dont nous avons rendu compte dans les pages qui précèdent, Olivi va défendre la thèse de l'identité spécifique de l'intellectualité humaine et de l'intellectualité angélique. Il invoque en sa faveur une série d'arguments presque exclusivement basés sur les actes propres de la faculté intellectuelle. Le premier fait appel aux actes et aux habitus de la grâce et de la gloire : les actes de vision et de charité par lesquels l'individu « Pierre » contemple et aime Dieu sont de la même espèce que ceux par lesquels l'ange voit et aime Dieu - et à plus forte raison si «Pierre» se trouve dans l'état de gloire ; Olivi en conclut que leurs facultés intellectuelles sont nécessairement de même nature.

Le deuxième argument invoque le principe actif de l'agir, à savoir la volonté libre : lorsque l'ange et l'être humain consentent en un même objet et dans le même but au point de vouloir la même chose, leur consensus est de la même espèce, ce qui implique que leurs puissances actives le soient également.

Le troisième argument repose sur la raison d'image commune à l'ange et à l'être humain. Etre à l'image de quelque chose signifie porter en soi une ressemblance spécifique ou de nature avec ce dont on est l'image ${ }^{294}$. Aussi, bien qu'on ne puisse parler de « raison spécifique » au sens propre à l'égard de Dieu, ce qui est fait à son image partage néanmoins une ressemblance de nature; et puisque l'ange et l'âme humaine sont deux images de la même nature, il faut en conclure que leurs facultés intellectuelles sont de la même espèce. Olivi précise bien que cette identité spécifique concerne uniquement la faculté intellectuelle, car il admet que l'image de la même réalité est de nature différente lorsqu'elle est présente dans des facultés de nature différente, comme le sont, par exemple, l'intellect et les facultés sensitives. Cela dit, il maintient fermement que différentes images d'un même objet dans des facultés intellectuelles appartenant à des sujets différents sont de même espèce : le cas échéant, cela est d'autant plus vrai que le fait d'être à l'image de Dieu n'est pas simplement de l'ordre de la représentation, mais concerne l'ange et l'homme dans leur substance même ${ }^{295}$.

\footnotetext{
292 Quaest. in II Sent., qu. LVI, vol. II, p. 298.

293 Comme, par exemple, Thomas d'Aquin, S. theol., I, 75, 7.

294 Cf. Quaest. in II Sent., qu. LVI, vol. II, p. 300: "imago dicitur similitudo speciei seu alicuius secundum suam speciem".

295 Cf. ibid. : « Ergo consimiliter illa quae respectu eiusdem obiecti sunt in natura seu potentia intellectuali erunt eiusdem speciei, et maxime, quando huiusmodi imagines habent rationem imaginis non solum quoad
} 
Notre auteur précise davantage sa pensée lorsqu'il affirme que les esprits ne sont pas l'image de Dieu selon des degrés de perfection plus ou moins grands. Bien au contraire, à la manière dont le Verbe de Dieu exprime toutes les idées et la sagesse du Père - au point où il ne peut y avoir plusieurs Verbes en Dieu -, ainsi la nature de l'esprit créé est virtuellement ouverte et peut être virtuellement amenée (deducibilis) à cette même sagesse et à l'ensemble de ses idées, si bien qu'il ne peut y avoir plusieurs espèces d'esprits créés ${ }^{296}$. Nous avons là une justification de l'égalité foncière des esprits créés dans leur nature d'esprit, avant et indépendamment de leur union avec une matière, qu'elle soit spirituelle ou corporelle. Bien que par «esprit» (mens) Olivi ne pense ici qu'aux facultés supérieures de l'intellect et de la volonté, il en résulte néanmoins une parenté remarquable entre l'être humain et l'ange ${ }^{297}$. Ceux-ci partagent une même finitude, mais aussi une même dignité : celle qui consiste à être des images de Dieu.

Le quatrième argument en faveur de l'identité spécifique des facultés intellectuelles humaine et angélique fait appel à leur finalité. Les réalités ordonnées par leur essence à une même finalité et perfection ultime partagent en effet une même nature. Or, l'esprit humain et l'esprit angélique sont ordonnés à la même béatitude comme à leur perfection propre et ultime ; il faut en conclure qu'ils partagent une même nature spirituelle ${ }^{298}$.

Le cinquième et dernier argument est axé sur l'étendue des facultés intellectuelles. En effet, leur nature est telle qu'elle embrasse virtuellement, à titre d'objets, la totalité des étants. Or, si la nature intellectuelle était partagée en différentes espèces, il faudrait attribuer la totalité des étants comme objet virtuel au genre englobant ces espèces, et non plus à chaque nature intellectuelle comme telle. Mais cela est manifestement faux, car le propre de chaque faculté intellectuelle est de s'étendre à la totalité des étants.

\footnotetext{
rationem exprimendi, sed etiam quoad suum esse substantiale, sicut utique habet respectu Dei omnis mens seu omnis natura intellectualis ».

296 Cf. ibid. : «Unde sicut Verbum Dei Patris est actualiter expressivum omnium idearum mentis paternae et totius sapientiae eius, et ideo non possunt esse in Deo plura Verba : sic mens creata secundum suam speciem est potentialiter deducibilis ad quaecumque. Ex quo videtur quod non possint dari plures species mentium".

Cette parenté pourrait rappeler l'idée origénienne de l'égalité originaire des esprits créés, différenciés ultérieurement seulement à cause des différents usages de la liberté. Mais il convient de préciser que l'égalité défendue par Olivi n'est pas celle d'une nature spirituelle originaire, incarnée successivement en raison d'une chute due au mauvais usage de la liberté, car - comme nous l'avons vu - la réalité individuelle n'est pas conçue par notre auteur comme une participation à une nature préalable et supérieure, mais comme le produit, à chaque fois inédit, d'un acte de création. L'égalité de nature concerne ici la faculté intellectuelle et réside dans l'octroi de cette faculté à chaque ange et à chaque être humain. Olivi a d'ailleurs critiqué le platonisme d'Origène, responsable, selon lui, de l'erreur commun à Origène et à Arius quant à la nature inférieure du Christ : cf. D. Burr, L'histoire de Pierre Olivi, cit., p. 83.

298 Cf. Quaest. in II Sent., qu. LVI, vol. II, p. 301: "Quae enim secundum suam essentiam sunt ordinabilia et aliqualiter inclinata ad eosdem principales et proprios fines et ad easdem proprias finales perfectiones videntur habere essentias eiusdem speciei; sed mens humana et angelica sunt huiusmodi, quia ultima beatitudo est propria perfectio ipsarum".
} 
La nature de l'acte cognitif, son objet, son étendue, son principe, sa finalité, ainsi que la raison d'image inscrite dans les natures intellectuelles créées fournissent ainsi pour notre auteur autant de points d'appui à la thèse de l'identité spécifique de l'intellectualité humaine et de l'intellectualité angélique $^{299}$. On aura remarqué que dans tous ces arguments la faculté intellectuelle est considérée absolute, c'est-à-dire en elle-même, isolée du sujet auquel elle appartient. La légitimité de cette considération abstraite, qui peut paraître surprenante dans le cas de la faculté intellectuelle humaine, repose sur la conception anthropologique d'Olivi, et notamment sur sa vision du rapport de l'âme au corps. Olivi considère en effet la doctrine aristotélicienne de l'âme/forme du corps comme la source de la thèse qu'il combat (à savoir celle de la différence spécifique de l'esprit humain et de l'esprit angélique), car prétendre que l'âme rationnelle est forme du corps par son essence conduit nécessairement à poser sa différence spécifique par rapport à l'esprit angélique $^{300}$. En revanche, si on envisage ce rapport d'une autre manière et on pose que l'âme rationnelle est forme du corps non pas par son essence, mais uniquement par sa partie sensitive, on peut alors considérer que cette union est en quelque sorte une nature annexe à la nature propre et spécifique de l'âme intellectuelle $\mathrm{e}^{301}$. Dès lors, tout en étant articulée aux autres parties de l'âme et au corps par la colligantia potentiarum ${ }^{302}$, la partie intellectuelle sauvegarde sa nature spécifique et sa distinction à l'égard des autres facultés, si bien qu'elle peut être envisagée séparément et de manière abstraite par rapport au reste de

\footnotetext{
299 Cette même identité est clairement affirmée dans la question XLVIII (« An ruina angelorum per homines reparanda sit »), où on lit que : «Ad secundum dicendum quod quidam non indocte volunt quod mens angelica et humana quoad absolutam quidditatem suarum specierum simpliciter sint aequales, in suis vero individuis iuxta beneplacitum creatoris possunt accipere dispares gradus quantum ad substantialia et quantum ad accidentalia et quantum ad naturalia et gratuita », vol. I, p. 759.

$300 \quad$ Cf. ibid., p. 302: "Qui enim volunt quod anima rationalis secundum totam formalem suam essentiam sit forma corporis coguntur dicere quod non solum secundum suam formam sensitivam, sed et secundum intellectivam differat specifice simpliciter a mente angelica, quia nihil essentialius est formae alicuius materiae quam quod sit forma et actus respectu illius materiae ».

301 Cf. ibid. : «Qui vero ponunt animam rationalem esse formam corporis secundum solam partem suam sensitivam non coguntur tenere quod unio vel unitiva inclinatio partis intellectivae ad partem sensitivam et ad corpus sensificatum sit omnino id ipsum quod absoluta essentia partis intellectivae, sed sufficit quod sit quaedam essentia relativa illi annexa $»$.

${ }_{302} \mathrm{La}$ « colligantia potentiarum » indique la continuité opérative entre les différentes puissances de l'âme résultant de leur enracinement dans la même matière spirituelle. La « colligantia » permet d'expliquer les relations complexes entre les facultés de l'âme ainsi que celle de l'âme au corps, tout en sauvegardant la transcendance de l'âme. Pour cette problématique nous renvoyons, entre autres, à E. Bettoni, I fattori della conoscenza umana secondo Olivi, cit. et Le dottrine filosofiche, cit., p. 459-466; A. Krömer, Potenzenhierchie, cit. ; Th. Schneider, Die Einheit des Menschen, cit., p. 227-237. Les notions de „colligantia, connexio, colligatio“ ne sont pas une invention d'Olivi, mais étaient déjà présentes dans les discussions sur l'âme humaine dans l'école franciscaine, comme par exemple chez Roger Marston (cf. à ce propos G. Bonafede, La conoscenza del singolare, cit.), et, bien avant, chez Jean de la Rochelle (cf. J. Rohmer, La théorie de l'abstraction dans l'école franciscaine d'Alexandre à Jean Peckham, Archives d'hist. doctr. et litt. du M. Age, 3 (1928), p. 105-184, en particulier p. 125); chez Olivi toutefois la théorie de la « colligantia » revêt une importance très particulière en raison de la distension du lien entre l'âme et le corps. Sur la conception olivienne de l'âme en relation à la condamnation du Concile de Vienne, cf. B. Jansen, Die Seelenlehre Olivis und ihre Verurteilung auf dem Vienner Konzil, Franziskanische Studien, 21 (1934), p. 297-314.
} 
l'âme: de là la légitimité d'associer en une même nature spécifique l'intellectualité humaine et l'intellectualité des anges.

Olivi clarifie le rapport particulier de l'âme intellective avec le reste de l'âme et, par ce biais, avec le corps, à travers un exemple très significatif : ce rapport - explique-t-il - est comme celui de la poire greffée sur un pommier ou celui de la branche qui peut être coupée de son arbre tout en restant en vie et en gardant sa nature ${ }^{303}$. Ce double exemple exprime clairement l'idée olivienne de la co-présence, de la coexistence et de l'articulation possible entre des réalités de même genre, mais de nature différente : celle qui est greffée sur l'autre garde sa nature spécifique tout en étant orientée et reliée à un ensemble de nature différente ${ }^{304}$. Olivi conçoit donc comme légitime l'articulation de natures différentes permettant de sauvegarder la spécificité de chacune : c'est ainsi que la partie intellective est unie à l'âme humaine sans en partager la nature toute entière, mais en sauvegardant sa propre spécificité. Son union avec les autres puissances de l'âme et avec le corps est comme annexée ou greffée sur elle sans que sa nature en soit affectée. De la sorte, l'âme intellective peut à la fois être unie à l'âme humaine et en transcender les parties, car cette union n'engage pas toute son essence ${ }^{305}$. Aussi, au-delà des rapports et de l'orientation mutuelle qui marquent l'être des créatures, il reste pour ainsi dire un recoin ultime de chaque chose, qui est le lieu de son identité irréductible, même si cette identité s'avère être relationnelle. C'est la raison pour laquelle nous avons vu Olivi défendre l'idée d'une nature propre de la matière indépendamment de la forme, et de la forme indépendamment de son union actuelle avec la matière ${ }^{306}$. Dans cet ordre d'idées, il est tout à fait concevable que l'intellectualité humaine reste partiellement en retrait par rapport à son engagement dans l'âme et maintienne ainsi son identité de nature avec l'intellectualité angélique - une identité qu'Olivi défend au prix inévitable d'une certaine distension de l'unité du composé humain $^{307}$.

\footnotetext{
303 Cf. Quaest. in II Sent., qu. LVI, vol. II, p. 302: “(...) sufficit quod sit quaedam essentia relativa illi annexa, sicut piro insertae in arborem pomum est annexa inclinatio et unio as pomum cui est inserta, aut sicut ramo qui vivit et salva sua specie potest a stipite et radice abscindi est annexa unio ad stipitem et radicem". Cette même articulation entre des réalités différentes ressort significativement dans la question XLVIII, où Olivi considère le fait que les démons ont été remplacés par des êtres humains bienheureux, qui sont ainsi associés aux anges bons : « Tertio relucet hic ordo et potentia insertionis ramorum unius arboris in stipitem alterius speciei et ordo mutuae supplitionis ; in quo partes universi sic sibi connecti et mutuo subservire noscuntur quod una sit apta nata et ordinata vel ordinabilis ad supplendum alterius incrementum vel decrementum », vol. I, p. 756.

305 Cf. ibid. : «Quae quidem unio non posset tolli ramo salva sua specie, si esset omnino id ipsum cum absoluta forma ipsius rami ».

306 Olivi le rappelle ici : « nec etiam actualis unio formae ad materiam est omnino idipsum cum forma », ibid.

307 Rappelons que la partie intellective n'est pas forme du corps au sens propre, mais lui est unie par la médiation des autres puissances de l'âme : cf. qu. LIX et Th. Schneider, Die Einheit des Menschen, cit., p. 230 sv. et E. Bettoni, Le dottrine filosofiche, cit., p. 313-319.
} 
Ces considérations nous suggèrent question : en quoi consiste l'humanité de la faculté intellectuelle dont l'homme dispose, si elle est de nature identique à celle de l'ange ? La réponse d'Olivi est claire : c'est son orientation (inclinatio) et son rapport (respectus) à l'âme humaine dont elle fait partie, malgré le fait que la nature de la faculté intellectuelle ne puisse pas être ramenée toute entière à cette union ${ }^{308}$. Nous retrouvons ici un motif fondamental de la spéculation d'Olivi : celui du mode d'existence relationnel de tout le créé. Ce mode affecte encore plus profondément l'existence humaine, car en réalisant l'union complexe de puissances de nature différente, elle se constitue intimement comme un réseau de respectus. De ce point de vue, l'humanité de l'homme peut être envisagée comme une nature éminemment relationnelle, car chaque être humain existe comme unité par ses relations internes (colligantia potentiarum) et se rapporte essentiellement par tout son être au reste du créé.

Avant de clore cette partie, signalons un dernier aspect qui permet de clarifier davantage le rapport de l'homme et de l'ange. Il a trait à la rationalité, et consiste à savoir si la parenté de l'intellectualité des hommes avec celle des anges résiste à la confrontation avec la discursivité qui caractérise la rationalité humaine. De prime abord plutôt surprenante, la réponse d'Olivi à cette interrogation est en parfaite continuité avec ce qui précède: la discursivité précise-t-il - n'est pas une détermination essentielle de la rationalité humaine, mais lui revient par le biais d'habitus et de dispositions annexes; pour cette raison, à partir du moment où l'habitus de la science et la capacité de saisir immédiatement les conclusions dans les principes sont acquis, le procédé discursif n'a plus raison d'être. Ce qui veut dire que ces capacités ne sont pas une exclusivité angélique, mais qu'elles sont à la portée des hommes, comme le montrent les exemples du Christ et des bienheureux ${ }^{309}$. Par cette réponse, Olivi refuse donc aux anges une prérogative naturelle dont les autres créatures intellectuelles seraient privées. Cette issue résulte de la dissociation de la discursivité et de la rationalité humaine, ce qui laisse intacte la possibilité d'associer en une même nature la puissance intellectuelle des hommes et celle des anges. Les premiers sont considérés virtuellement capables des performances des seconds et les natures spirituelles, de leur côté, ne sont pas totalement exemptes des imperfections de la démarche cognitive humaine, puisque l'exemple des démons montre qu'ils peuvent eux aussi faire recours à la discursivité.

\footnotetext{
$308 \quad$ Cf. Quaest. in II Sent., qu. LVI, vol. II, p. 303: "Si etiam intellectivo humano auferretur a Deo omnis inclinatio ad corpus et ad sensitivam humanam, ita quod in se et in sua materia absolute stabiliretur, tunc eo ipso fieret non humanum et faceret quandam novam speciem entis".

309 Cf. ibid. : « Causa enim non discutendi est plenitudo scientialis habitus conclusionum aut praeclaritas habitualis ingenii et vivacis aspectus ad varias conclusiones ex principiis et in principiis subito capiendas. Unde tam anima Christi quam homines beati non solum in Deo sed etiam in proprio genere ita repente vident naturales conclusiones sicut et angeli ».
} 
Au bout du compte, il s'avère que le partage entre la faculté cognitive humaine et celle des anges ne s'inscrit pas pour Olivi dans un ordre de nature, mais relève de la volonté divine et de la modalité de la création : c'est pourquoi il aurait suffi que Dieu donne aux anges moins d'habitus de connaissance pour qu'ils connaissent leurs objets à la manière des êtres humains ${ }^{310}$. Il en va de même de l'immutabilité de la volonté angélique: selon notre auteur cette prérogative ne revient pas par essence aux créatures spirituelles et ne les caractérise pas plus qu'elle ne concerne l'être humain ${ }^{311}$. Ce même raisonnement vaut aussi à l'égard des représentations cognitives: être privé d'espèces - c'est-à-dire être une tabula rasa à la manière aristotélicienne - n'est pas une condition qui se rattache de manière plus essentielle à l'intellect humain qu'à l'intellect angélique, car dans les deux cas les espèces n'inhèrent aux facultés cognitives que de manière accidentelle; les différences dans la possession de telles espèces ne relèvent en réalité que de la volonté divine, qui aurait pu donner plus ou moins de représentations à l'ange et changer de la sorte les données du problème ${ }^{312}$.

Cette triple clarification prive l'ange des prérogatives que les partisans de sa nature spécifique lui accordaient comme nécessairement inhérentes à son statut et le rapproche ainsi sensiblement de la réalité humaine. En niant le caractère essentiel de certains traits distinctifs, Olivi réussit à justifier l'identité spécifique de l'intellectualité humaine et de l'intellectualité angélique et à attribuer leurs différences à la seule volonté divine. Cette mise en perspective nous paraît significative de la manière dont le franciscain conçoit les créatures intellectuelles ainsi que le rapport de l'esprit humain aux facultés sensitives et au corps. Le rapprochement des puissances intellectuelles angélique et humaine va en effet de pair avec un desserrement du lien de la faculté intellectuelle avec les autres puissances de l'âme humaine - un desserrement résultant de la dissociation de l'essence de la faculté intellectuelle d'avec son union à l'âme. Aussi bien du côté de l'ange que du côté de l'individu humain, l'identité de nature de leurs facultés intellectuelles résulte d'une dissociation opérée par rapport à l'essence : du côté humain cela signifie que la faculté intellectuelle n'est pas forme du corps par son essence, et du côté de l'ange cela implique que le procédé intuitif, l'immutabilité de la volonté ou la possession de la totalité des espèces intelligibles ne relèvent pas de l'essence de son intellectualité. Ce double dépouillement permet la rencontre de l'être humain et de l'ange sur le

\footnotetext{
310 Cf. ibid. : « Et si Deus a principio ita paucos habitus inseruisset intellectui angelico sicut nostro, ita indigeret discursu sicut et noster ; quamvis nec omni discursu careat, saltem in daemonibus, sicut alibi est ostensum ».

311 Cf. ibid. : «Illud etiam de invertibilitate angelicae voluntatis est erroneum; non enim hoc competit sibi essentialiter plus quam homini ».

312 Cf. ibid. : «Dicendum quod esse ex se nudum ab omni specie non est essentialius intellectui humano quam angelico, quia nec species rerum sunt minus accidentales intellectui angelico quam humano, quamvis Deus ex suo beneplacito plures species plenius et inseparabilius inseruerit angelis a principio quam hominibus praeterquam Christo homini ». Dans le même sens, cf. qu. XLVIII, vol. I, p. 760.
} 
terrain d'une intellectualité de même nature parce qu'exerçant les mêmes actes, embrassant le même domaine, ordonnée à une même finalité et image du même principe. L'identité ainsi focalisée n'est donc pas celle d'un statut ontologique figé, mais plutôt celle d'une capacité et d'un dynamisme communs.

\section{Olivi ou l'humanisation de l'ange}

Au terme de ce parcours il nous est permis de cerner plus précisément la conception olivienne de la subjectivité angélique. Nous avons appris que l'ange est composé de matière (spirituelle) et de forme, qu'il est inscrit dans les coordonnées spatio-temporelles, qu'il est un individu au sens propre du terme et que son intellectualité est de même nature que l'intellectualité humaine. Cette suite de clarifications - résultant en partie de la confrontation polémique avec d'autres conceptions angélologiques - dessine le chemin de ce que nous pouvons considérer come un processus d'humanisation de l'ange. La condition angélique est en effet progressivement et constamment rapprochée de la condition humaine : avec celle-ci elle partage la composition hylémorphique, la détermination dans un même espace et un même temps, la subsistance en tant qu'individu, la privation des représentations connaturelles ou innées, un même rapport aux objets de l'intellect et de la volonté, une même capacité de saisie simultanée, une même articulation nécessaire à ce qui l'entoure, une même nature intellectuelle. L'ange est un sujet de même type que l'être humain, la corporéité en moins. Il ne figure donc pas comme une subjectivité qualitativement différente - comme c'était le cas chez les penseurs critiqués par Olivi -, mais est une créature dont le privilège réside uniquement dans la noncorporéité. Chaque ange est une réalité individuelle créée par Dieu, et sa valeur comme celle de toute autre individualité - tient au fait d'être objet du vouloir divin. Cette valeur étant partagée par la création toute entière, l'ange ne possède pas de prérogatives exclusives, si ce n'est d'avoir été voulu et créé par Dieu tel qu'il est. La subjectivité angélique est ainsi privée des privilèges qu'elle possédait dans des conceptions axées sur une idée de l'ordre des choses qui, en exigeant la médiation des substances séparées, leur octroyait un statut nécessairement supérieur par rapport au reste du créé. Olivi combat vigoureusement une telle supériorité et il la critique d'autant plus qu'elle est posée comme inhérente à la nature de l'ange. Pour le franciscain, accorder à une créature de tels privilèges naturels ce serait considérer que ces attributs lui sont dus, ce qui signifierait introduire une contrainte et une nécessité dans l'agir même de Dieu ${ }^{313}$. Mais Dieu crée chaque chose comme il le veut et n'est tenu

\footnotetext{
313 En critquant la thèse philosophique de l'éternité du monde, Olivi s'insurge contre toute nécessité
} introduite dans l'agir divin : «Si enim Deus omnia quae facit necessario facit nec aliter agere aut non agere 
d'aucune façon à accorder à tel ou tel être des dons particuliers : aussi - comme on l'a vu -, Dieu aurait-il pu doter l'ange ou l'homme d'un nombre plus ou moins grand d'espèces intelligibles, selon son bon vouloir.

Le refus de privilèges d'ordre naturel, le combat contre un statut supérieur à celui du reste du créé, en un mot : l'humanisation de l'ange, répondent chez Olivi à plusieurs exigences. La première est celle de l'égalité foncière des créatures, c'est-à-dire de l'homogénéité du créé en tant que tel. Chaque chose est voulue et produite par Dieu dans sa singularité, car chaque acte de création est une création totale de la chose : ce rapport à l'acte créateur est le même pour tout le créé, qui est ainsi associé en une même condition de dépendance originaire. Nous savons que pour Olivi les raisons les plus communes et les plus universellement partagées l'emportent sur les raisons spécifiques et particulières : dès lors, même si les anges possédaient des privilèges particuliers, ceux-ci seraient secondaires par rapport à la condition commune qu'ils partagent avec l'ensemble de la création.

Cette homogénéisation de la réalité créée repose aussi sur l'exigence d'articulation que notre auteur fait valoir constamment : chaque entité créée est un "être en rapport» ou susceptible de l'être. Mais les liens qui articulent les choses les unes aux autres présupposent précisément un horizon d'homogénéité, comme celle qui réside, par exemple, dans l'appartenance au même espace et au même temps. Olivi a un sens très vif de ces rapports : pour cette raison il insiste fortement sur l'intentionnalité, c'est-à-dire sur l'ouverture et la réceptivité des choses les unes à l'égard des autres.

L'homogénéité du créé, son association et sa réduction à une même condition, répond encore à une exigence métaphysique et théologique majeure, à savoir la sauvegarde de ce qu'on pourrait appeler «la divinité exclusive de Dieu » ou l'exclusivité des prérogatives divines. Pour notre auteur, en effet, l'accentuation de l'homogénéité du créé permet de maintenir clairement et fermement l'abîme qui sépare le créé du créateur et empêche de jeter un quelconque pont entre ces deux entités irréductibles. L'absolu d'un côté et le relatif de l'autre représentent deux modalités d'existence entre lesquelles on ne peut poser aucune solution de continuité. Le fossé qui les sépare ne peut pas être comblé, et leur rapport est uniquement celui que Dieu a instauré par la création. Aussi, poser à l'intérieur même du créé une réalité de condition supérieure reviendrait à poser un intermédiaire entre le relatif et l'absolu, autrement dit une réalité sur-humaine et quasi-divine. En réalité, derrière la thèse de

potest : omnis timor et reverentia, amicitia et gratia, spes ac deprecatio seu imploratio frustra habetur ad eum nihilque veri dominii habet in rebus ; ex quo ab eo libertas in opposita tollitur, multo magis ab omnibus quae sunt sub ipso ; ex quo iterum vorago infernalis impietatis consurgit, sicut in materia de libertate voluntatis humanae est abunde monstratum », Quaest. in II Sent., qu. V, vol. I, p. 97. 
l'hétérogénéité du créé se cache pour Olivi le piège du paganisme et de l'idôlatrie, et la discussion sur le statut de l'ange cristallise, plus que toute autre, cette problématique. C'est la raison pour laquelle les questions angélologiques sont parsemées d'invectives virulentes contre la philosophie païenne, jugée coupable d'avoir divinisé les substances séparées: Et ideo in iis quae de intelligentiis dixerunt sic debemus eos fugere tamquam idolatras plures deos ponentes $^{314}$. Cette divinisation est précisément le résultat des privilèges qui leur ont été accordés et que certains théologiens chrétiens, aveugles de cette conséquence, ont repris à leur compte, en faisant de chaque ange une espèce, en le soustrayant à l'espace et au temps et en lui attribuant des représentations universelles innées. Ces capacités sur-humaines sont synonymes d'une condition semi-divine que notre auteur ne peut tolérer, car elle va à l'encontre de l'absoluité de Dieu : entre l'absolu et le relatif il n'y a pas de moyen terme, pas de médiation possible ${ }^{315}$. Dans cette perspective, l'humanisation de l'ange apparaît comme une réponse radicale face à ce que le franciscain considérait comme une divinisation illégitime des créatures spirituelles: il fallait donc détrôner les anges pour mieux reconnaître et célebrer Dieu dans sa majesté et sa transcendance.

Si le combat de l'idôlatrie est un axe majeur de la réflexion angélologique d'Olivi, un autre élément - qui ne figure pas au premier plan des questions analysées ici, mais qui est capital dans sa vision globale et sa sensibilité franciscaine - détermine aussi de manière importante cette conception des créatures spirituelles: il s'agit du motif christologique. En effet, le fait d'accorder à l'ange des privilèges naturels exclusifs ne va pas seulement à l'encontre de la divinité et de l'absoluité de Dieu, mais compromet également la valeur de l'humanité du Christ. Nous l'avons constaté à quelques reprises lors des analyses précédentes : parmi les inconvénients résultant de la thèse de l'ange-espèce figurait aussi le fait que son existence et sa durée seraient éternelles et que par conséquent elles se rapporteraient à celles de l'âme humaine et à celles de l'âme du Christ comme l'infini au fini ou comme l'universel au particulier ${ }^{316}$. Olivi relevait encore un autre inconvénient allant dans le même sens, à savoir que la grâce, la gloire, les mérites et les habitus angéliques dépasseraient ceux de l'âme du Christ et des bienheureux à la manière dont l'universel transcende le particulier et l'infini le fini ${ }^{317}$. Un statut

\footnotetext{
314 Quaest. in II Sent., qu. XXXV, vol. I, p. 628.

315 La critique olivienne de Thomas d'Aquin que nous avons rencontrée à plusieurs reprises concerne, en fin de compte, la sauvegarde d'une distinction radicale entre le créateur et le créé : cf. D. Burr, Olivi and the Philosophers, cit., p. 66.

$316 \quad$ Rappelons ce texte : « ergo existentia et duratio angeli se habebit ad existentiam et durationem animae meae vel animae Christi sicut infinita duratio ad finitam et sicut universalis ad particularem », Quaest. in II Sent., qu. XXXIII, vol. I, p. 598.

317 Cf. ibid., p. 599: "Et tunc sequetur quod gratia et gloria et omnes actiones et habitus cuiuslibet angeli transcendant gratiam et gloriam, meritum et praemium et omnes habitus et actus animae Christi et aliarum animarum beatarum, sicut universale transcendit suum particulare et sicut infinitum transcendit finitum".
} 
privilégié de l'ange signifierait par conséquent sa supériorité par rapport à l'âme du Christ - qui est une âme pleinement humaine, car en lui Dieu s'est fait véritablement homme. Cette perspective rend impensable le fait de poser à l'intérieur du créé une condition supérieure à celle de l'âme humaine, car elle irait à l'encontre de la divino-humanité du Christ ${ }^{318}$. Pour Olivi, le Christ est le seul véritable médiateur entre Dieu et l'homme, et cette médiation repose précisément sur l'humanité du Dieu-homme ${ }^{319}$ : c'est ainsi que Dieu s'est révélé à l'être humain, en prenant chair comme lui, en assumant l'humanité jusqu'au bout $^{320}$. Dans le Christ, Dieu a exhalté l'humanité au point où rien ne peut lui être supérieur, sinon Dieu lui-même ${ }^{321}$.

Dans cette perspective de salut, qui met l'homme et Dieu face à face grâce à l'humanité du Christ, l'ange ne peut occuper qu'une place secondaire. Sa dignité est d'abord celle de toute créature voulue par Dieu, et celle, ensuite, des créatures intellectuelles faites à l'image de Dieu. Mais cette dignité ne lui est pas réservée de manière exclusive, car il la partage avec l'être humain. Aussi, sa spécificité et sa valeur n'est-elle pas à chercher du côté d'un statut ontologique supérieur par nature, mais du côté de son agir et de sa fonction : l'ange est un instrument de la reductio in Deum, une aide dans le cheminement vers Dieu grâce à l'exercice de l'illumination, de la purification, de la fortification et du perfectionement $^{322}$. Il y a donc lieu de croire que l'humanisation de l'ange répond aussi, bien qu'en second lieu, à une exigence de proximité à l'égard des hommes, requise précisément par l'exercice de ces fonctions dans la dynamique du salut. L'exaltation de l'humanité du Christ et de sa fonction médiatrice imposait donc une révision du statut de l'ange tel qu'il avait été conçu par les theologi philosophantes: une révision consistant à le rattacher fermement au

\footnotetext{
318 Pour cette raison, après avoir réitéré l'idée de l'égalité homme-ange, dans la question XLVIII («An ruina per homines reparanda sit ») Olivi déclare : « Unde et animam Christi quoad omnia credimus nobiliorem omni mente angelica », vol. I, p. 759 ; Olivi a d'ailleurs rédigé des questions - aujourd'hui perdues (cf. S. Piron, Les oeuvres perdues d'Olivi, cit., p. 370) - sur le thème de la supériorité de l'âme du Christ : « de altitudine animae Christi et matris eius super omnia alia ». Un dépassement analogue de la condition angélique vaut aussi, à certaines conditions, pour les bienheureux : «Sanctus superioris ordinis praeabundabit angelo inferioris non solum quoad actus substantialis gloriae, sed etiam, ut a quibusdam probabiliter aestimatur, quoad omnes actus intellectus et voluntatis », ibid., p. 760 .

319 Pour Olivi l'humanité du Christ n'est pas l'humanité abstraite de l'espèces humaine, mais l'humanité concrète d'un individu qui possède un corps de chair: cet aspect ressort particulièrement de la discussion olivienne des problèmes liés à la transsubstantiation:cf. D. Burr, Eucharistic Presence, cit., p. 51-55.

$320 \quad$ Cf. De angelicis influentiis, cit., p. 387 : «Admirabile enim est quod illa humanitas, per quam de morte aeterna sumus redempti et a vitiis expurgati et divinis gratiis repleti, iustificati et sanctificati et per quam sumus quidquid boni in Deo sumus et cuius totaliter sumus tamquam membra et servi emptitii eius et sine cuius merito nec hic nec ibi sumus digni Dei gratia, societate et gloria, ita quod principale meritum omnium redemptorum est meritum caritatis suae quam in passione singularius ostendit $(\ldots) »$.

321 C'est pourquoi, pour Olivi, d'une part l'humanité du Christ doit être objet d'adoration, et d'autre part l'union avec Dieu dans l'au-delà est aussi une union avec le Christ en tant qu'homme : "Praeterea, constat quod hic tenemur adorare Christi personam non solum in sua deitate, sed etiam in sua humanitate et in sua carne; ergo multo magis beati ad hoc tenebuntur in patria, quanto clarius Christi veritatem et veram unitatem in utraque natura conspiciunt. (...) Praeterea, constat quod multo supernaturalius et intimuis uniemur Christo homini in patria quam in ista vita » (ibid., p. 388).

Cet aspect est largement illustré dans le De angelicis influentiis.
} 
reste du créé afin de réaffirmer et de souligner sa finitude, son imperfection, son manque et sa dépendance à l'égard de Dieu.

Les éléments relevés jusqu'ici pour rendre compte des choix d'Olivi en matière d'angélologie résultent en grande partie de sa démarche apologétique, visant à écarter les inconvénients et les absurdités liés à la conception de "l'ange-espèce ». Le but apologétique paraît d'ailleurs largement suffisant dans la justification de cette doctrine, si l'on tient compte de la tâche culturelle qui s'imposait à la conscience du franciscain à partir de sa théologie de l'histoire : le plus urgent était pour lui d' »identifier et de combattre les attaques lancés contre la doctrine et la vie chrétienne ${ }^{323}$. Dans cette optique, la révision du statut de l'ange était d'autant plus urgente que les doctrines des philosophes sur les substances séparées étaient des plus trompeuses, puisqu'elles véhiculaient une forme de paganisme ${ }^{324}$. Au-delà de cette visée polémique et apologétique il y a cependant un autre motif qui contribue de manière significative à expliquer le processus d'humanisation de l'ange que nous avons retracé jusqu'ici: il s'agit du thème de la liberté.

Thème central de sa psychologie, la réflexion olivienne sur la liberté a produit la tractation «la plus ample et organique de toute la littérature philosophique médiévale $»^{325}$. La liberté n'a pas à être démontrée : elle est une donnée incontournable de l'expérience humaine. Elle s'impose à l'observation et à l'analyse philosphique à tel point qu'Olivi en fait le fondement de la personne humaine, son élément distinctif à l'égard du monde et le facteur déterminant de la supériorité de l'homme: omnis existentia non libera nec personalis est incomparabiliter minor quacumque libera vel personali ${ }^{326}$. Priver l'être humain de sa liberté serait le priver de sa personnalité et de son humanité ${ }^{327}$. Toute la valeur des êtres humains tient à la liberté, sans laquelle ils ne seraient que des bêtes douées d'intelligence: quaedam bestiae intellectuales seu intellectum habentes $^{328}$. Cette affirmation représente sans doute une des expressions les plus

\footnotetext{
323 D. Burr, L'histoire, cit., p. 94.

$324 \quad$ Cf. De perlegendis philosophorum libris, p. 43 : « De substantia vero intellectuali separata minimum invenerunt. (...) Omnes etiam proprietates, quas eis attribuunt, sunt ut plurimum erroneae, quia locuti sunt de eis tamquam de quibusdam diis ».

325 Cf. E. Bettoni, Le dottrine filosofiche, cit., p. 399 ; B. Jansen, Introduction à l'édition des Quaestiones in II Sententiarum, vol. II, p. XI.

326 Quaest. in II Sent., qu. I, vol. I, p. 11.

327 Cf. ibid., qu. LIV, vol. II, p. 249-250: "Periculosissima autem est omnis opinio ex qua in fortitudine videtur posse destrui libertas arbitrii (...). Quod non est aliud quam potestas plenarie possessiva sui et aliorum sine qua non est intelligere rationem personae ».

328 Ibid., qu. LVII, vol. II, p. 338. Ce passage mérite d'être cité en entier : « Patet igitur quod hic error [scilicet negatio libertatis] omne bonum humanum et etiam divinum exterminat, et si quis ad praedicta attendat, advertere poterit quod omni facinori et impudicitate et iniquitati habenas totis viribus laxat. Nec mirum, quia, ut ita dicam, id quod proprie sumus, personalitatem scilicet nostram, a nobis tollit nihilque amplius nobis dat nisi quod simus quaedam bestiae intellectuales seu intellectum habentes ». Sur la conception olivienne de la liberté, exposée dans la question LVII, voir, entre autres, F. Simoncioli, Il problema della libertà umana in Pietro di Giovanni Olivi, Studi francescani, 55 (1958), p. 176-197 ; E. Bettoni, La libertà come fondamento dei valori
} 
radicales du primat franciscain de la volonté et de la liberté ${ }^{329}$. Par conséquent l'intellect, tout en restant un trait distinctif des créatures supérieures, passe au second plan, car il ne qualifie pas la dignité de l'homme : celui-ci, privé de sa liberté, ne serait qu'une bête intellectuelle, une bête certes supérieure aux autres, mais néanmoins une bête. C'est dire que l'hypothèse d'un être qui coïnciderait avec son intellectualité et qui serait une « intelligence subsistante » ne peut pas gagner la faveur d'Olivi, tout simplement parce que la pure intellectualité ne représente pas à ses yeux une valeur inconditionnelle. Seule la liberté possède cette valeur, car en tant que faculté d'autodétermination elle fait de l'homme un sujet au sens propre. Dans cet ordre d'idées, on comprend aisément que les anges, conçus par les theologi philosophantes comme des intelligences séparées, ou - à la suite du Pseudo-Denys - comme des intellects célestes, ne constituent pas pour Olivi une condition supérieure par nature, susceptible de valoir comme paradigme pour l'être humain. En déclassant l'intellectualité au deuxième rang, le primat de la liberté ramène l'ange au niveau de l'être humain et le prive de sa valeur de modèle sur le plan ontologique. Individu au même titre que les humains et doué, comme eux, d'intelligence et de liberté, la valeur de l'ange tient à cette même liberté et aux choix qui en résultent ${ }^{330}$. Aussi, l'ange est-il un être faillible, comme en témoigne clairement le mauvais choix des démons ${ }^{331}$ : les créatures spirituelles ne sauraient par conséquent représenter une subjectivité-modèle. Angélicité et humanité sont deux modes d'existence issus du même principe et possédant une même dignité essentielle, avant et au-delà des prérogatives résultant pour les créatures spirituelles de la non-corporéité ${ }^{332}$. Olivi ne mesure donc pas la subjectivité humaine à partir d'une subjectivité considérée de nature supérieure, parce que subsistant comme intellectualité pure,

umani in Pier di Giovanni Olivi, Atti del XII congresso internazionale di filosofia, Firenze 1960, p. 39-47; du même A., Le dottrine filosofiche, cit., p.338-420 ; F.-X. Putallaz, Insolente liberté, Fribourg-Paris 1995, p. 139162.

329 Dans son article sur La contribution de l'école franciscaine à la naissance de la notion de liberté politique : les données préalables chez Pierre de Jean Olivi (in : A. Boureau - S. Pyron (éd.), Pierre de Jean Olivi, cit., p. 251-263), L. Parisoli a montré comment la liberté ainsi conçue représente le fondement métaphysique de la liberté politique (cf. en particulier p. $258 \mathrm{sv}$.).

330 Ce choix implique, bien entendu, la possibilité du péché : «potentia peccandi, et maxime prout sumitur active, non dicit purum defectum seu negationem, immo magnam et nobilem entitatem libertatis creatae et substantialis, cum defectu tamen essentiali suae limitationi per quam deficit a summa libertate Dei substantialiter impeccabili et indefectibili », Quaest. in II Sent., vol. II, qu XLI, p. 696.

$331 \quad$ Selon Olivi il est d'ailleurs formellement impossible qu'une puissance intellective ou volitive créée soit exempte d'erreur ou de péché : «Quod impossibile est aliquam praedictarum potentiarum fieri essentialiter inerrabilem et impeccabilem. - Unde Damascenus, libro II, capitulo 17, loquens de angelo dicit : 'Est igitur natura intellectualis et arbitrio libera vertibilis secundum mentem, scilicet voluntatem (...). Ut creabilis et vertibilis est habens facultatem manendi et proficiendi in bono et ad malum vertendi' », ibid., qu. XL, vol. II, p. 684.

332 Les prérogatives de l'esprit angélique, qu'Olivi admet volontiers, se situent pour lui sur un plan qui n'est pas essentiel, mais accidentel : «Quod igitur mens angelica a sua creatione nobiliorem statum accepit quam natura humana factum est hoc quoad accidentia sibi inserta. Unde quod angelus clarius et altius et copiosius potuit omnia intelligere quam homo non fuit ex absoluta essentia intellectorum suorum, sed potius ex variis habitibus et habitualibus claritatibus et dispositionibus sibi annexis ; quae pro tanto sunt naturales, tum quia ab initio naturae acceptae, tum quia plures ex eis inseparabiliter infixae, tum quia spectant ad debitum statum naturae », qu. XLVIII, vol. I, p. 759-760. 
mais la mesure par rapport à elle-même, à partir de la liberté. Par ce biais, c'est l'ordre de la volonté et l'ordre moral qui l'emporte et qui qualifie l'être et l'agir des créatures raisonnables. La subjectivité angélique et la subjectivité humaine se situent fondamentalement à un même niveau et sont plus proches l'une de l'autre que leurs différences ne le laissent imaginer. Le primat de la liberté, et de l'ordre moral qu'elle bâtit, rend le créé homogène, et accorde à tout sujet raisonnable, qu'il soit homme ou ange, d'acquérir des prérogatives qui ne relèvent pas d'un statut ontologique donné, mais du bon usage de la liberté. C'est d'ailleurs par ce biais qu'Olivi rend justice à l'âme des bienheureux et surtout à celle du Christ, qui jouissent des mêmes privilèges que les créatures angéliques $^{333}$. L'humanisation de l'ange opérée par le franciscain doit ainsi beaucoup à une sensibilité accrue pour la liberté et la dignité de l'humain et à une reconnaissance sans mesure pour le Dieu qui n'a pas choisi d'assumer la condition angélique, mais celle d'un individu humain parmi les êtres humains.

\section{Appendice : les anges et la pauvreté}

Nous voudrions clore cette exploration de l'angélologie d'Olivi en soulevant une dernière interrogation, qui nous semble importante pour mieux comprendre l'enjeu de cette doctrine. Elle concerne le thème qui a le plus retenu l'attention des commentateurs de l'œuvre du franciscain: la pauvreté. Sans aucune prétention d'apporter une réponse définitive, nous nous demandons quel pourrait être le rapport entre le thème de la pauvreté et la conception olivienne des créatures spirituelles. Car si l'articulation de ces deux domaines n'apparaît pas immédiatement, il ne nous paraît pas pour autant légitime de la négliger ou de l'ignorer totalement.

Bien entendu, une mise en parallèle rigoureuse de l'angélologie avec le thème de la pauvreté présuppose un examen précis de ce dernier - ce que nous n'allons pas faire ici, parce que cela déborde le cadre de cette enquête et parce que cela a déjà été savamment entrepris ${ }^{334}$. Nous nous bornerons donc à présupposer les études déjà consacrées à ce thème et à en retenir les éléments susceptibles de poser quelques liens significatifs entre les deux domaines qui nous intéressent.

\footnotetext{
$333 \quad$ Rappelons un texte cité plus haut : « Unde tam anima Christi quam homines beati non solum in Deo, sed etiam in proprio genere ita repente vident naturales conclusiones sicut et angeli », Quaest. in II Sent., qu. LVI, vol. II, p. 303.

334 On ne peut que renvoyer ici au travaux de R. Manselli, D. Burr, J. Schlageter, D. Flood, R. Lambertini et A. Tabarroni, dont on trouvera les indications bibliographiques exhaustives dans : Storia della teologia nel Medioevo, III, Casale Monferrato 1996, p. 216-217 et dans R. Lambertini - A. Tabarroni, Dopo Francesco, cit., p. 98-100 ; voir aussi la récente étude de R. Lambertini, La povertà pensata, Modena 2000.
} 
Source d'incompréhensions, de difficultés et de censure, la question de la pauvreté était celle qu'Olivi avait le plus à cœur, car elle concernait l'engagement de toute une vie ainsi que le sens et la mission de l'ordre de Saint François. La défense de la pauvreté de la part d'Olivi n'était pas un geste purement théorique, mais relevait d'un choix existentiel qui s'imposait à lui comme le seul ayant véritablement un sens. Or, pour le franciscain, le sens de la vie individuelle, comme celui de l'histoire de l'humanité, est christologique : la révélation de Dieu dans le Christ représente à la fois une norme théorique et un événement historique qui irradie l'histoire toute entière. Comme norme théorique, la révélation chrétienne dicte au franciscain la nécessité de libérer la théologie des interférences de la philosophie païenne : nous avons vu que cette tâche est particulièrement importante dans le domaine angélologique, où le travail d'Olivi a consisté à libérer les créatures spirituelles du statut de « semidivinités 》 - une démarche que nous avons caractérisée comme « humanisation de l'ange ». Comme événement historique, la révélation chrétienne fonde par ailleurs une théologie de l'histoire qui donne sens aux vicissitudes de l'humanité.

Se servant de différents modèles de division de l'histoire - celui de Joachim de Flore par l'intermédiaire de Bonaventure ${ }^{335}$, mais aussi celui de Richard de St. Victor ${ }^{336}$-, Olivi la partage en sept périodes. La première est celle de l'Eglise primitive, aux prises avec le judaïsme, dont la pression conduira au transfert de la papauté de Jérusalem à Rome ; la deuxième période est celle de la persécution de la part des païens ; la troisième voit la confrontation de l'Eglise avec l'hérésie - en particulier avec celle d'Arius ; la quatrième oppose l'Eglise aux hypocrites ${ }^{337}$; cette période est aussitôt suivie de la cinquième, qui est la plus longue, puisqu'elle naît avec l'avènement de l'empire carolingien et se termine à l'époque d'Olivi. Cette cinquième période est celle de la corruption interne de l'Eglise qui, en passant des compromis avec le monde, s'est enrichie, a gagné le pouvoir et de ce fait a entamé sa déchéance. Olivi vit au terme de cette période et au début de la sixième, qui est celle de la résurgence de la vie apostolique et qui marque l'avènement de l'âge de l'Esprit Saint. Cette période décisive, qui fait suite au déclin de l'Eglise et doit amener le renouvellement de

\footnotetext{
335 Cf. D. Burr, L'histoire, cit., p. 42.

336 Cf. R. Manselli, La terza età, Babylon e l'Anticristo mistico, Bullettino dell'istituto storico italiano per il Medio Evo e Archivio Muratoriano, 28 (1970), p. 47 sv., qui critique la trop grande importance attribuée à Joachim de Flore dans l'interprétation d'Olivi proposée par M. Reeves, The Influence of Profecy in the Later Middle Ages. A Study in Joachimism, Oxford 1969. D. Flood se range par contre du côté de l'interprétation de M. Reeves et affirme que "Olivi est le joachimite que Manselli ne veut pas accepter": cf. Le projet franciscain de $P$. Olivi, Etudes franciscaines, XXIII (1973), p. 374.

Cette période se chevauche chronologiquement avec la précédente, dont elle ne se distingue que par le genre d'activité ou de combat que l'Eglise doit mener. En réalité, les sept périodes ne sont pas clairement délimitées du point de vue chronologique, mais passent l'une dans l'autre, si bien que la fin d'une période coexiste avec le début de celle qui lui succède : cf. D. Burr, L'histoire, cit., p.44 : c'est à cette étude que nous empruntons le résumé de la périodisation d'Olivi.
} 
la vie évangélique, est à l'enseigne de Joachim de Flore, précurseur de l'âge nouveau ${ }^{338}$, et surtout de Saint François. Celui-ci est le rénovateur principal de la vie évangélique, le seul, parmi les saints, à qui il a été donné de vivre la perfection de 1'Evangile: Saint François est donc pour Olivi la figure la plus importante après le Christ $^{339}$. Notre auteur insiste fortement sur ce que François a renouvelé la vie du Christ, et ce témoignage existentiel devient pour lui l'emblème de la mission dont l'ordre franciscain est investi ${ }^{340}$.

Or, la vie et la perfection du Christ, et celle de François après lui, est a été à l'enseigne de la pauvreté. Dans le Christ, Dieu s'est fait pauvre et misérable pour sauver l'humanité, car c'est en refusant tout pouvoir sur les choses temporelles qu'il allait manifester pleinement sa souveraineté spirituelle ${ }^{341}$. Le renouvellement de la vie évangélique promu par Saint François impose donc le choix de la pauvreté : c'est la condition pour que l'ordre franciscain réalise sa mission dans l'Eglise et pour l'humanité, une mission qui fait de cet ordre le «fer de lance du nouvel âge ${ }^{342}$. Mais si l'idéal d'une vie évangélique à l'enseigne de la pauvreté était au cœur même de l'ordre fondé par le Poverello, vers la fin des années 1270 et au début des années 1280 la manière dont Olivi concevait la pauvreté devait susciter les plus âpres querelles. Rappelons ici que le franciscain défendait l'usus pauper, c'est-à-dire non seulement le renoncement à toute propriété privée et en commun, mais aussi l'usage pauvre

\footnotetext{
338 Joachim de Flore est considéré par Olivi comme un prophète : cf. D. Burr, Olivi on Prophecy, in : Cristianesimo nella storia, 17 (1996), p. 369-391 (en particulier p. 378).

$339 \quad$ Cf. Quaestiones de perfectione evangelica, qu. 8, éd. J. Schlageter, Das Heil der Armen und das Verderben der Reichen, Werl 1989, p. 148-149: „Sicut enim in primo Christi adventu electus fuit Johannes non solum propheta, (...), ita ante secundum adventum electus est alius [scilicet Franciscus] eodem nomine prius in baptismo vocatus non solum sanctus, sed plus quam sanctus, quo nullus antea sanctorum in vita maior apparuerat, ad introducendum et renovandum Christi vitam in mundum. (...) Et sicut ille plus quam propheta fuit in notitia et manifestatione personae Christi, sic et iste in notitia et manifestatione vitae Christi. Nulli enim antea sanctorum post apostolos ita data est notitia vitae Christi seu evangelicae perfectionis sicut et isti ». D. Burr, L'histoire, cit., p. 47-51, signale d'autres passages, notamment du Commentaire de l'Apocalypse, où Olivi célèbre la valeur de St. François ; on lira aussi, du même A., Franciscan Exegesis and Saint Francis as Apocalyptic Angel, dans : Monks, Nuns and Friars in Medieval Society, Sewanee 1989, p. 51-62.

Chez Olivi, l'idéal franciscain authentiquement vécu remplit la mission d'une présence providentielle dans l'histoire de l'humanité : cf. Gratien de Paris, Une lettre inédite de Pierre de Jean Olivi, Etudes franciscaines, 29 (1913/1), p. 415-422 (en particulier p. 421 : «Ordo Francisci flagellis ac temptationibus innumeris primitus excussus, cribratus aut expurgatus in universo orbe Domini cultum altissime reparabit »), ainsi que le commentaire d'Olivi à la Règle de St. François, éd. D. Flood, Peter Olivi's Rule Commentary, Wiesbaden 1972 , et les considérations de R. Lambertini - A. Tabarroni, Dopo Francesco, cit., p. 86. $341 \quad$ Cf. Quaest. de perfectione evangelica, qu. 8, p. 135: "Sublimitas quidem suae potestatis hoc ostendit. Quia magnae esset indignitatis Christo universali omnium Domino appropriatum dominium super aliquid et maxime temporale sibi vindicare, et modo illo maxime quo sibi homines vindicant. Unde paupertas haec magis fuit ostensiva universalis potestatis Christi quam esset affluentiam quarumcumque humanarum divitiarum, cum etiam verus dominus temporalium sit earum contemptor et conculator. Alias enim non est eis plene superpositus. Si Christus non ostendisset se tamquam summum contemptorem et conculatorem rerum, non plene ostendisset suum spiritualissimum dominium quo superfertur omnibus etiam secundum humanitatem. (...) Quando autem pauperrimus existens mira fecit, non potuit hoc attribui alicui potestati temporali, sed solum divinae et spirituali ».
} $342 \quad$ D. Burr, L'histoire, cit., p. 57. 
des biens de subsistance ${ }^{343}$. La pauvreté ainsi comprise était la condition nécessaire à l'accomplissement de la mission qu'Olivi attribuait à son ordre dans le cadre de sa théologie de l'histoire. Pour cette raison, il ne pouvait pas la concevoir comme un simple instrument de perfectionnement: bien au contraire, la pauvreté - inférieure seulement à la charité - était la première des vertus recommandées par le Christ et la première des béatitudes ${ }^{344}$.

Sa valeur résidait de surcroît en ce qu'elle suscitait une série d'autres vertus conduisant à la perfection celui qui la pratiquait ${ }^{345}$. Olivi en énumère quinze, dont nous retiendrons ici l'humilité, l'amour, le courage, la foi, la générosité ou encore la contemplation. Ces vertus sont favorisées par la pauvreté, car elles reposent toutes sur le renoncement, voire le mépris des biens de ce monde. En effet, la pauvreté n'est pas simplement une privation, mais c'est une manière de se rapporter aux choses qui inclut la volonté délibérée de ne rien posséder: Dicit enim statum et modum se habendi ad temporalia altissimum et includit in se voluntatem affirmativam et perfectam nihil habendi $i^{346}$. Par ce biais, la vraie pauvreté ne définit pas seulement le rapport aux choses, mais aussi à soi-même : elle prend alors la forme de l'humilité, qui dans son sens authentique signifie abnégation de soi. Les formulations d'Olivi sont radicales: la pauvreté suscite la conscience de n'être rien, elle provoque le mépris et l'abjection à l'égard de soi-même, en un mot: elle est presqu'un anéantissement de soi $^{347}$. La pauvreté est donc une certaine conscience de soi : la conscience de sa propre finitude et de l'indigence de son être. Cette conscience du peu de valeur des choses et de soi-même s'avère être la condition nécessaire à la recherche d'une vie désormais à l'enseigne des valeurs spirituelles. Mais si la pauvreté est renoncement à tout dominium et implique un détachement radical, il importe de souligner que pour le sujet qui la pratique elle est l'objet d'un acte de liberté. Nous savons que celle-ci qualifie l'humanité et fonde la dignité de chaque être raisonnable : la pauvreté qui fait l'objet d'un acte libre perfectionne ainsi l'humanité de l'homme et l'achemine vers sa fin dernière, à savoir la contemplation et l'amour de Dieu.

\footnotetext{
343 Olivi explique sa conception de l' »usus pauper » principalement dans deux textes : la question 9 des Questions sur la perfection évangélique, et le traité De usu paupere.

$344 \quad$ A ce propos, Olivi critique fortement Thomas d'Aquin : cf. M.-Th. D'Alverny, Un adversaire de Saint Thomas : Pierre de Jean Olivi, in : St. Thomas Aquinas 1274-1974. Commemorative Studies, Toronto 1974, p. 179-218. Selon D. Burr, L'histoire, cit., p. 39, « Olivi n'est pas un extrémiste dans la question de l'usus pauper », celui-ci ne devant pas être fixé dans des règles juridiques strictes, mais devant inspirer un comportement menant à la perfection. A ce propos voir aussi R. Lambertini - A. Tabarroni, Dopo Francesco, cit., p. 87.

345 Cf. Quaest. de perfectione evangelica, qu. 8, p. 85: "Sed paupertas altissima inter omnia quae cogitari possunt, et fere super omnia valet ad altissimam et universalissimam virtutum et statuum perfectionem »; voir aussi : Tria scripta sui ipsius apologetica, éd. D. Laberge, Archivum franciscanum historicum 28 (1935).

$346 \quad$ Quaest. de perfectione evangelica, qu. 8, p. 169.

$347 \quad$ Cf. ibid., p. 87: "Unde inopia summa est occasio sentiendi se esse nihil (...). Eo enim ipso quo quis afficitur et movetur ad talem paupertatem assumendam et tenendam, eo ipso movetur ad amplexum summae vilificationis et abiectionis et quasi annihilationis sui. Et iste est actus summae humilitatis ». A ce propos cf. J. Schlageter, Das Heil der Armen, cit., p. 28.
} 
A partir de ce tour d'horizon sommaire de la conception et de la valeur de la pauvreté chez Olivi, nous pouvons renouer avec la question initiale et poser quelques liens susceptibles de parfaire notre compréhension de son angélologie. Nous venons de constater que le choix de la pauvreté est étroitement lié à la conscience du peu de valeur des choses, sinon de leur néant. La pauvreté est donc une arme contre la surestimation des réalités de ce monde, contre la valorisation du créé considéré en lui-même et pour lui-même. La possession des richesses et la recherche du pouvoir ne sont que la face externe d'une valorisation excessive et injustifiée des biens de ce monde. Or, si nous reconsidérons la conception philosophique des substances séparées, ainsi que celle des anges qui lui est apparentée, il est aisé de constater que les créatures spirituelles sont investies de prérogatives qui en font des créatures privilégiées, des sujets «riches » et supérieurs aux autres créatures au point de devenir selon le jugement d'Olivi - des semi-divinités (quosdam deos). La critique de notre auteur à l'égard de l'ange comme forme pure, pourvu des représentations intelligibles de toutes choses (plenus formis), intemporel et non-spatialisé, visait précisément à détrôner l'ange de son statut semi-divin. Les philosophes et les theologi philosophantes étaient coupables d'une valorisation de l'ange qu'il ne pouvait admettre, car attibuant à une créature des richesses et des prérogatives propres de Dieu. Dans cette optique, la conception angélologique d'Olivi ne semble donc pas dépourvue de liens avec l'exigence de la pauvreté : en tant que conscience du néant des créatures, cette exigence imposait la révision du statut des substances séparées par l'accentuation de leur créaturalité et de leur finitude.

Par ailleurs, le choix de la pauvreté s'est avéré être la condition nécessaire au renouvellement de la vie évangélique. Ce projet repose sur la figure paradigmatique du Christ, qui dans la conception olivienne de la marche de l'histoire représente le seul modèle légitime et le seul médiateur véritable ${ }^{348}$. Aussi, c'est par l'imitation du Christ que les hommes pourront atteindre leur finalité ultime ${ }^{349}$. Cette vision christocentrique sous-tend également la conception des créatures spirituelles : d'une part, en effet, la critique olivienne visait les privilèges accordés aux créatures spirituelles en tant qu'ils entraînaient

\footnotetext{
348 Le christocentrisme de la conception olivienne a été relevé et souligné dans plusieurs études : cf., entre autres, R. Manselli, La «Lectura super Apocalipsim » di Pietro di Giovanni Olivi. Ricerche sull'escatologismo medievale, Roma 1955, p. 191 et La terza età, Babylon e l'Anticristo mistico, cit., où l'A. corrige l'interprétation présentée par M. Reeves dans : The Influence of Profecy, cit. ; E. Pasztor, Giovanni XXII e il gioachimismo di P. di G. Olivi, Bullettino dell'istituto storico italiano per il Medio Evo e Archivio muratoriano, 28 (1970), p. 81111 ; P. Peano, article :Olieu, cit., col. 751-762.
}

\footnotetext{
349 Ce dernier aspect a suscité la réaction de Jean XXII dans un sermon de 1325/26, où le pape condamne l'idée que les hommes ne seraient plus des « viatores », mais des « comprehensores » n'ayant plus besoin de médiation pour la vision béatifique : cf. E. Pasztor, Le polemiche sulla « Lectura super Apocalipsim » di Pietro di Giovanni Olivi fino alla sua condanna, Bullettino dell'istituto storico italiano per il Medioevo e Archivio Muratoriano, 70 (1958), p. 365-426 (voir en particulier p. 412). Cet aspect fait partie des éléments doctrinaux qui ont provoqué la condamnation du Commentaire de l'Apocalypse en 1326 : cf. D. Burr, L'histoire, cit., p. 255.
} 
leur supériorité par rapport à l'âme humaine et à celle du Christ; de ce point de vue l'angélologie doit donc être clairement soumise à la christologie, en ce qu'elle doit adapter la conception de la nature angélique au primat de l'âme du Christ en tant qu'homme. D'autre part, le rôle salvifique du Christ, c'est-à-dire sa fonction médiatrice dans l'histoire du salut, en font pour notre auteur le paradigme par excellence, que seul François d'Assise a su imiter. Il convient de souligner que la valeur paradigmatique est ici d'ordre existentiel : c'est à la pratique de la vie pauvre qu'il revient de manifester la supériorité des valeurs spirituelles. L'imitation de ce modèle résulte donc d'un choix existentiel et non pas d'un statut ontologique donné. Aussi, quand bien même l'ange serait pourvu de certains privilèges d'ordre naturel, il ne serait pas pour autant et nécessairement un paradigme pour l'homme. L'humanisation de l'ange opérée par Olivi le prive précisément de ce qui chez les adversaires en faisait un modèle sur le plan ontologique. Olivi récuse un tel modèle, aussi bien au nom de la finitude et de l'imperfection du créé, qu'en vertu d'un christocentrisme qui situe l'exemplarité au niveau d'un choix existentiel et non pas sur le plan d'une condition ontologique figée. Dans cette perspective christocentrique, l'ange ne possède donc qu'une valeur instrumentale: celle de sa participation et de sa contribution au plan du salut.

En troisième lieu, la conception angélologique de notre auteur s'avère marquée par la question de la pauvreté à travers le thème de la liberté. Nous savons que la liberté, en tant que capacité d'autodétermination, est à la fois le fondement et le signe de la noblesse et de la dignité des créatures raisonnables. Elle dépasse donc l'intellect, qui reste déterminé par son objet en tant que cause terminative. A partir de là - comme nous l'avons déjà remarqué - l'intellectualité qui définit la nature angélique ne saurait plus représenter un statut supérieur : le primat de la liberté retentit ainsi par lui même sur l'appréciation olivienne des créatures spirituelles. Or, nous savons également que la pauvreté est liée de manière particulière à la liberté, car d'une part la vraie pauvreté garantit la liberté - l'attachement aux choses rendant l'homme esclave - et d'autre part elle est l'objet d'un choix volontaire. La pauvreté est donc à la fois une condition et un objet privilégié de la liberté humaine, et pour Olivi son choix est celui d'une vertu et d'une perfection recommandée par le Christ lui-même. L'association pauvreté-liberté et le primat qui lui est accordé place ainsi l'ordre moral au premier rang : ce qui compte pour notre auteur c'est le choix existentiel qui situe le sujet humain dans la trajectoire de l'histoire du salut. La dignité, donnée avec la liberté, trouve son accomplissement dans l'ordre moral, où l'homme déploie sa capacité d'autodétermination et peut adhérer au modèle du «Dieu-faithomme». Il apparaît que cette primauté n'a pas manqué d'exercer son influence sur la conception des créatures spirituelles: comme pour les autres créatures douées de liberté, leur valeur et leur fonction s'inscrivent désormais dans l'ordre du salut. 
La réflexion angélologique d'Olivi est enfin marquée par le thème de la pauvreté à travers la doctrine eschatologique. Développant des éléments déjà présents dans les Collationes in Hexaemeron de Bonaventure, notre auteur recentre la théologie autour de l'histoire du salut, en polémique avec la conception de la théologie comme science qui - à travers l'intégration progressive de la doctrine aristotélicienne de l'épistéme - avait abandonné la dimension temporelle et historique au profit d'un procédé argumentatif dominé par la rigueur logique ${ }^{350}$. La perspective temporelle et historique adoptée par le franciscain a donné lieu à la théorie, rappelée plus haut, des âges de l'humanité et de la marche de l'histoire, dans laquelle l'ordre franciscain est appelé à jouer un rôle prééminent. Le renouvellement de la vie évangélique exige en effet le choix d'une pauvreté authentique : celle de l'usus pauper, qui est le seul choix convenant véritablement à l'identité franciscaine ${ }^{351}$ et permettant à cet ordre de jouer le rôle d'une présence providentielle dans la marche de l'histoire. Pauvreté et eschatologie sont donc intimement liées dans la doctrine d'Olivi et ne peuvent être séparées d'aucune manière ${ }^{352}$. Mais le primat de la dimension eschatologique impliquait à son tour une critique de l'aristotélisme, car il avait fourni à la théologie un modèle de science privilégiant un critère de validité strictement logique. L'aristotélisme était coupable de la transformation de la théologie en une spéculation dialectique intemporelle, désormais dissociée du déroulement de l'histoire du salut ${ }^{353}$. Or, c'est bien de la tradition péripatéticienne que les theologi philosophantes - partisans de la théologie comme science - avaient dérivé leur conception des substances séparées : une conception qui les considérait comme des entités formelles soustraites à l'espace et au temps. En opposition à cette doctrine, Olivi adoptait une «logique du concret »: celle des êtres individuels engagés dans le temps de l'histoire, une logique qui était donc intimement associée à la perspective eschatologique. Celle-ci ne pouvait pas manquer de retentir sur la manière de concevoir les

350 Cf. T. Gregory, Escatologia e aristotelismo nella scolastica medievale, Giornale critico della filosofia italiana, 40 (1961), p. 163-174; voici un passage de cet article qui nous paraît significatif pour notre propos : « La teologia scienza, sostituendo il « modus argumentativus » al « modus narrativus, typologicus » della « lectio historiae », perde la tensione escatologica che sottende la storia sacra : il tema della fine dei tempi non orienta più la speculazione teologica, ma diviene un questionario di fisica in cui si cerca di superare il radicale contrasto tra la concezione aristotelica e quella cristiana della natura ; in tale questionario i destini escatologici della storia e del mondo vengono sommersi : anche la prospettiva « sociale » di salvezza che investe tutta la collettività dei credenti passa in secondo piano rispetto al problema della salvezza individuale dopo la morte » (p. 166-167).

Les discussions et les querelles sur la pauvreté à l'intérieur de l'ordre franciscain résultaient de ce que la pauvreté représentait précisément l'élément majeur de l'identité franciscaine : cf. R. Lambertini - A. Tabarroni, Dopo Francesco, cit., p. 141.

$352 \quad$ Olivi conçoit aussi la prophétie dans la perspective eschatologique et enracine sa réflexion sur la prophétie plus dans le Livre de l'Apocalypse que dans l'Ancien Testament, comme c'était le cas habituellement : cf. D. Burr, Olivi on Prophecy, cit., p. 388.

353 Le poète Jacopone da Todi avait traduit cette évolution néfaste comme un abandon d'Assise au profit de Paris : « Mal vedemmo Parisi, c’hane distrutto Ascisi » (Laudi, XXXI, 2) : cf. T. Gregory, Escatologia, cit., p. 169. 
créatures spirituelles : la révision de leur statut consistait alors à les situer dans l'espace et le temps des hommes et à les associer à leur histoire. L'humanisation de l'ange est donc aussi redevable d'une doctrine eschatologique qui le rend solidaire des vicissitudes humaines et de leur marche vers le salut.

Si - comme nous espérons l'avoir montré - l'angélologie de Pierre de Jean Olivi présente en elle-même un intérêt spéculatif certain, aussi bien en raison de sa logique et de sa cohérence interne que du projet qui la guide, nous pouvons conclure à présent qu'elle s'articule de manière organique à l'ensemble de sa spéculation et de son engagement: étroitement liée à sa conception de l'homme, de l'âme, de ses facultés, de leurs fonctions et de leurs rapports dans l'univers créé, elle se rattache également au thème majeur de la pauvreté, qui a empreigné la pensée d'Olivi après avoir orienté, comme un idéal toujours présent, les choix de son existence. 